\title{
REQUEST FOR APPLICATIONS
}

\section{Special Education Research Grants CFDA Number: 84.324A}

\begin{tabular}{lll}
\hline \hline Milestone & Date & Website \\
\hline \hline Letter of Intent Due & June 5, 2014 & https://iesreview.ed.gov/
\end{tabular}

Application Package June 5, 2014

http://www.grants.gov/

Available

\section{Application Due \\ By 4:30:00 p.m. Washington DC time August 7, 2014}

Applicants Notified

Possible Grant

Start Dates
By July 1, 2015

https://iesreview.ed.gov/ http://www.grants.gov/ 


\section{Table of Contents}

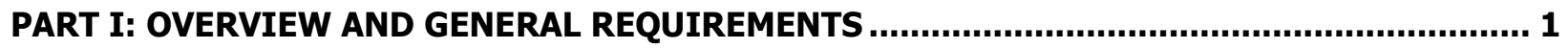

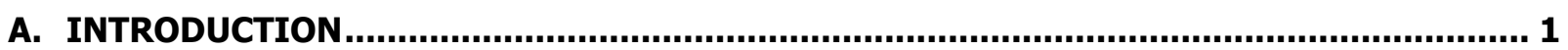

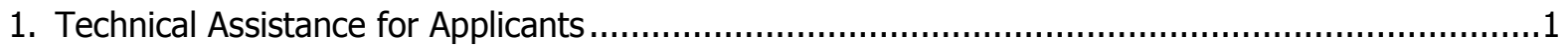

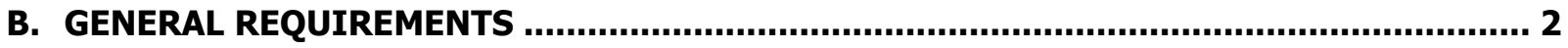

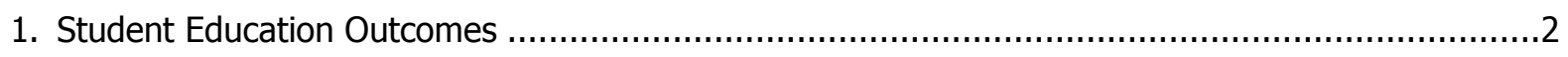

2. Authentic Education Settings .....................................................................................

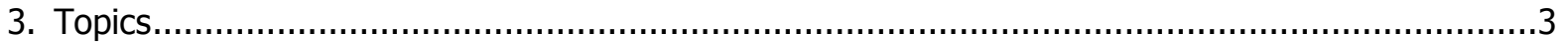

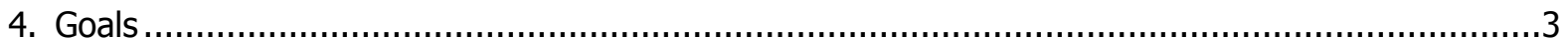

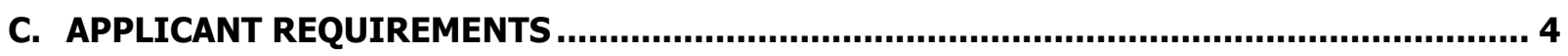

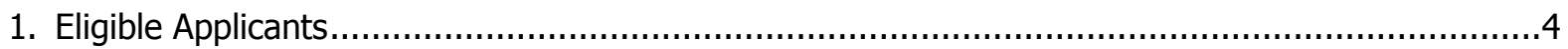

2. The Principal Investigator and Authorized Organization Representative...................................4

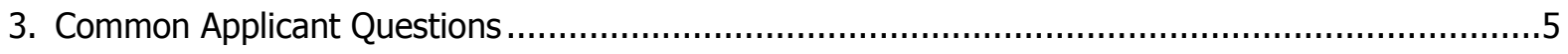

D. CHANGES IN THE FY 2015 REQUEST FOR APPLICATIONS......................................... 5

E. READING THE REQUEST FOR APPLICATIONS ............................................................... 7

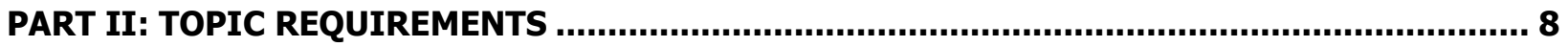

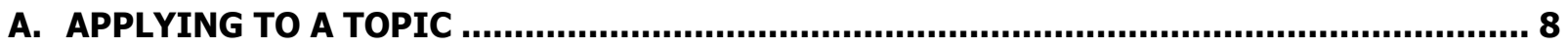

1. Autism Spectrum Disorders .............................................................................. 10

2. Cognition and Student Learning in Special Education ..................................................... 12

3. Early Intervention and Early Learning in Special Education ............................................... 14

4. Families of Children with Disabilities ............................................................................. 16

5. Mathematics and Science Education ........................................................................... 18

6. Professional Development for Teachers and Related Services Providers .................................20

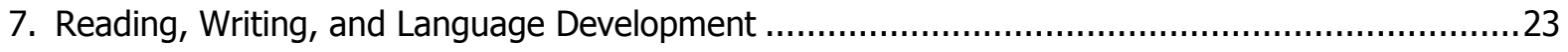

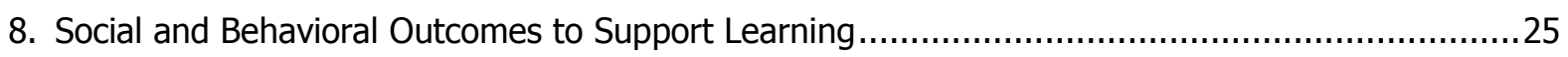

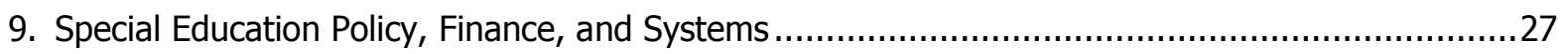

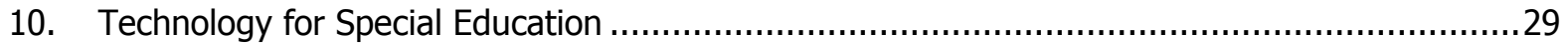

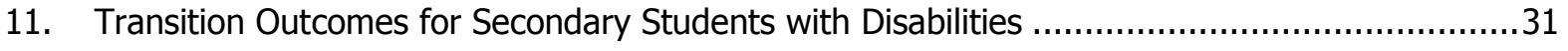

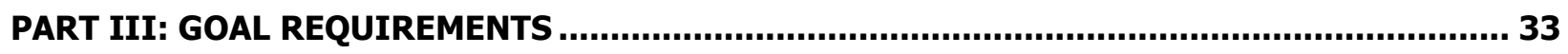

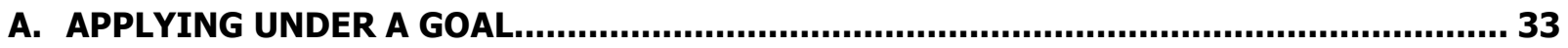

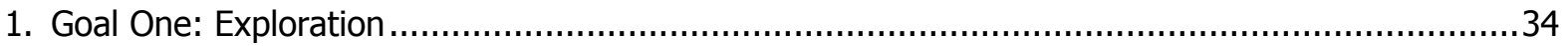

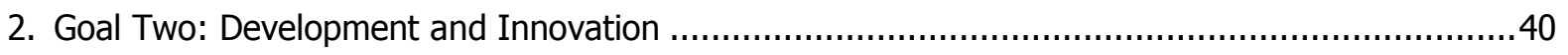

3. Goal Three: Efficacy and Replication ...................................................................... 49

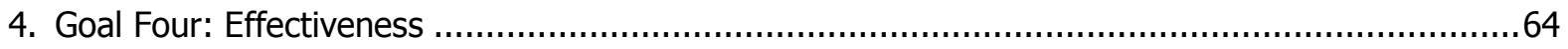

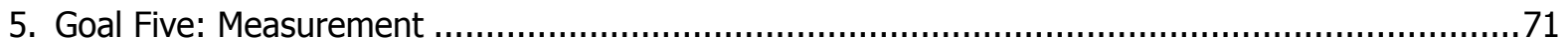

PART IV: COMPETITION REGULATIONS AND REVIEW CRITERIA ........................................ 77 
A. FUNDING MECHANISMS AND RESTRICTIONS .......................................................... 77

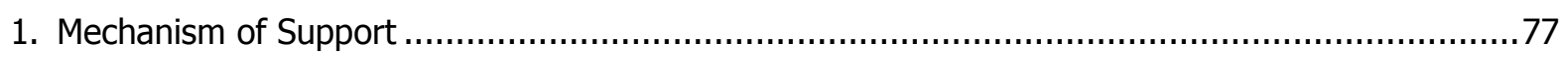

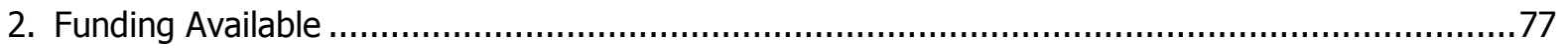

3. Special Considerations for Budget Expenses .............................................................. 77

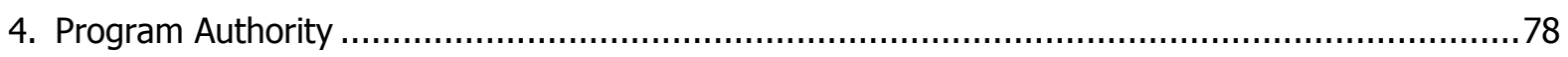

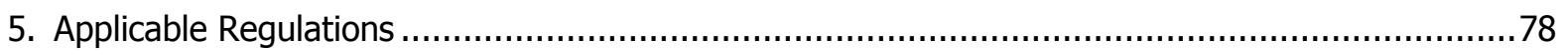

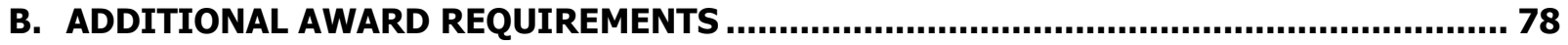

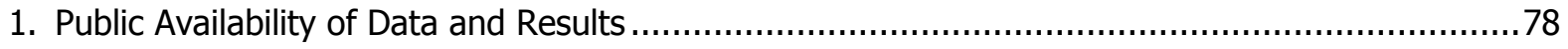

2. Special Conditions on Grants ................................................................................... 78

3. Demonstrating Access to Data and Authentic Education Settings ...........................................78

C. OVERVIEW OF APPLICATION AND PEER REVIEW PROCESS................................. 79

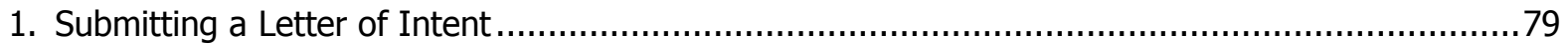

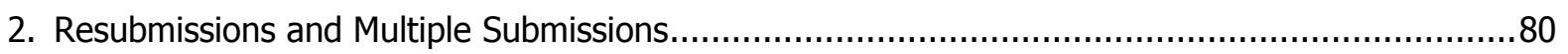

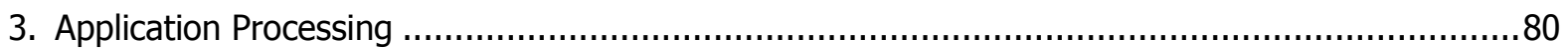

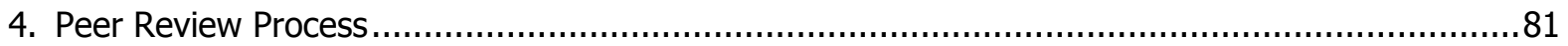

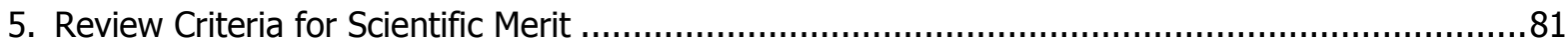

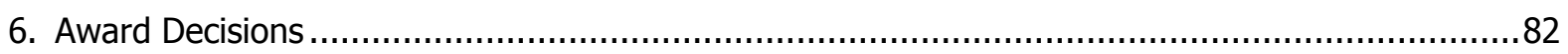

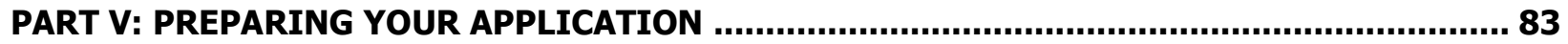

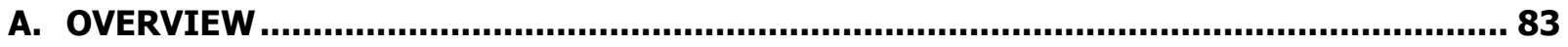

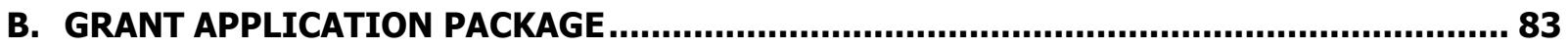

1. Date Application Package is Available on Grants.gov ...................................................... 83

2. How to Download the Correct Application Package ........................................................ 83

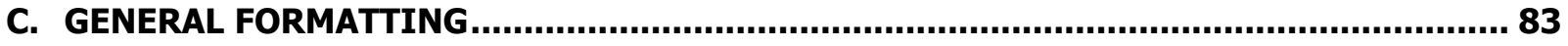

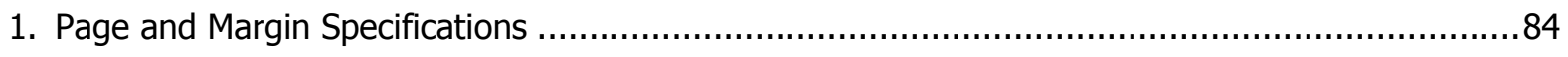

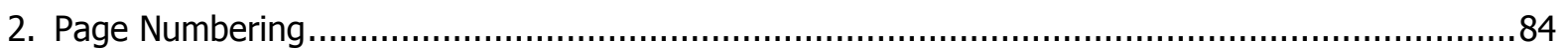

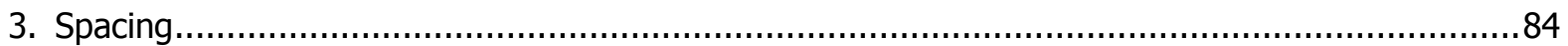

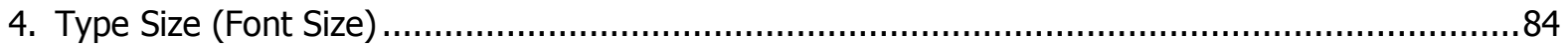

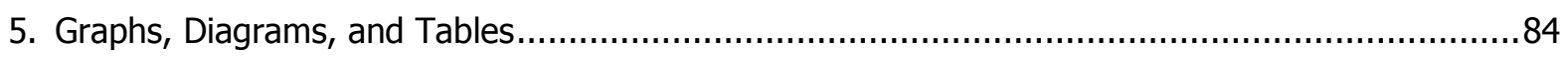

D. PDF ATTACHMENTS .................................................................................................. 84

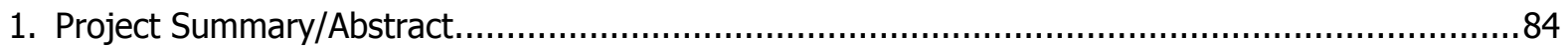

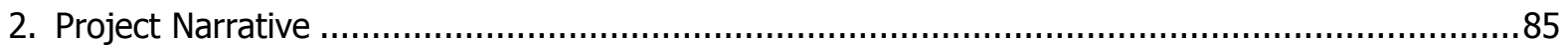

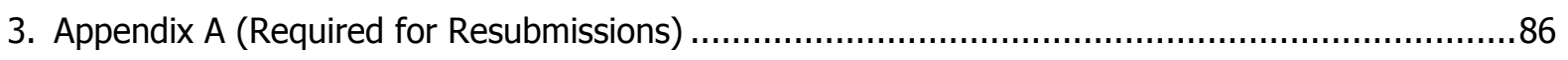

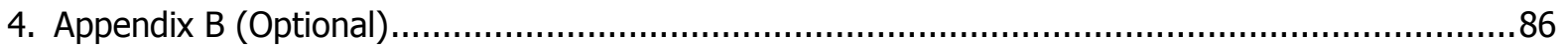

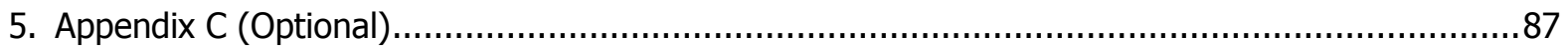

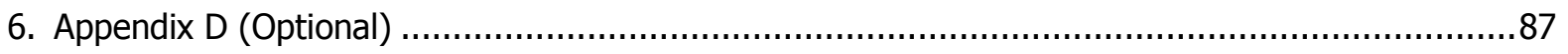

7. Appendix E (Efficacy/Replication and Effectiveness Applications) ......................................... 87

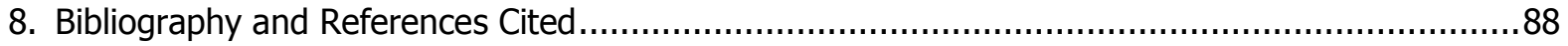




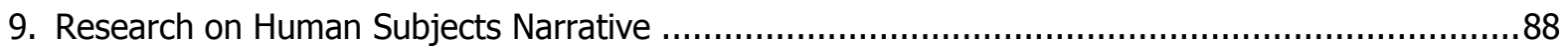

10. Biographical Sketches of Senior/Key Personnel........................................................... 89

11. Current \& Pending Support of Senior/Key Personnel ...................................................... 89

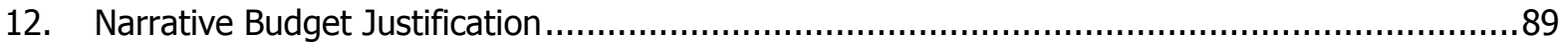

PART VI: SUBMITTING YOUR APPLICATION .................................................................. 91

A. MANDATORY ELECTRONIC SUBMISSION OF APPLICATIONS AND DEADLINE.............. 91

B. REGISTER ON GRANTS.GOV .................................................................................... 91

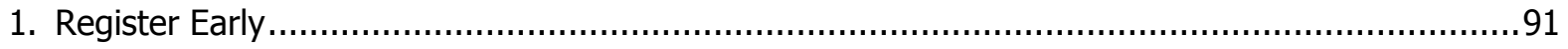

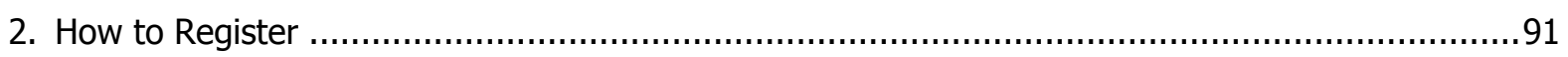

C. SUBMISSION AND SUBMISSION VERIFICATION................................................. 92

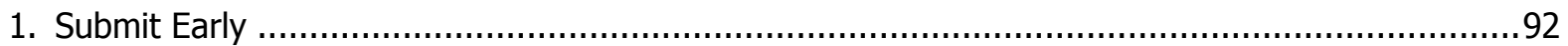

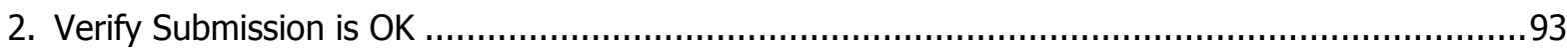

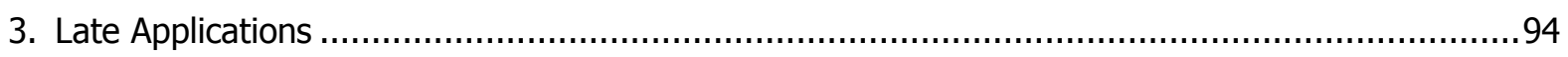

D. TIPS FOR WORKING WITH GRANTS.GOV .............................................................. 94

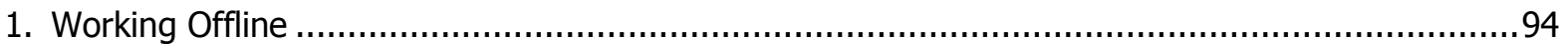

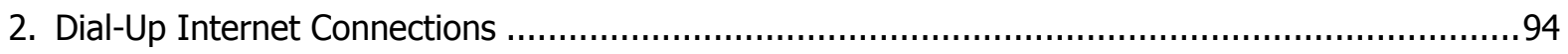

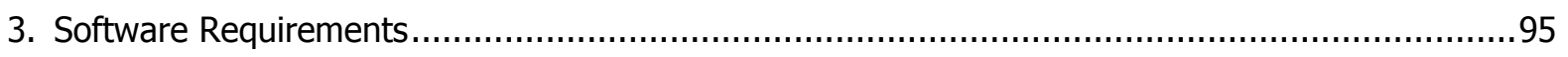

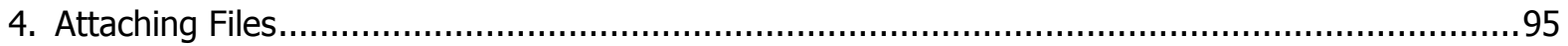

E. REQUIRED RESEARCH \& RELATED (R\&R) FORMS AND OTHER FORMS...................... 95

1. Application for Federal Assistance SF 424 (R\&R) ........................................................... 96

2. Research \& Related Senior/Key Person Profile (Expanded) ............................................. 100

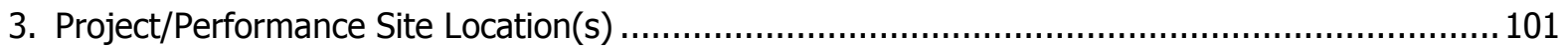

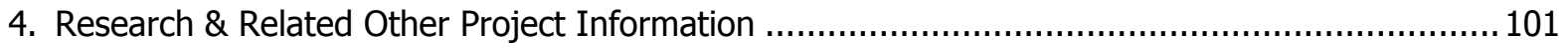

5. Research \& Related Budget (Total Federal+Non-Federal)-Sections A \& B; C, D, \& E; F-K ......... 104

6. R\&R Subaward Budget (Fed/Non-Fed) Attachment(s) Form ............................................... 108

7. Other Forms Included in the Application Package .............................................................. 109

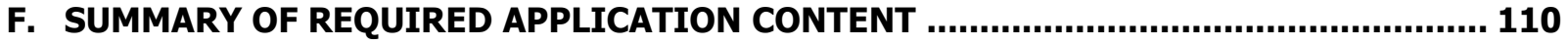

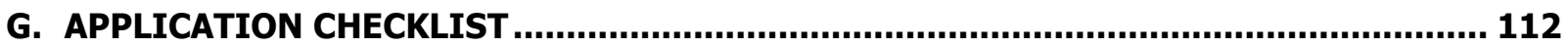

H. PROGRAM OFFICER CONTACT INFORMATION........................................................ 114

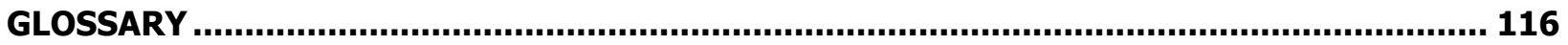

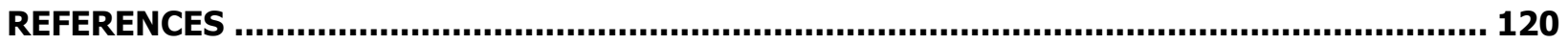

ALLOWABLE EXCEPTIONS TO ELECTRONIC SUBMISSIONS .............................................. 122 


\section{PART I: OVERVIEW AND GENERAL REQUIREMENTS}

\section{A. INTRODUCTION}

In this announcement, the Institute of Education Sciences (Institute) requests applications for research projects that will contribute to its Special Education Research Grants program (CFDA 84.324A). Through this program, the Institute seeks to expand the knowledge base and understanding of infants, toddlers, children, and youth with disabilities through advancing the understanding of and practices for teaching, learning, and organizing education systems.

For the FY 2015 competition, the Institute will consider only applications that are responsive and compliant to the requirements described in this Request for Applications (RFA) and submitted electronically via Grants.gov (http://www.grants.gov) on time. Separate funding announcements are available on the Institute's website that pertain to the research training grant program funded through the Institute's National Center for Special Education Research (http://ncser.ed.gov) and to the grant competitions funded through the Institute's National Center for Education Research (http://ncer.ed.gov). An overview of the Institute's research grant programs is available at http://ies.ed.gov/funding/overview.asp.

The work of the Institute is grounded in the principle that effective education research must address the interests and needs of education practitioners and policymakers, as well as students, parents, and community members (see http://ies.ed.gov/director/board/priorities.asp for the Institute's priorities). The Institute encourages researchers to develop partnerships with education stakeholder groups to advance the relevance of their work and the accessibility and usability of their findings for the day-to-day work of education practitioners and policymakers. In addition, researchers should plan for disseminating their results to a wide range of audiences that includes researchers, policymakers, practitioners, and the public.

The Special Education Research Grants program uses a topic and goal structure to divide the research process into stages by field for both theoretical and practical purposes (i.e., applicants must submit to both one topic and one goal). Individually, the topics and goals are intended to help focus the work of researchers. Together, they are intended to cover the range of research, development, and evaluation activities necessary for building a scientific enterprise that can provide solutions to the education problems in our nation. Education has always produced new ideas, new innovations, and new approaches, but only appropriate empirical evaluation can identify those that are in fact improvements. Taken together, work across the Institute's topics and goals should not only yield information about the practical benefits and the effects of specific interventions on education outcomes but also contribute to the bigger picture of scientific knowledge and theory on learning, instruction, and education systems.

This RFA is organized in the following fashion. Part I sets out the general requirements for your grant application. Parts II and III provide further detail on two of those requirements, topics and goals, respectively. Part IV provides general information on applicant eligibility and the review process. Part V describes how to prepare your application. Part VI describes how to submit an application electronically using Grants.gov. You will also find a Glossary of important terms located at the end of this RFA. The first use of each term is hyperlinked to the Glossary.

\section{Technical Assistance for Applicants}

The Institute encourages you to contact the Institute's Program Officers as you develop your application. Program officers can provide guidance on substantive aspects of your application and answer any questions prior to submitting an application. Program Officer contact information is listed by topic in Part II and in a list in Part VI.H Program Officer Contact Information. 
The Institute asks potential applicants to submit a Letter of Intent 60 days prior to the application submission deadline. Letters of Intent are optional but strongly encouraged by the Institute. If you submit a Letter of Intent, a Program Officer will contact you regarding your proposed research. Institute staff also uses the information in the letters of intent to identify the expertise needed for the scientific peer-review panels and to secure a sufficient number of reviewers to handle the anticipated number of applications.

In addition, the Institute encourages you to sign up for the Institute's Funding Opportunities Webinars for advice on choosing the correct research competition, grant writing, or submitting your application. For more information regarding the webinar topics, dates, and registration process, see http://ies.ed.gov/funding/webinars/index.asp.

\section{B. GENERAL REQUIREMENTS}

1. Student Education Outcomes

All research supported under the Special Education Research Grants program must address the education outcomes of students. The Institute is most interested in student developmental outcomes, academic outcomes, and functional outcomes that support success in school and afterwards.

The Institute supports research on a diverse set of student outcomes of interest by education level as follows:

- For infants and toddlers (birth to 3-year-olds), the primary outcomes are developmental outcomes pertaining to cognitive, communicative, linguistic, social, emotional, adaptive, functional or physical development.

- For preschool (3- to 5-year-olds), the primary outcomes are developmental outcomes (cognitive, communicative, linguistic, social, emotional, adaptive, functional or physical development) and school readiness (e.g., pre-reading, language, vocabulary, early science and mathematics knowledge, social and behavioral competencies that prepare young children for school).

- For kindergarten through Grade 12, student outcomes include learning, achievement, and higher-order thinking in the core academic content areas of reading, writing, mathematics, and science measured by specific assessments (e.g., researcher-developed assessments, standardized tests, grades, end-of-course exams, exit exams) and student progression through education (e.g., high school graduation, and dropout). A range of student social skills, attitudes, and behaviors may be important to students' education and post-school success, so important outcomes also include behaviors that support learning in academic contexts. In addition, the Institute is interested in functional outcomes that improve educational results and transitions to employment, independent living, and postsecondary education for students with disabilities.

\section{Authentic Education Settings}

Proposed research must be relevant to education in the United States and must address factors under the control of the U.S. education system (be it at the national, State, and/or local level). To help ensure such relevance, the Institute requires research to address authentic education settings, which include both inschool settings and formal programs (e.g., early intervention and early childhood special education, afterschool programs, distance learning programs, on-line programs) used by schools or state and local education agencies. These settings are defined as follows: 


\section{- Authentic Education Settings for Infants and Toddlers:}

○ Homes

- Child care

- Natural settings for early intervention services

\section{- Authentic Preschool Settings:}

- Homes

- Child care

- Preschool programs

- Natural settings for early childhood special education services

\section{- Authentic K-12 Education Settings:}

- Schools and alternative school settings (e.g., alternative schools or juvenile justice settings)

- School systems (e.g., local education agencies or state education agencies)

- Settings that deliver supplemental education services (as defined in Section 1116(e) of the Elementary and Secondary Education Act of 1965, as amended by the No Child Left Behind Act of 2001) (http://www2.ed.gov/policy/elsec/leg/esea02/index.html)

\section{Topics}

Your application must be directed to 1 of 11 research topics (see Part II Topic Requirements): Autism Spectrum Disorders; Cognition and Student Learning in Special Education; Early Intervention and Early Learning in Special Education; Families of Children with Disabilities; Mathematics and Science Education; Professional Development for Teachers and Related Services Providers; Reading, Writing, and Lanquage Development; Social and Behavioral Outcomes to Support Learning; Special Education Policy, Finance, and Systems; Technology for Special Education; or Transition Outcomes for Secondary Students with Disabilities. The research topic identifies your field of research.

The Institute recognizes that some applications may meet the requirements of more than one topic. In such cases, you may choose either topic as long as your application meets the specific Sample, Outcome, Setting, and Intervention Provider requirements for that topic. Each topic has one Program Officer who can offer advice on which topic provides the better fit for your work. Program Officer contact information is provided by topic in Part II and in Part VI.H Program Officer Contact Information.

\section{Goals}

Your application must also be directed to 1 of 5 research goals (see Part III Goal Requirements): Exploration; Development and Innovation; Efficacy and Replication; Effectiveness; or Measurement. The research goal identifies the type and purpose of the work you will be doing within the topic-defined field.

- The Exploration goal supports the identification of malleable factors associated with student education outcomes and/or the factors and conditions that mediate or moderate that relationship, and by doing so, Exploration projects are intended to build and inform theoretical foundations for (1) the development of interventions or the evaluation of interventions, or (2) assessment frameworks for the development and validation of assessments.

- The Development and Innovation goal (Development/Innovation) supports the development of new interventions and the further development of existing interventions that are intended to produce beneficial impacts on student education outcomes when implemented in authentic education settings.

- The Efficacy and Replication (Efficacy/Replication) goal supports the evaluation of fully developed and/or widely used education interventions to determine whether they produce a beneficial 
impact on student education outcomes relative to a counterfactual when they are implemented under ideal or routine conditions by the end user in authentic education settings.

- The Effectiveness goal supports the independent evaluation of fully-developed education interventions with prior evidence of efficacy to determine whether they produce a beneficial impact on student education outcomes relative to a counterfactual when they are implemented by the end user under routine conditions in authentic education settings.

- The Measurement goal supports (1) the development of new assessments or refinement of existing assessments (Development/Refinement Projects) or (2) the validation of existing assessments for specific purposes, contexts, and populations (Validation Projects).

\section{APPLICANT REQUIREMENTS}

1. Eligible Applicants

Applicants that have the ability and capacity to conduct scientifically valid research are eligible to apply. Eligible applicants include, but are not limited to, non-profit and for-profit organizations, public and private agencies and institutions, such as colleges and universities.

\section{The Principal Investigator and Authorized Organization Representative} The Principal Investigator

The Principal Investigator (PI) is the individual who has the authority and responsibility for the proper conduct of the research, including the appropriate use of federal funds and the submission of required scientific progress reports ${ }^{1}$.

Your institution is responsible for identifying the PI on a grant application and may elect to designate more than one person to serve in this role. In so doing, your institution identifies him or her as sharing the authority and responsibility for leading and directing the research project intellectually and logistically. All PIs will be listed on any grant award notification. However, institutions applying for funding must designate a single point of contact for the project. The role of this person is primarily for communication purposes on the scientific and related budgetary aspects of the project and should be listed as the PI. All other PIs should be listed as Co-Principal Investigators.

The PI will attend one meeting each year (for up to 3 days) in Washington, DC with other Institute grantees and Institute staff. The project's budget should include this meeting. Should the PI not be able to attend the meeting, he/she can designate another person who is key personnel on the research team to attend.

\section{The Authorized Organization Representative}

The Authorized Organization Representative (AOR) for the applicant institution is the official who has the authority to legally commit the applicant to (1) accept federal funding and (2) execute the proposed project. When your application is submitted through Grants.gov, the AOR automatically signs the cover sheet of the application, and in doing so, assures compliance with U.S. Department of Education policy on public access to scientific publications and data as well as other policies and regulations governing research awards (see Part IV.B. Additional Award Requirements).

\footnotetext{
${ }^{1}$ The Institute uses the uniform format for reporting performance progress on Federally-funded research projects, the Research Performance Progress Report (RPPR http://www.nsf.gov/bfa/dias/policy/rppr/) for these reports. 


\section{Common Applicant Questions}

- May I submit an application if I did not submit a Letter of Intent? Yes, but the Institute strongly encourages you to submit a Letter of Intent. If you miss the deadline for submitting a Letter of Intent, contact the appropriate program officer for the topic you are interested in and that seems to best fit your research. Please see Part IV.C.1 Submitting a Letter of Intent for more information.

- Is there a limit on the number of times I may revise and resubmit an application? No. Currently, there is no limit on resubmissions. Please see Part IV.C.2. Resubmissions and Multiple Submissions for information about requirements for resubmissions.

- May I submit the same application to more than one of the Institute's grant programs? No.

- May I submit multiple applications? Yes. You may submit multiple applications if they are substantively different from one another. Multiple applications may be submitted within the same topic, across different topics, or across the Institute's grant programs.

- May I apply if I work at a for-profit developer or distributor of an intervention or assessment? Yes. You may apply if you or your collaborators develop, distribute, or otherwise market products or services (for-profit or non-profit) that can be used as interventions, components of interventions, or assessments in the proposed research activities. However, the involvement of the developer or distributor must not jeopardize the objectivity of the research. In cases where the developer or distributor is part of the proposed research team, you should discuss how you will ensure the objectivity of the research in the project narrative.

- May I apply if I intend to copyright products (e.g., curriculum) developed using grant funds? Yes. Products derived from Institute-funded grants may be copyrighted and used by the grantee for proprietary purposes, but the U.S. Department of Education reserves a royalty-free, nonexclusive, and irrevocable right to reproduce, publish, or otherwise use such products for Federal purposes and to authorize others to do so [34 C.F.R. § 74.36(a) (2013) (http://www.ecfr.gov/cgibin/retrieveECFR?gp =1\&SID=28ac4dbfeabba7d842fc8544fc835881\&ty=HTML\&h=L\&r=SECTION

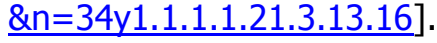

- May I apply to do research on non-U.S. topics or using non-U.S. data? Yes, but research supported by the Institute must be relevant to education in the United States.

- May I apply if I am not located in the United States or if I want to collaborate with researchers located outside of the United States? Yes, you may submit an application if your institution is not located in the territorial United States. You may also propose working with sub-awardees who are not located in the territorial United States. In both cases, your proposed work must be relevant to education in the United States. Also, institutions not located in the territorial U.S. (both primary grantees and sub-awardees) cannot charge indirect costs.

\section{CHANGES IN THE FY 2015 REQUEST FOR APPLICATIONS}

There are a number of changes to the RFA and the Special Education Research Grants program (CFDA 84.324A) competition in FY 2015. You should carefully read the requirements listed under each topic (see Part II Topic Requirements) and each goal (see Part III Goal Requirements), as well as the instructions for preparing your application (see Part V Preparing your Application) to ensure that you understand and follow these changes. Major changes include the following: 
- Information about how to prepare and submit applications electronically through Grants.gov is now included in the Request for Applications.

- The Institute has modified the formatting of the RFA to clarify the minimum requirements for an application to be sent forward for peer review.

- In Part II Topic Requirements, each topic includes a set of Sample, Outcomes, and Setting requirements that must be met for an application to be considered responsive and sent forward for scientific peer review. In addition, the Institute identifies additional considerations in each topic domain and encourages applications that address these issues. The Institute's peer-review process however, is not designed to give preferential treatment to applications that address these issues.

- In Part III Goal Requirements, for each Goal, each section of the Project Narrative (Significance, Research Plan, Personnel, and Resources) includes a set of Requirements that must be met for an application to be considered responsive and sent forward for scientific peer review. These Requirements are followed by a set of Recommendations that the Institute offers in order to improve the quality of your application.

- The Institute has added a Glossary of important terms at the end of this document; the first use of each term is hyperlinked to the Glossary within each Part of this RFA, and within each Goal section within Part III.

- The Requirements for the Research Plan for each Goal include a Dissemination Plan in which you are to identify the audiences that you expect will be most likely to benefit from your research (e.g., other researchers, federal or state policymakers, state and local school system administrators, principals, teachers, counselors, parents, students, and others) and to discuss the ways in which you intend to reach these audiences through the major publications, presentations, and products you expect from your project.

- There are two changes in requirements for applications under the Efficacy and Replication goal:

- A Data Management Plan is required in anticipation of forthcoming federal policy changes regarding data access, but will not be evaluated in the peer review of an application. Instead, the Institute's Program Officers will be responsible for reviewing the completeness of the proposed plan for applications that are recommended for funding.

- A Cost Analysis plan is required to help schools and districts understand the monetary costs of implementing the intervention that is being evaluated.

- The Appendices have been modified as follows:

- Appendix $A$ is now limited to 3 pages and is required if you are resubmitting an application that received peer reviewer feedback in a prior competition year. You must use this appendix to describe how the revised application is responsive to prior reviewer comments.

- Given this change to Appendix A, the other appendices have been modified as follows:

- Appendix B is now used for tables, charts, and figures that supplement the 25page project narrative;

- Appendix $\mathrm{C}$ is now used for examples of materials used in an intervention or assessment that is the focus of your proposed research;

- Appendix $D$ is now used for letters of agreement from partners (e.g., schools or districts) or data sources (e.g., agencies that hold data to be analyzed); and

- Appendix E is new and is only used for Efficacy and Replication or Effectiveness applications to describe your Data Management Plan. 


\section{E. READING THE REQUEST FOR APPLICATIONS}

The Institute encourages both Principal Investigators and Authorized Organization

Representatives to read this Request for Applications to learn how to prepare an application that meets all of the following criteria. These criteria are required for an application to be sent forward for peer review.

- RESPONSIVE

- Meets Sample, Outcome, and Setting requirements for the selected Topic (see Part II).

- Meets Project Narrative and Award requirements for the selected Research Goal (see Part III).

- COMPLIANT (see Part V)

$\circ \quad$ Follows formatting and font size requirements.

○ Follows page limits.

- Includes only allowable content.

- Includes all required content

- SUBMITTED ELECTRONICALLY VIA GRANTS.GOV ON TIME - THE INSTITUTE DOES NOT ACCEPT LATE APPLICATIONS (see Part VI)

- Submitted no later than 4:30:00 p.m., Washington, DC time, on August 7, 2014.

- Completed using the correct application package downloaded from Grants.gov.

- Includes PDF files that are named and formatted appropriately and that are attached to the proper forms in the application package. 


\section{PART II: TOPIC REQUIREMENTS}

\section{A. APPLYING TO A TOPIC}

For the FY 2015 Special Education Research Grants program, you must submit to 1 of the 11 research topics described in Part II. ${ }^{2}$ The Institute strongly encourages you to contact the relevant Program Officer listed under each topic if you have questions regarding the appropriateness of a particular project for submission under a specific topic.

The research topic identifies your field of research. The Institute recognizes that some applications may meet the requirements of more than one topic. For example, an application to develop technology to support elementary students' mathematical skills could meet the requirements of the Technology for Special Education topic or the Mathematics and Science Education topic. In such cases, you may choose either topic as long as your application meets the specific Sample, Outcomes, Setting, and Intervention Provider requirements for that topic.

The requirements of the grade or age range as well as the disability status covered under each topic may vary as indicated in the following chart. This information is also presented under the topic descriptions later in this section.

\begin{tabular}{|c|c|c|c|c|c|}
\hline \multirow[t]{2}{*}{ Topics } & \multicolumn{3}{|c|}{ Grade Level } & \multicolumn{2}{|c|}{ Disability Status } \\
\hline & Infant/Toddler & Preschool & $\mathrm{K}-12$ & $\begin{array}{l}\text { Identified } \\
\text { Disability }\end{array}$ & $\begin{array}{l}\text { At risk for } \\
\text { a disability }\end{array}$ \\
\hline Autism Spectrum Disorders & & $\mathrm{X}$ & $\mathrm{X}$ & $\mathrm{X}$ & \\
\hline $\begin{array}{l}\text { Cognition and Student Learning } \\
\text { in Special Education }\end{array}$ & $\mathrm{X}$ & $\mathrm{X}$ & $\mathrm{X}$ & $x$ & $x$ \\
\hline $\begin{array}{l}\text { Early Intervention and Early } \\
\text { Learning in Special Education }\end{array}$ & $\mathrm{X}$ & $\mathrm{X}$ & & $\mathrm{x}$ & $\mathrm{X}$ \\
\hline $\begin{array}{l}\text { Families of Children with } \\
\text { Disabilities }^{3}\end{array}$ & & & $\bar{x}$ & $\mathrm{X}$ & \\
\hline $\begin{array}{l}\text { Mathematics and Science } \\
\text { Education }\end{array}$ & & & $x$ & $\mathrm{X}$ & $x$ \\
\hline $\begin{array}{l}\text { Professional Development for } \\
\text { Teachers and Related Services } \\
\text { Providers }\end{array}$ & & & $\mathrm{X}$ & $x$ & $x$ \\
\hline $\begin{array}{l}\text { Reading, Writing, and Language } \\
\text { Development }\end{array}$ & & & $X$ & $x$ & $x$ \\
\hline $\begin{array}{l}\text { Social and Behavioral Outcomes } \\
\text { to Support Learning }\end{array}$ & & & $\mathrm{X}$ & $\mathrm{X}$ & $\mathrm{X}$ \\
\hline $\begin{array}{l}\text { Special Education Policy, } \\
\text { Finance, and Systems }\end{array}$ & & & $\mathrm{X}$ & $\mathrm{X}$ & $\mathrm{X}$ \\
\hline $\begin{array}{l}\text { Technology for Special } \\
\text { Education }\end{array}$ & $\mathrm{X}$ & $\mathrm{X}$ & $\bar{x}$ & $x$ & $x$ \\
\hline $\begin{array}{l}\text { Transition Outcomes for } \\
\text { Secondary Students with } \\
\text { Disabilities }\end{array}$ & & & $\begin{array}{c}\mathrm{X} \\
\begin{array}{c}\text { (secondary } \\
\text { only) }\end{array} \\
\end{array}$ & $\mathrm{X}$ & \\
\hline
\end{tabular}

\footnotetext{
${ }^{2}$ You must identify your chosen topic area on the SF-424 Form (Item 4b) of the Application Package (see Part VI.E.1.), or the Institute may reject your application as nonresponsive to the requirements of this RFA.

${ }^{3}$ Applicants interested in research on families of infants, toddlers, and preschool children should refer to the Early Intervention and Early Learning in Special Education topic. 


\section{Student Grade Level}

An application may span grade ranges for several topics. For research that runs from preschool through early elementary grades, you may apply to Early Intervention and Early Learning in Special Education or to another topic that focuses on grades $\mathrm{K}-12$ and has the appropriate sample, outcomes, setting, and intervention provider requirements. The Institute recommends that you consider the key student outcomes, the grade(s) from which data will be collected, and the setting in which the research will be most relevant when choosing a topic. Contact the Institute's Program Officers with any questions you may have about topics.

\section{Student Disability}

For the purpose of Institute's special education research programs, a student with a disability is defined in Public Law 108-446, the Individuals with Disabilities Education Improvement Act of 2004 (IDEA), as a child "(i) with mental retardation, hearing impairments (including deafness), speech or language impairments, visual impairments (including blindness), serious emotional disturbance (referred to in this title as 'emotional disturbance'), orthopedic impairments, autism, traumatic brain injury, other health impairments, or specific learning disabilities; and (ii) who, by reason thereof, needs special education and related services" (Part A, Sec. 602). An infant or toddler with a disability is defined in IDEA as, "an individual under 3 years of age who needs early intervention services because the individual (i) is experiencing developmental delays, as measured by appropriate diagnostic instruments and procedures in 1 or more of the areas of cognitive development, physical development, communication development, social or emotional development, and adaptive development; or (ii) has a diagnosed physical or mental condition that has a high probability of resulting in developmental delay" (Part C, Sec. 632).

The Institute encourages research on high-incidence and low-incidence disabilities, and English learners with disabilities, across all topic areas and goals.

For topics that allow you to study children at risk for a disability, you must present researchbased evidence of an association between risk factors in your proposed sample and the potential identification of specific disabilities. The determination of at risk for disabilities status must be made on an individual child basis and may include, for example, factors used for moving children to higher tiers in a Response to Intervention model. The method to be used for determining if a child is at risk for developing a specific disability must be made explicit in applications and must be completed as part of the sample selection process. Evidence consisting only of general population characteristics (e.g., labeling children as "at risk for disabilities" because they are from low income families or are English learners) is not sufficient for this purpose. In addition, you must identify the disability or disability categories that the sampled children are at risk of developing.

Across all topics, students without disabilities may be included in your sample (e.g., an inclusive classroom) if appropriate for the research questions. For example, students without disabilities may be part of the comparison population or part of the research sample for assessment development and validation.

For each topic, the following pages describe the purpose and requirements, list the Program Officer, and describe considerations when conducting your research. 


\section{Autism Spectrum Disorders}

Program Officer: Kimberley Sprague, Ed.M. (202-208-1609; Kimberley.Spraque@ed.gov)

\section{a) Purpose}

The Autism Spectrum Disorders (ASD) topic supports research on the development, implementation, and evaluation of comprehensive school-based interventions (i.e., interventions that directly target, in a coordinated fashion, multiple outcomes) intended to improve outcomes for students identified with ASD.

Disability Focus: With disability only

According to the Centers for Disease Control and Prevention (2014), 1 in 68 children is classified as having an ASD. This prevalence creates an extraordinary demand on schools to provide interventions that meet the educational needs of students identified with ASD. The highly variable cognitive and behavioral phenotype associated with ASD creates a significant challenge in developing and implementing effective interventions that address the range of developmental and academic needs of students with ASD.

The long-term outcome of this program will be an array of comprehensive programs and assessments that have been documented to be effective for improving the developmental, cognitive, communicative, academic, social, behavioral, and functional outcomes of students identified with ASD from preschool through Grade 12.

\section{b) Requirements}

Applications under the ASD topic must meet the sample, outcomes, setting, and intervention provider requirements listed below in order to be responsive and sent forward for scientific peer review.

(1) Sample

- Your research must focus on students with ASD in preschool through Grade 12.

(2)

\section{Outcomes}

- Your research must address two or more of the following distinct categories: developmental, cognitive, communicative, academic, social, behavioral, or functional outcomes.

- Applicants who wish to study interventions that focus exclusively on one outcome, even though that outcome fits more than one category (e.g., a particular social-communication skill), are not eligible for the ASD topic.

(3)

\section{Setting}

- Your research must be conducted in authentic preschool or K-12 education settings, or use data collected from such settings.

$\circ$ For interventions in K-12 settings, school-based interventions may be integrated with home-based or clinic-based interventions.

(4)

\section{Intervention Provider}

- Interventions may be delivered by:

- Teachers or other school professionals (e.g., related services providers, paraprofessionals), and/or

- Parents or clinic-based staff if the interventions are integrated with home-based or clinic-based interventions.

\section{c) Considerations for ASD Research}

Through this funding mechanism, the Institute supports field-generated research that meets the requirements for the ASD topic and the requirements for one of the Institute's five research goals (see Part III Goal Requirements). The Institute also encourages applicants to consider the issues listed below. 
Some of these considerations are research gaps that the Institute has identified, and others are issues to keep in mind when you conduct this type of research. The Institute's peer-review process is not designed to give preferential treatment to applications that address these issues; rather, the Institute encourages such applications because, if found to have scientific merit by the Institute's independent peer reviewers, they have the potential to lead to important advances in the field.

- Investigators studying children with ASD frequently have difficulty obtaining the necessary sample size for group designs, particularly for randomized controlled trials. Therefore, to conduct research using group designs, applicants are urged to consider challenges in recruiting and retaining participants with ASD when they determine sample size. Such solutions may, but are not required to, include recruiting participants at multiple sites, setting sample goals greater than what would normally be required for adequate power, or obtaining letters of agreement from schools and districts that explicitly state the number of attending students with ASD who meet your proposed sample requirements.

- Systematic experimentation of intervention content, features (e.g., instructional strategies, frequency, duration), and implementation variables (e.g., grouping, setting) as well as analyses of mediators and moderators of treatment effects are needed to determine which interventions may have the best short- and long-term effects for which students with ASD.

- The field needs development and efficacy testing of comprehensive ASD interventions designed for students in secondary school. There is a relative dearth of research on comprehensive school-based interventions for older children and adolescents with ASD, particularly in the middle school years (Fleury et al., 2014).

For more information on this topic and to view the abstracts of previously funded projects, please visit: http://ies.ed.gov/funding/ncser_rfas/ncser_autism.asp. Please contact the program officer for this topic to discuss your choice of topic and goal, and to address other questions you may have. 


\section{Cognition and Student Learning in Special Education}

Program Officer: Kimberley Sprague, Ed.M. (202-208-1609; Kimberley.Spraque@ed.gov)

\section{a) Purpose}

The Cognition and Student Learning in Special Education (Cognition) topic supports research that utilizes cognitive science to develop, implement, and evaluate approaches that are intended to improve developmental outcomes for infants and toddlers with disabilities or at risk for disabilities and learning for students with or at risk for disabilities in preschool through Grade 12.

The Institute intends to establish a scientific foundation for learning and development in special education by building on the theoretical and empirical advances that have been gained through the cognitive sciences and applying them to special education practice.

\section{Disability Focus: With or at risk for disability}

The long-term outcome of this program will be an array of tools and strategies (e.g., instructional approaches) that are based on principles of learning and information processing gained from cognitive science and demonstrated effective for improving developmental outcomes for infants and toddlers with or at risk for disabilities and learning for students with or at risk for disabilities in preschool through Grade 12.

\section{b) Requirements}

Applications under the Cognition topic must meet the sample, outcomes, setting, and intervention provider requirements listed below in order to be responsive and sent forward for scientific peer review.

(1)

\section{Sample}

- Your research must focus on infants, toddlers, or students in preschool through Grade 12 with disabilities or at risk for disabilities.

- Research with college students is allowable provided that (1) you are proposing an exploration study and within the award period you also examine the relation between the malleable factors and outcomes with the student population of interest, OR (2) you are proposing a development study and research with college students provides a means to identify underlying principles or to test critical components of an intervention that is being developed. However, within the award period, the interventions must be tested for use with the student population for which the intervention is intended.

\section{(2)}

\section{Outcomes}

- Your research must focus on student developmental (e.g., cognitive, communication, language skills) or academic outcomes of pre-reading, reading, pre-writing, writing, early mathematics, mathematics, early science, science, or study skills.

\section{(3) Setting}

- Your research must be conducted in authentic education settings for infants and toddlers, preschool settings, or K-12 education settings, or use data collected from such settings.

\section{(4) Intervention Provider}

- Interventions may be delivered by teachers, school psychologists, related services providers, other school-based or school-affiliated staff (e.g., clinical psychologists working with a school district), and/or 
- Parents or service delivery professionals who are implementing the intervention in another natural setting.

\section{c) Considerations for Cognition Research}

Through this funding mechanism, the Institute supports field-generated research that meets the requirements for the Cognition topic and the requirements for one of the Institute's five research goals (see Part III Goal Requirements). The Institute also encourages applicants to consider the issues listed below. Some of these considerations are research gaps that the Institute has identified, and others are issues to keep in mind when you conduct this type of research. The Institute's peer-review process is not designed to give preferential treatment to applications that address these issues; rather, the Institute encourages such applications because, if found to have scientific merit by the Institute's independent peer reviewers, they have the potential to lead to important advances in the field.

- Collaboration between cognitive scientists and special education researchers is needed to examine the similarities and differences in cognitive processing between children with and without disabilities, to explore explicit links between the underlying process and developmental or academic outcomes, or to develop interventions based on knowledge of cognitive processing in children with or at risk for disabilities.

- Research is needed to determine the efficacy of interventions for children with or at risk for disabilities who feature impairments in cognitive processes.

- Measures are needed that are valid for testing cognitive processes associated with learning in children with disabilities or can be used to assess whether children have or are at risk for a specific type of cognitive impairment.

For more information on this topic and to view the abstracts of previously funded projects, please visit: http://ies.ed.gov/funding/ncser rfas/ncser casl.asp. Please contact the program officer for this topic to discuss your choice of topic and goal, and to address other questions you may have. 


\section{Early Intervention and Early Learning in Special Education}

Program Officer: Amy Sussman, Ph.D., (202-219-2126; Amy.Sussman@ed.gov)

\section{a) Purpose}

The Early Intervention and Early Learning in Special Education (Early Intervention) topic supports research that contributes to the improvement of developmental outcomes and school readiness of infants, toddlers, and young children (from birth through age 5) with disabilities or at risk for disabilities.

More than one million infants, toddlers, and young children (birth through five years old) receive early intervention or early childhood special education services under IDEA, representing a 35\% increase in the number of children served over the last ten years (U.S. Department of Education, 2012). As the population of children identified with disabilities increases, more research is needed to determine the most effective practices, programs, and systems, including assessments for screening and monitoring progress, for improving child outcomes and ultimately success in school.

The Institute supports research on early intervention and early learning practices, curricula, professional development, measurement, and systems-level programs and policies. The Institute also supports research in this topic that contributes to the identification of effective strategies for improving family involvement in the development of their child with a disability and family support of their child with a disability in ways that improve outcomes for children birth to age 5 .

The long-term outcome of this program will be an array of tools and strategies (e.g., assessment tools, curricula, programs, services, interventions) that have been documented to be effective for improving developmental outcomes or school readiness of infants, toddlers, and young children with disabilities or at risk for disabilities.

\section{b) Requirements}

Applications under the Early Intervention topic must meet the sample, outcomes, setting, and intervention provider requirements listed below in order to be responsive and sent forward for scientific peer review.

(1) Sample

- Your research must focus on infants, toddlers, or preschool children with disabilities or at risk for disabilities.

- Research focused on early interventionists or preschool educators (including professional development or assessment) should be submitted to the Early Intervention topic. Professional development interventions must target professionals or paraprofessionals who provide services to infants, toddlers, or preschool children with disabilities or at risk for disabilities.

- Interventions may include training provided to parents to enable them to deliver interventions to their child.

\section{(2)}

\section{Outcomes}

- Your research must address either developmental outcomes pertaining to cognitive, communicative, linguistic, social, emotional, adaptive, functional or physical development or school readiness outcomes (i.e., pre-reading, pre-writing, early mathematics, early science, or social-emotional skills that prepare young children for school). 


\section{Setting}

- Your research must be conducted in authentic education settings for infants and toddlers or preschool settings, or use data collected from such settings.

(4)

\section{Intervention Provider}

- Interventions may be delivered by early intervention specialists, teachers, school or centerbased staff, related services providers (e.g., speech-language pathologists, physical therapists), or parents.

\section{c) Considerations for Early Intervention Research}

Through this funding mechanism, the Institute supports field-generated research that meets the requirements for the Early Intervention topic and the requirements for one of the Institute's five research goals (see Part III Goal Requirements). The Institute also encourages applicants to consider research gaps that the Institute has identified. The Institute's peer-review process is not designed to give preferential treatment to applications that address these issues; rather, the Institute encourages such applications because, if found to have scientific merit by the Institute's independent peer reviewers, they have the potential to lead to important advances in the field.

- There is a need for research on systemic interventions intended to directly or indirectly improve developmental outcomes or school readiness of infants, toddlers, or young children with or at risk for disabilities. Examples of systemic interventions include (a) programs to improve the development and implementation of Individualized Family Service Plans or preschoolers' Individualized Education Programs; (b) programs or procedures intended to better coordinate service delivery systems; (c) Response to Intervention approaches; and (d) interventions intended to improve collaboration among families, services providers, and educators and promote smooth transitions as children move from Early Intervention services to preschool settings.

- Research is needed to improve the quality and effectiveness of the early intervention and early learning workforce so that these professionals have the skills and abilities necessary to improve young children's developmental, social-emotional, and cognitive outcomes. For example, more research is needed related to the format and content of professional development that optimizes the development and skill acquisition for infants, toddlers and young children with or at risk for disabilities. Specific areas of research include methods for supporting systemic implementation of professional development programs, identifying the "active ingredients", assessing implementation, and determining the effects of professional development on both proximal and distal outcomes.

- Additional research with infants and toddlers is needed to ensure that those with or at risk for disability can be identified early and access appropriate services leading to improved developmental and school readiness outcomes. There is a lack of research related to the long-term effects of early intervention, the optimal frequency and intensity levels of interventions that lead to the biggest and most sustainable effects, the best ways to support infants and toddlers with or at risk for disabilities during critical transition phases (e.g., to out-of-home care or preschool), the most effective models for family support and collaboration, and assessments to measure intervention programs or policies to ensure accountability to their intended purpose and in line with existing standards.

For more information on this topic and to view the abstracts of previously funded projects, please visit: http://ies.ed.gov/funding/ncser rfas/ncser earlyintervention.asp. Please contact the program officer for this topic to discuss your choice of topic and goal, and to address other questions you may have. 


\section{Families of Children with Disabilities}

Program Officer: Jacquelyn Buckley, Ph.D. (202-219-2130; Jacquelyn.Buckley@ed.gov)

\section{a) Purpose}

The Families of Children with Disabilities (Families) topic supports research that contributes to the identification of effective strategies for improving family involvement in the education of their child with a disability and family support of their child with a disability in ways that improve education or transition outcomes for students with disabilities from kindergarten through Grade 12.

There is a long-standing belief that parent involvement in education and strong family-school partnerships are critical for achieving optimal developmental outcomes and educational success for students with disabilities. Legislation supports this thesis: The Individuals with Disabilities Education Act (IDEA) mandates parental rights and involvement in their child's education. As active members of their child's Individualized Education Program (IEP) team, parents act in partnership with school personnel in planning and making educational decisions about their child with a disability. Little is known, however, about effective ways for supporting the involvement of parents of children with disabilities in ways that improve the education, social, behavioral, functional, or transition outcomes of children with disabilities.

The long-term outcome of this program will be an array of tools and strategies (e.g., assessment tools, programs, services, interventions) that have been documented to be effective for improving family involvement and support of children with disabilities in ways that ultimately improve education or transition outcomes of students with disabilities from kindergarten through Grade 12.

\section{b) Requirements}

Applications under the Families topic must meet the sample, outcomes, setting, and intervention provider requirements listed below in order to be responsive and sent forward for scientific peer review.

(1) Sample

- Your research must focus on students with disabilities in kindergarten through Grade 12.

(2) Outcomes

- Research must address either education or transition outcomes.

- By education outcomes, the Institute means those measures of learning and achievement that are important to parents, teachers, and school administrators (e.g., grades, achievement test scores, graduation rates, percentage of time spent in the general education environment, goals identified on students' IEPs).

- By transition outcomes, the Institute means those behavioral, social, communicative, functional, occupational, and basic academic skills that enable young adults with disabilities to obtain and hold meaningful employment, live independently, and obtain further training and education (e.g., college, vocational education programs).

- Interventions that target parents directly must be interventions that are intended to support students' education or transition outcomes.

\section{(3) Setting}

- Research must be conducted in authentic K-12 education settings, or use data collected from such settings.

- Interventions must be school-based interventions (i.e., programs must be coordinated through the school or district). However, the delivery of the 
intervention may occur in other settings (e.g., home settings, residential treatment programs).

\section{(4) Intervention Provider}

- Interventions may be delivered by:

- Teachers, school psychologists, related services providers, other school-based or school-affiliated staff (e.g., clinical psychologists working with a school district), and/or

- Parents or service delivery professionals who are implementing the school-based intervention in another setting.

\section{c) Considerations for Families Research}

Through this funding mechanism, the Institute supports field-generated research that meets the requirements for the Families topic and the requirements for one of the Institute's five research goals (see Part III Goal Requirements). This topic has only recently been added to the portfolio of research in NCSER and thus a wide variety of work in this field is encouraged. Nonetheless, the Institute encourages applicants to consider the issues listed below. The Institute's peer-review process is not designed to give preferential treatment to applications that address these issues; rather, the Institute encourages such applications because, if found to have scientific merit by the Institute's independent peer reviewers, they have the potential to lead to important advances in the field.

- Collaboration between highly qualified researchers in related fields, such as developmental psychology, and special education researchers is needed to examine families of children with disabilities, including the development and evaluation of school-based interventions aimed at this population.

- Collaboration between those with established research programs in parent-education linkages in typically developing populations and special education researchers is needed to determine how the needs, and therefore effective interventions, of these populations differ.

For more information on this topic and to view the abstracts of previously funded projects, please visit: http://ies.ed.gov/funding/ncser rfas/ncser families.asp. Please contact the program officer for this topic to discuss your choice of topic and goal, and to address other questions you may have. 


\section{Mathematics and Science Education}

Program Officer: Rob Ochsendorf, Ed.D. (202-219-2234; Robert.Ochsendorf@ed.gov)

\section{a) Purpose}

The Mathematics and Science Education (Math/Science) topic supports research that contributes to the improvement of mathematics and science outcomes for students with disabilities or at risk for disabilities from kindergarten through Grade 12.

Students with disabilities lag behind their peers without disabilities in both mathematics and science achievement. For example, in the 2013 National Assessment of Educational Progress (NAEP) mathematics assessment, 65 percent of Grade 8 students with disabilities who participated in the assessment scored below the basic level compared to 21 percent of students without disabilities. In the 2011 NAEP science assessment, 66 percent of Grade 8 students with disabilities who participated in the assessment scored below the basic level in the science assessment compared to 31 percent of Grade 8 students without disabilities.

Through this topic, the Institute is primarily interested in research that addresses core mathematics and science content (e.g., Mathematics: addition/subtraction, fractions, algebra, geometry, trigonometry, calculus; Science: physical science, earth science, life science).

The long-term outcome of this program will be an array of tools and strategies (e.g., assessments, instructional approaches) that have been demonstrated to be effective for improving mathematics and science learning and achievement for students with or at risk for disabilities from kindergarten through Grade 12.

\section{b) Requirements}

Applications under the Math/Science topic must meet the sample, outcomes, setting, and intervention provider requirements listed below in order to be responsive and sent forward for scientific peer review.

(1) Sample

- Your research must focus on students with or at risk for disabilities from kindergarten through Grade 12.

(2)

(3)

\section{(4)}

\section{Outcomes}

- Your research must address mathematics or science outcomes.

\section{Setting}

- Your research must be conducted in authentic K-12 education settings, or use data collected from such settings.

\section{Intervention Provider}

- Interventions may be delivered by teachers, related services providers, or other instructional staff.

\section{c) Considerations for Math/Science Research}

Through this funding mechanism, the Institute supports field-generated research that meets the requirements for the Math/Science topic and the requirements for one of the Institute's five research goals (see Part III Goal Requirements). The Institute also encourages applicants to consider the issues listed below. Some of these considerations are research gaps that the Institute has identified, and others are issues to keep in mind when you conduct this type of research. The Institute's peer-review process is not designed to give preferential treatment to applications that address these issues; rather, the Institute 
encourages such applications because, if found to have scientific merit by the Institute's independent peer reviewers, they have the potential to lead to important advances in the field.

- Under the Math/Science topic, the Institute accepts applications on interventions that could be used as a tier in a Response to Intervention model (e.g., a math intervention delivered in small groups or individually to students who do not make appropriate progress in the general curriculum). This research can include students who have not been identified with a disability but require intensive interventions (e.g., supplementary or tertiary interventions in a Response to Intervention model).

- A number of interventions (e.g., Nemeth code tutorials for students or teachers) have been developed to make mathematics or science content more accessible for students with blindness, visual impairments, deafness, or hearing impairments. Relatively little systematic research has been conducted on the impact of interventions such as these, and the field would benefit from rigorous evaluations of interventions designed to improve outcomes for these student populations.

- Development and evaluation of assessment tools designed to improve instruction are also needed. For example, to improve mathematics and science skills, instruction may need to be tailored to the sources of difficulty that individual students experience. An ideal learning environment might involve regular and frequent assessment of skills and the possibility of individualized instruction for students based on the particular source of their difficulties.

For more information on this topic and to view the abstracts of previously funded projects, please visit: http://ies.ed.gov/funding/ncser rfas/ncser mathsci.asp. Please contact the program officer for this topic to discuss your choice of topic and goal, and to address other questions you may have. 


\section{Professional Development for Teachers and Related Services Providers} Program Officer: Rob Ochsendorf, Ed.D (202-219-2234; Robert.Ochsendorf@ed.gov)

\section{a) Purpose}

The Professional Development for Teachers and Related Services Providers (Professional Development) topic supports research that contributes to the identification of effective strategies for improving the performance of current teachers, other instructional personnel, and related services providers in ways that increase reading, writing, language, mathematics, science, social, behavioral, or secondary transition outcomes, as well as functional skills that improve the educational outcomes of students with disabilities or at risk for disabilities from kindergarten through Grade $12 .{ }^{4}$

\section{Disability Focus: With or at risk for disability (see Sample requirements for exceptions)}

Most students with disabilities (95\%) are educated in general education classrooms for at least some portion of their school day, with more than half of all students with disabilities (57\%) educated in the general education classroom for most of the school day (U.S. Department of Education, 2012). Thus, general and special educators share educational responsibilities for students with disabilities. In the most recent Schools and Staffing Survey nearly one third of the public school teachers indicated that they are not provided the support necessary to teach students with disabilities. Of the teachers surveyed, 36 percent had received professional development during the previous year on addressing the needs of students with disabilities (U.S. Department of Education, 2013).

Through the Professional Development research program, the Institute funds research to improve professional development activities for special education teachers and general education teachers of students with disabilities. Professional development refers to in-service training, tools and other supports, and must be for current personnel. Pre-service training of prospective teachers, related services providers, or other instructional personnel is not eligible for support under this research program. In addition, the Institute does not provide support for development of or research on professional certificate programs and other training programs intended to give non-special education teachers or personnel certification in special education or related services.

Long-term outcomes of the Professional Development program will be an array of tools and strategies (e.g., in-service programs, teacher supports, and assessments) that have been demonstrated to be effective for improving and assessing performance of teachers, related services providers, and other instructional personnel in ways that are linked to improvements in student outcomes.

\section{b) Requirements}

Applications under the Professional Development topic must meet the sample, outcomes, setting, and intervention provider requirements listed below in order to be responsive and sent forward for scientific peer review.

\section{(1)}

\section{Sample}

- Your research must focus on teachers, related services personnel, or other instructional personnel for students with disabilities or at risk for disabilities from kindergarten through Grade 12.

- If related services outcomes are the outcomes of interest, then the research must be relevant to students with disabilities only.

\footnotetext{
${ }^{4}$ Applicants interested in professional development for teachers and other personnel who work with infants, toddlers, and preschool children should see the Early Intervention and Early Learning in Special Education topic.
} 
- If secondary transition outcomes are the student outcomes of interest, then the research must be relevant to secondary (middle or high school) students with disabilities only.

- Professional development for related services professionals must focus on personnel delivering one of the following related services (as defined in $\S 300.34$ of the Part B regulations to the 2004 reauthorization of IDEA): speech-language pathology and audiology services, interpreting services, psychological services, physical and occupational therapy, counseling services, including rehabilitation counseling, orientation and mobility services, and social work services in schools.

- Research on parent training must be submitted to the Families of Children with Disabilities research topic.

(2)

\section{Outcomes}

- Your research must address one or more of the following child outcomes: cognitive, communication, language, reading, writing, mathematics, science, study skills, social skills, emotional and behavioral skills, functional skills, or secondary transitional skills.

\section{(3)}

\section{Setting}

- Your research must be conducted in authentic K-12 education settings, or use data collected from such settings.

\section{(4) Intervention Provider}

- A range of personnel can deliver Professional Development interventions including, but not limited to:

- District and school administrators and leaders or their designees, and/or

- Teachers, school psychologists, related services providers, other school-based or school-affiliated staff (e.g., clinical psychologists working with a school district).

\section{c) Considerations for Professional Development Research}

Through this funding mechanism, the Institute supports field-generated research that meets the requirements for the Professional Development topic and the requirements for one of the Institute's five research goals (see Part III Goal Requirements). The Institute also encourages applicants to consider the issues listed below. Some of these considerations are research gaps that the Institute has identified, and others are issues to keep in mind when you conduct this type of research. The Institute's peer-review process is not designed to give preferential treatment to applications that address these issues; rather, the Institute encourages such applications because, if found to have scientific merit by the Institute's independent peer reviewers, they have the potential to lead to important advances in the field.

- Research on professional development interventions should consider both the content of the programs (i.e., what is it that personnel are expected to learn) as well as the delivery of the content (e.g., coaches, online resources, workshops). Very little research exists that allows for clear causal interpretations of the effect of specific professional development programs or for knowing which elements of professional development programs (e.g., coaching) are critical or relatively more important than others.

- More research is needed to test different delivery modes using content (e.g., instructional practices or intervening strategies) that has already been shown to be effective for improving student outcomes. In all instances, researchers are encouraged to design studies that will provide evidence to help rule out competing hypotheses. 
For more information on this topic and to view the abstracts of previously funded projects, please visit: http://ies.ed.gov/funding/ncser rfas/ncser_professionaldev.asp. Please contact the program officer for this topic to discuss your choice of topic and goal, and to address other questions you may have. 


\section{Reading, Writing, and Language Development}

Program Officer: Kristen Rhoads, Ph.D. (202-219-0377; Kristen.Rhoads@ed.gov)

\section{a) Purpose}

The Reading, Writing, and Language Development (Reading/Language) topic supports research that improves reading, writing, and language skills of students with or at risk for disabilities.

Compared to their peers without disabilities, students with disabilities continue to struggle in reading. For example, in the 2013 National Assessment of Educational Progress (NAEP) reading assessment, 69 percent of Grade 4 students with disabilities who participated in the assessment scored at below the basic level compared to 27 percent of students without disabilities. For the $8^{\text {th }}$ grade assessment, $60 \%$ of students with disabilities scored at the below basic level compared to $18 \%$ of their peers without disabilities.

The long-term outcome of this program will be an array of tools and strategies (e.g., assessments, instructional approaches) that have been documented to be effective for improving reading, writing, or language outcomes for students with or at risk for disabilities from kindergarten through Grade 12.

\section{b) Requirements}

Applications under the Reading/Language topic must meet the sample, outcomes, setting, and intervention provider requirements listed below in order to be responsive and sent forward for scientific peer review.

\section{(1) Sample}

- Your research must focus on students with disabilities or at risk for disabilities in kindergarten through Grade 12.

(2)

\section{Outcomes}

- Research must address pre-reading, reading, pre-writing, writing, or language outcomes.

(3)

\section{Setting}

- Research must be conducted in authentic K-12 education settings, or use data collected from such settings.

(4)

\section{Intervention Provider}

- Interventions may be delivered by teachers, related services providers, or other instructional staff.

\section{c) Considerations for Reading/Language Research}

Through this funding mechanism, the Institute supports field-generated research that meets the requirements for the Reading/Language topic and the requirements for one of the Institute's five research goals (see Part III Goal Requirements). The Institute also encourages applicants to consider the issues listed below. Some of these considerations are research gaps that the Institute has identified, and others are issues to keep in mind when you conduct this type of research. The Institute's peer-review process is not designed to give preferential treatment to applications that address these issues; rather, the Institute encourages such applications because, if found to have scientific merit by the Institute's independent peer reviewers, they have the potential to lead to important advances in the field.

- Under the Reading/Language topic, the Institute accepts applications on interventions that could be used as a tier in a Response to Intervention model (e.g., a reading intervention delivered in small groups or individually to students who do not make appropriate progress in the general curriculum). This research can include students who have not been 
identified with a disability but require intensive interventions (e.g., supplementary or tertiary interventions in a Response to Intervention model).

- There continues to be a need for research that develops and evaluates literacy-focused interventions for students with low-incidence disabilities, including students with intellectual disabilities and sensory impairments. Many of these students typically demonstrate minimal literacy skills. However, recent research suggests that comprehensive interventions that teach all critical components of reading, including foundational skills like phonemic awareness and phonics, show great promise for improving literacy outcomes (Allor, Mathes, Roberts, Cheatham, \& Champlin, 2010; Bergeron, Lederberg, Easterbrooks, Miller, \& Connor, 2009; Browder, Mimms, Spooner, \& Ahlgrim, 2008).

- On the 2011 NAEP writing assessment, 43 percent of $4^{\text {th }}$ graders scored at below basic levels, and outcomes declined for students in later grades with 63 percent of $8^{\text {th }}$ graders and 64 percent of $12^{\text {th }}$ graders scoring below basic. Research is needed that focuses on improving writing skills and preventing their decline as use of language and writing tasks become more complex.

- Additional research is needed on the development and evaluation of intensive reading interventions for students with specific learning disabilities or at risk for specific learning disabilities with the most intractable learning problems. Increasing instructional intensity incrementally via tiered models of intervention may not be the most efficient, effective, or appropriate approach for these students (Fuchs, Fuchs, \& Compton, 2010; Vaughn et al., 2011). Further research in this area is needed especially for students in late elementary school and higher.

For more information on this topic and to view the abstracts of previously funded projects, please visit: http://ies.ed.gov/funding/ncser rfas/ncser readwrite.asp. Please contact the program officer for this topic to discuss your choice of topic and goal, and to address other questions you may have. 


\section{Social and Behavioral Outcomes to Support Learning}

Program Officer: Jacquelyn Buckley, Ph.D. (202-219-2130; Jacquelyn.Buckley@ed.gov)

\section{a) Purpose}

The Social and Behavioral Outcomes to Support Learning (Social/Behavioral) topic supports research that contributes to the prevention or amelioration of behavior problems in students with or at risk for disabilities and concomitantly, improves their education outcomes.

Behavior problems continue to be a concern for school staff and parents of students with and at risk for disabilities. Research on behavioral interventions and supports designed to manage, control, and prevent a range of behavior and antisocial problems (e.g., social skills deficits, violence toward peers or adults, self-injury, noncompliance, bullying, withdrawal, truancy) in a range of settings (e.g., school, general and special education classrooms, home, work, community) is historically robust. However, much remains to be done to understand and advance the application, scalability, and sustainability of these behavioral interventions and supports in school settings, particularly in alternative settings such as alternative schools or juvenile justice settings.

The long-term outcome of this program will be an array of tools and strategies (e.g., assessments, interventions) that have been documented to be effective for preventing behavior problems and improving the behavioral, emotional, social skills, and likewise, the academic performance of students with or at risk for disabilities from kindergarten through Grade 12.

\section{b) Requirements}

Applications under the Social/Behavioral topic must meet the sample, outcomes, setting, and intervention provider requirements listed below in order to be responsive and sent forward for scientific peer review.

\section{(1) Sample}

- Your research must address students with or at risk for disabilities from kindergarten through Grade 12.

(2) Outcomes

- Your research must address student social, emotional, and behavioral outcomes that support learning and

- Student education outcomes. By education outcomes, the Institute means those measures of learning and achievement that are important to parents, teachers, and school administrators (e.g., grades, achievement test scores, graduation rates, percentage of time spent in the general education environment).

(3)

\section{Setting}

- Research must be conducted in authentic K-12 education settings, or use data collected from such settings

- Interventions must be school-based interventions (i.e., programs must be coordinated through the school or district). However, the delivery of the intervention may occur in other settings (e.g., home settings, residential treatment programs). 


\section{(4) Intervention Provider}

- Interventions may be delivered by teachers, school psychologists, related services providers, other school-based or school-affiliated staff (e.g., clinical psychologists working with a school district), or parents.

\section{c) Considerations for Social/Behavioral Research}

Through this funding mechanism, the Institute supports field-generated research that meets the requirements for the Social/Behavioral topic and the requirements for one of the Institute's five research goals (see Part III Goal Requirements). The Institute also encourages applicants to consider the research gaps that the Institute has identified. The Institute's peer-review process is not designed to give preferential treatment to applications that address these issues; rather, the Institute encourages such applications because, if found to have scientific merit by the Institute's independent peer reviewers, they have the potential to lead to important advances in the field.

- There continues to be a need for research that integrates the disciplines of special education and mental health with the goal of preventing school-based behavior problems and improving the academic outcomes for students with disabilities. Considerable work focusing on interventions that are aimed at preventing or ameliorating behavior disorders in children and youth has been conducted in the areas of developmental psychopathology, prevention research, and children's mental health services. Much of this work focuses on improving social and behavioral functioning in schools and other community settings, yet there continue to be a need to bridge these efforts with prevention and intervention research in special education, particularly evaluating the impact of those programs on school-based behavior and academic outcomes, including referral and classification for special education.

- $\quad$ Research is needed to understand the interplay among internalizing disorders, externalizing disorders, and educational difficulties. Although externalizing problems account for the majority of identified children's mental health problems, internalizing problems can cooccur in children (e.g., Kessler, Berglund, Demler, Jin, \& Walters, 2005; Masten et al., 2005; van Steensel, Bögels, \& de Bruin, 2013). A more comprehensive understanding of the relationship between both types of problems, and the development of interventions that address this understanding, is needed. There is also much to learn regarding the association among internalizing problems, externalizing problems, and achievement. The extant literature on the link between mental health symptoms and educational difficulties suggests that the early treatment of internalizing, externalizing, and learning problems has important educational and mental health implications (Reddy, Newman, De Thomas, \& Chun, 2009).

For more information on this topic and to view the abstracts of previously funded projects, please visit: http://ies.ed.gov/funding/ncser rfas/ncser socialbeh.asp. Please contact the program officer for this topic to discuss your choice of topic and goal, and to address other questions you may have. 


\section{Special Education Policy, Finance, and Systems}

Program Officer: Kristen Rhoads, Ph.D. (202-219-0377; Kristen.Rhoads@ed.gov)

\section{a) Purpose}

The Special Education Policy, Finance, and Systems

(Policy/Systems) topic supports research that contributes to the improvement of education for students with disabilities or at risk for disabilities from kindergarten through Grade $12^{5}$.

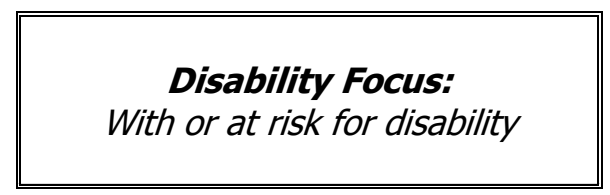

Intervention and education for students with disabilities typically require the coordination of a variety of programs and services. Little rigorous research has examined either direct causal relations or indirect associations between student outcomes and various systemic or organizational strategies. Through the Policy/Systems program, the Institute supports research to improve outcomes for students with disabilities or at risk for disabilities by identifying systemic processes, procedures, and programs that may be directly or indirectly linked to student outcomes. That is, rather than focusing on improving student outcomes by changing curricula or student-level intervention approaches, researchers will conduct research on systems-level practices and policies (e.g., organizational strategies, financial and management practices) that are intended to improve the management, coordination, and implementation of systemic programs and services in ways that directly enhance the overall intervention or education environment, and indirectly improve student outcomes.

The long-term outcome of this program will be an array of systems-level practices and policies that have been documented to be effective for improving the education or intervention environment and thereby improving outcomes for students with or at risk for disabilities from kindergarten through Grade 12.

\section{b) Requirements}

Applications under the Policy/Systems topic must meet the sample, outcomes, setting, and intervention provider requirements listed below in order to be responsive and sent forward for scientific peer review.

\section{(1) Sample}

- Your research must focus on finance, policies, systemic interventions, or assessments of schools or districts that serve students with or at risk for disabilities from kindergarten through Grade 12.

(2)

\section{Outcomes}

- Your research must include measures of classroom-, school-, or district-level outcomes that are to be improved through the programs or polices.

- Your research must include measures of student outcomes (e.g., graduation, achievement tests, grades, transition to post-school settings, and behavioral outcomes).

(3)

\section{Setting}

- Research must be conducted in authentic K-12 education settings, or use data collected from such settings.

\section{(4) Intervention Provider}

- A range of personnel can implement Policy/Systems interventions, including:

$\circ$ District and school administrators and leaders or their designees,

\footnotetext{
${ }^{5}$ Research that focuses on finance, policies, systemic interventions, or assessments relevant to infants, toddlers, or young children (i.e., birth through age 5) should apply to the Early Intervention and Early Learning in Special Education research program. 
- Teachers, school psychologists, related services providers, other school-based or school-affiliated staff (e.g., clinical psychologists working with a school district), and/or

- Parents or service delivery professionals who are implementing the school-based intervention in another setting.

\section{c) Considerations for Special Education Policy, Finance, and Systems Research}

Through this funding mechanism, the Institute supports field-generated research that meets the requirements for the Policy/Systems topic and the requirements for one of the Institute's five research goals (see Part III Goal Requirements). The Institute also encourages applicants to consider the research gaps that the Institute has identified. The Institute's peer-review process is not designed to give preferential treatment to applications that address these issues; rather, the Institute encourages such applications because, if found to have scientific merit by the Institute's independent peer reviewers, they have the potential to lead to important advances in the field.

- Many states have adopted state standards that define knowledge and skills that all students, including students with disabilities, should acquire in $\mathrm{K}-12$ education to be college and career ready. Much research is needed to understand how these standards are taught and assessed for students with disabilities. For example, research is needed to evaluate the impact of state or district policies or programs for implementing the standards and outcomes for students with disabilities. In addition, research is needed related to supports and accommodations that maximize students' access to these standards.

- Although there have been advances in the development and evaluation of assessments of students with disabilities for school accountability purposes, much work remains to better understand, for example, (1) assessment of students with the most significant cognitive disabilities, (2) valid accommodations for students with a range of disability types and severity, and (3) reliable measurement and reporting of schools' progress in improving academic performance of students with disabilities.

- Questions remain as to the most effective and efficient allocation of resources for educating students with and at risk for disability. The Institute encourages research that explores meaningful links among special education financing, allocation of resources, and improvements in student outcomes.

For more information on this topic and to view the abstracts of previously funded projects, please visit: http://ies.ed.gov/funding/ncser rfas/ncser systemic.asp. Please contact the program officer for this topic to discuss your choice of topic and goal, and to address other questions you may have. 


\section{Technology for Special Education}

Program Officer: Rob Ochsendorf, Ed.D. (202-219-2234; Robert.Ochsendorf@ed.gov)

\section{a) Purpose}

The Technology for Special Education (Technology) topic supports research on education technology tools that are designed to improve outcomes for infants, toddlers, preschool children, and students from kindergarten through Grade 12 with or at risk for disabilities.

Through the Technology research program, the Institute supports research on a wide-array of special education technology products that are intended (a) to improve reading, writing, mathematics, and science outcomes or general study skills for students with or at risk for disabilities from kindergarten through Grade 12; (b) to improve developmental outcomes or school readiness for infants, toddlers, preschoolers with or at risk for disabilities; (c) to assess student learning; (d) to improve social and behavioral, functional and adaptive outcomes for students with or at risk for disabilities from prekindergarten through Grade 12; and (d) to improve transition outcomes for secondary students with disabilities. Also appropriate under this topic is research on technology to improve professional development of teachers, related services providers, or other instructional personnel who work with students with or at risk for disabilities.

The long-term outcome of this program will be an array of education technology tools that have been documented to be effective for improving outcomes for children with or at risk for disabilities.

\section{b) Requirements}

Applications under the Technology topic must meet the sample, outcomes, setting, and intervention provider requirements listed below in order to be responsive and sent forward for scientific peer review.

(1) Sample

- Your research must focus on infants, toddlers, preschool children, or students from kindergarten through Grade 12 with disabilities or at risk for disabilities, OR

- Your research must focus on teachers, related services providers, or other instructional personnel who work with infants, toddlers, preschool children, or students from kindergarten through Grade 12 with disabilities or at risk for disabilities.

(2)

\section{Outcomes}

- Your research on students in K-12 must address technology products that are intended to improve reading, writing, mathematics, science, social and behavioral, functional and adaptive, transition, or general study skills.

- Your research on infants, toddlers, and preschool children must address technology products that are intended to improve either developmental outcomes pertaining to cognitive, communicative, linguistic, social, emotional, adaptive, functional or physical development, or school readiness outcomes.

\section{(3) Setting}

- Your research must be conducted in authentic education settings for infants and toddlers, preschool settings, or K-12 education settings, or use data collected from such settings 


\section{(4) Intervention Provider}

- Education technology products may be for direct use by children with or at risk for disabilities or by teachers, related services providers, other instructional personnel, or parents.

\section{c) Additional Considerations for Technology Research}

Through this funding mechanism, the Institute supports field-generated research that meets the requirements for the Technology topic and the requirements for one of the Institute's five research goals (see Part III Goal Requirements). The Institute also encourages applicants to consider the research gaps that the Institute has identified. The Institute's peer-review process is not designed to give preferential treatment to applications that address these issues; rather, the Institute encourages such applications because, if found to have scientific merit by the Institute's independent peer reviewers, they have the potential to lead to important advances in the field.

- Additional development research is needed for technology-based interventions, such as simulations, multimedia, and virtual reality, to support students with physical disabilities as they experiment with science concepts or to support students with disabilities in learning science and mathematics (e.g., supported electronic text).

- The field would also benefit from the development and validation of education technology measurement tools to be used for instructional purposes (e.g., progress monitoring).

For more information on this topic and to view the abstracts of previously funded projects, please visit: http://ies.ed.gov/funding/ncser rfas/ncser tech.asp. Please contact the program officer for this topic to discuss your choice of topic and goal, and to address other questions you may have. 


\section{Transition Outcomes for Secondary Students with Disabilities}

Program Officer: Kimberley Sprague, Ed.M. (202-208-1609; Kimberley.Spraque@ed.gov)

\section{a) Purpose}

The Transition Outcomes for Secondary Students with

Disabilities (Transition) topic supports research that contributes to the improvement of transition outcomes of secondary students with disabilities. Transition outcomes include the behavioral, social, communicative, functional, occupational, and academic skills that enable young adults with disabilities to obtain and hold meaningful employment, live independently, and obtain further training and education (e.g., postsecondary education, vocational education programs).

Education practitioners and policymakers face considerable challenges in improving transition outcomes for secondary students with disabilities. According to reports from the National Longitudinal Transition Study-2 (NLTS2; Wagner, Newman, Cameto, \& Levine, 2006; Newman, Wagner, Cameto, \& Knokey, 2009), six to eight times as many students with disabilities scored more than two standard deviations below the mean (i.e., scores below 70) on measures of academic performance when compared to students without disabilities. Individuals with disabilities were also significantly less likely to attend postsecondary education ( 45 percent) than were individuals without disabilities ( 53 percent). In addition, about 15 percent of youth with disabilities were not engaged in their community either through postsecondary education, job training, or employment.

The long-term outcome of this program will be an array of tools and strategies (e.g., assessments, intervention programs) that have been documented to be effective in improving transition outcomes for secondary students with disabilities.

\section{b) Requirements}

Applications under the Transition topic must meet the sample, outcomes, setting, and intervention provider requirements listed below in order to be responsive and sent forward for scientific peer review.

(1) Sample

- Your research must focus on secondary (middle or high school) students with a disability.

- Students with disabilities who are 18 years or older and are still receiving services under IDEA are allowed to be included in the sample.

- Your sample may also include students with disabilities at the post-secondary level if the purpose is to improve services and interventions provided at the secondary level (e.g., you may collect data from recent high school graduates to inform the development of a school-based or community-based transition program for high school students with disabilities).

(2)

\section{Outcomes}

- Your research must include measures of transition outcomes. By transition outcomes, the Institute means those behavioral, social, communicative, functional, occupational, and basic academic skills that enable youth and young adults with disabilities to obtain and hold meaningful employment, live independently, and obtain further training and education (e.g., college, vocational education programs). By basic academic skills, the Institute refers to functional literacy and math skills (e.g., adding and subtracting whole numbers or fractions, as well as calculations involving money or time). 
(3)

\section{Setting}

- Your research must be conducted in authentic K-12 education settings (secondary only), or use data collected from such settings

- Eligible intervention programs are those that are school-based alone, school-based

with a home component or community-based component, alternate school settings, or community-based programs that primarily serve individuals receiving IDEA services.

- You may continue interventions that began in secondary school settings to postsecondary settings as a bridge to improving post-school outcomes.

\section{(4) Intervention Provider}

- Interventions may be provided by:

- Teachers, school psychologists, related services providers, other school-based or school-affiliated staff (e.g., clinical psychologists working with a school district), and/or

- Parents or service delivery professionals who are implementing a component of the school-based intervention in another setting.

\section{c) Considerations for Transition Outcomes for Secondary Students with Disabilities Research}

Through this funding mechanism, the Institute supports field-generated research that meets the requirements for the Transition topic and the requirements for one of the Institute's five research goals (see Part III Goal Requirements). The Institute also encourages applicants to consider the issues listed below. Some of these considerations are research gaps that the Institute has identified, and others are issues to keep in mind when you conduct this type of research. The Institute's peer-review process is not designed to give preferential treatment to applications that address these issues; rather, the Institute encourages such applications because, if found to have scientific merit by the Institute's independent peer reviewers, they have the potential to lead to important advances in the field.

- A gap continues to exist between post-high school outcomes for students with disabilities and their peers without disabilities. More rigorous studies, particularly randomized controlled trials, are needed to develop and evaluate interventions intended to improve students' transition from high school to work settings, independent living, or further education and training.

- In order to better understand the causal relationships between intervention and transition outcomes, research on transition outcomes should be broken out by type and severity of disability, not only in the sample description but in the analytic plan.

- Whenever possible and appropriate, research should measure directly post-high school outcomes of interest including for example, post-high school employment, postsecondary education, or independent living.

For more information on this topic and to view the abstracts of previously funded projects, please visit: http://ies.ed.gov/funding/ncser rfas/ncser transition.asp. Please contact the program officer for this topic to discuss your choice of topic and goal, and to address other questions you may have. 


\section{PART III: GOAL REQUIREMENTS}

\section{A. APPLYING UNDER A GOAL}

For the FY 2015 Special Education Research Grants program, you must select one of the five research goals described below. ${ }^{6}$ The Institute strongly encourages you to contact the program officer listed under the topic you intend to apply to in order to discuss your choice of research goal.

The research goals are designed to span the range from basic research with practical implications to applied research (the latter includes development of education interventions and assessments and the evaluation of the impact of interventions when implemented under both ideal conditions and conditions of routine practice).

- The Institute considers interventions to encompass the wide range of education curricula, instructional approaches, professional development, technology, and practices, programs, and policies that are implemented at the student, classroom, school, district, state, or federal level to improve student education outcomes.

- The Institute considers assessments to include "any systematic method of obtaining information from tests and other sources, used to draw inferences about characteristics of people, objects, or programs" (AERA, 1999).

For each goal, the Purpose, Project Narrative Requirements and recommendations, and Award Requirements are listed.

- The requirements for each goal are the minimum necessary for an application to be sent forward for peer review. Your application must meet all Project Narrative and Award Requirements listed for the goal you select in order for your application to be considered responsive and sent forward for peer review.

- In order to improve the quality of your application, the Institute offers recommendations following each set of Project Narrative requirements. The Institute strongly encourages you to incorporate the recommendations into your project narrative.

\footnotetext{
${ }^{6}$ You must identify a specific research goal for your application on the SF-424 Form (Item 4b) of the Application Package (see Part VI.E.1.) or the Institute may reject the application as nonresponsive to the requirements of this Request for Applications. 


\section{Goal One: Exploration}

\section{a) Purpose}

The Exploration goal supports projects that will identify malleable factors associated with student education outcomes and/or the factors and conditions that mediate or moderate that relationship. Exploration projects are intended to build and inform theoretical foundations to support (1) the development of interventions (see Goal Two: Development and Innovation) or the evaluation of interventions (see Goal Three: Efficacy and Replication), or (2) assessment frameworks for the development and validation of assessments (see Goal Five: Measurement).

Projects under the Exploration goal must analyze primary data, secondary data, or both and will result in a conceptual framework that identifies the following: ${ }^{7}$

- A relationship between a malleable factor and a student education outcome, or

- Factors that mediate or moderate this relationship, or

- Both a relationship between a malleable factor and a student education outcome and the factors that mediate or moderate this relationship.

\section{b) Requirements and Recommendations}

Applications under the Exploration goal must meet the requirements set out under (1) Project Narrative and

(2) Awards in order to be responsive and sent forward for scientific peer review. The requirements are the minimum necessary for an application to be sent forward for peer review.

In order to improve the quality of your application, the Institute offers recommendations following each set of Project Narrative requirements.

\section{(1) Project Narrative}

The 25-page project narrative for an Exploration project application must include four sections Significance, Research Plan, Personnel, and Resources.

a. Significance - The purpose of this section is to explain why it is important to study these particular malleable factors and their potential association with student education outcomes.

Requirements: In order to be responsive and sent forward for peer review, applications under the Exploration goal must include a Significance section that describes the following:

(i) Research aims that focus on malleable factors under the control of the education system and the relationship between these factors and student education outcomes.

Recommendations: In order to address the above requirements, the Institute recommends that you include the following in your Significance section to provide a compelling rationale for the proposed exploratory work.

\footnotetext{
${ }^{7}$ Under the Exploration goal, the Institute does not support work to develop an intervention or to test the causal impact of an intervention. If you intend to examine an intervention that first requires further development, you should apply under the Development and Innovation goal. Similarly, if you intend to combine existing interventions (or components from different interventions) into a single new intervention and examine that new intervention, you should apply under the Development and Innovation goal. If you intend to estimate the causal impact of an intervention, you should apply under the Efficacy and Replication goal.

For awards beginning in FY 2015

Special Education Research, p. 34

Posted April 16, 2014
} 
Project Aims:

- Include a description of the malleable factors, the relationships you expect them to have with specific student education outcomes, and any mediators or moderators you will be studying.

Rationale:

- Include your theory for and evidence that the malleable factors may be associated with beneficial student education outcomes or that the mediators and moderators may influence such an association.

Practical Importance:

- Discuss how the results will go beyond what is already known and how the results will be important both to the field of special education research and to education practice and education stakeholders (e.g., practitioners and policymakers). If you are studying an existing intervention (or a major component of an intervention), discuss how widely the intervention is used and why an Exploration study, in contrast to an Efficacy/Replication evaluation, will have practical importance.

Future Work:

- Discuss how the results of this work will inform the future development of an intervention or assessment or the future decision to evaluate an intervention.

b. Research Plan - The purpose of this section is to describe the methodology you will use to study these particular malleable factors (and mediators or moderators, if applicable) and their potential association with better student education outcomes. Include a description of your research design, sample, measures, data analysis procedures, and plan to disseminate the project's findings.

A variety of methodological approaches are appropriate under the Exploration goal including, but not limited to, the following: (1) primary data collection and analyses, (2) secondary data analyses, (3) meta-analyses that go beyond a simple identification of the mean effect of interventions (Shadish, 1996), or (4) some combination of these three approaches.

Requirements: In order to be responsive and sent forward for peer review, applications under the Exploration goal must include a Research Plan section that describes the following:

(i) A research design (including sample and measures),

(ii) Data analysis procedures, and

(iii) A plan for dissemination.

Recommendations: In order to address the above requirements, the Institute recommends that you include the following in your Research Plan section to strengthen the methodological rigor of the proposed exploratory work and to optimize the dissemination plan.

Research Design:

- Describe your research design with enough detail to show how it is appropriate for addressing your research aims. 
- For Exploration projects involving primary data collection, you may propose to do some laboratory research as long as it adheres to the sample and outcome requirements outlined for the topic you select.

- If you propose laboratory research, justify the amount that you are choosing to do and describe how it will provide relevant evidence for identifying malleable factors that could improve education outcomes in authentic education settings. In addition, the materials and procedures should allow for generalizability to authentic education settings.

Sample:

- Consider your sample and its relation to addressing the overall aims of the project (e.g., what population the sample represents).

- For primary data collection and secondary data analysis, include the following:

- Describe the base population, the sample, and the sampling procedures (including justification for any exclusion and inclusion criteria).

- For all quantitative inferential analyses, demonstrate that the sample provides sufficient power to address your research aims.

- For longitudinal studies using primary data collection, describe strategies to reduce attrition.

- If you intend to link multiple data sets, provide sufficient detail for reviewers to be able to judge the feasibility of the linking plan.

- For meta-analysis, include the following:

- Describe and justify the criteria for including or excluding studies.

- Describe the search procedures for ensuring that a high proportion of eligible studies (both published and unpublished) will be located and retrieved.

- Describe the coding scheme and procedures that will be used to extract data from the respective studies and the procedures for ensuring the reliability of the coding.

- Demonstrate that sufficient numbers of studies are available to support the meta-analysis and that the relevant information is reported frequently enough and in a form that allows an adequate data set to be constructed.

\section{Measures:}

- Describe the measures and key variables you will be using in the study. For the outcome measures, discuss their validity and reliability for the intended purpose and population.

- $\quad$ For secondary data, note the response rate or amount of missing data for the measures.

- If the data will be transformed to create any of the key variables, describe this process.

- For primary data collection, include the following:

- Describe the data to be collected and the procedures for data collection.

- If the data will be transformed to create any of the key variables, describe this process. 
- If observational data or qualitative data are to be collected and analyzed statistically, describe how the data will be collected and coded (including the procedures for monitoring and maintaining inter-rater reliability), and describe the mechanism for quantifying the data if one is needed.

- For meta-analysis, include the following:

- Define the effect size statistics to be used, along with the associated weighting function, procedures for handling outliers, and any adjustments to be applied (e.g., reliability corrections).

- Describe the procedures for examining and dealing with effect size heterogeneity.

\section{Data Analysis:}

- Describe the statistical models to be used. Discuss why they are the best models for testing your hypotheses, how they address the multilevel nature of education data, and how well they control for selection bias.

- Discuss analyses to explore alternative hypotheses.

- Discuss how you will address exclusion from testing and missing data. Propose to conduct sensitivity tests to assess the influence of key procedural or analytic decisions on the results.

- Provide separate descriptions for any mediator or moderator analyses.

- For qualitative data, describe the intended approach to data analysis, including any software that will be used.

\section{Dissemination Plan:}

- Identify the audiences that you expect will be most likely to benefit from your research (e.g., other researchers, federal or state policymakers, state and local school system administrators, principals, teachers, counselors, parents, students, and others).

- Discuss the ways in which you intend to reach these audiences through the major publications, presentations, and products you expect from your project.

- Be cognizant of the particular research goal of your project and how this affects the type and use of your findings. Exploration projects are expected to identify potentially important associations between malleable factors and student education outcomes.

- Exploration projects are not intended to evaluate the impact of interventions. Therefore, your findings are likely to be most useful in pointing out potentially fruitful areas for further attention from researchers, policymakers and practitioners rather than providing proof or strong evidence for taking specific actions.

\section{Timeline:}

- Provide a timeline for each step in your project including such actions as sample selection and assignment, data collection, data analysis, and dissemination.

- The timeline may be discussed in the project narrative and/or presented in Appendix B.

c. Personnel - The purpose of this section is to describe the relevant expertise of your research team, the responsibilities of each team member, and each team member's time commitments. 
Requirements: In order to be responsive and sent forward for peer review, applications under the Exploration goal must include a Personnel section that describes the following:

(i) The research team at both the primary applicant institution and any subaward institutions.

Recommendations: In order to address the above requirements, the Institute recommends that you include the following in your Personnel section to demonstrate that your team possesses the appropriate training and experience and will commit sufficient time to competently implement the proposed research.

- Identify and briefly describe the following for all key personnel (i.e., Principal Investigator, co-Principal Investigators, co-Investigators) on the project team: qualifications to carry out the proposed work, roles and responsibilities within the project, percent of time and calendar months per year (academic plus summer) to be devoted to the project, and past success at disseminating research findings in peer-reviewed scientific journals and to policymaker or practitioner audiences.

- Identify the management structure and procedures that will be used to keep the project on track and ensure the quality of its work. This is especially important for projects involving multiple institutions carrying out different tasks that must be coordinated and/or integrated.

- Key personnel may be from for-profit entities; however, you should include a plan describing how their involvement will not jeopardize the objectivity of the research.

- If you have previously received an Exploration award, indicate whether your work under that grant has contributed to (1) the development of a new or refinement of an existing intervention, (2) the rigorous evaluation of an intervention, or (3) the development, refinement or validation of an assessment.

d. Resources - The purpose of this section is to describe both how you have the institutional capacity to complete a project of this size and complexity and your access to the resources you will need to successfully complete this project.

Requirements: In order to be responsive and sent forward for peer review, applications under the Exploration goal must include a Resources section that describes the following:

(i) Access to and/or a plan to acquire the resources you will need to successfully complete this project at the primary applicant institution and any subaward institutions.

Recommendations: In order to address the above requirements, the Institute recommends that you include the following in your Resources section to demonstrate that your team has a plan for acquiring or accessing the facilities, equipment, supplies, and other resources required to support the proposed Exploration work and the commitments of each partner for the implementation and success of the project.

- Describe your institutional capacity and experience to manage a grant of this size.

- Describe your access to resources available at the primary institution and any subaward institutions.

- Describe your plan for acquiring any resources that are not currently accessible, will require significant expenditures, and are necessary for the successful completion of the project (e.g., equipment, test materials, curriculum or training materials). 
- Describe your access to the schools (or other authentic education settings) in which the research will take place. Include letters of agreement in Appendix D documenting the participation and cooperation of the schools. Convincing letters will convey that the organizations understand what their participation in the study will involve (e.g., annual student and teacher surveys, student assessments, classroom observations).

- Include information about teacher and school incentives, if applicable.

- Describe your access to any data sets that you will require. Include letters of agreement, data licenses, or existing Memoranda of Understanding in Appendix D to document that you will be able to access the data for your proposed use.

\section{(2) Awards}

An Exploration project must conform to the following limits on duration and cost:

\section{Duration Maximums:}

- The maximum duration of an Exploration award that solely involves secondary data analysis or meta-analysis is $\mathbf{2}$ years. An application of this type proposing a project length of greater than 2 years will be deemed nonresponsive to the Request for Applications and will not be accepted for review.

- The maximum duration of an Exploration award that involves primary data collection is $\mathbf{4}$ years. An application of this type proposing a project length of greater than 4 years will be deemed nonresponsive to the Request for Applications and will not be accepted for review.

\section{Cost Maximums:}

- The maximum award for an Exploration project solely involving secondary data analysis or meta-analysis is $\$ \mathbf{7 0 0 , 0 0 0}$ (total cost $=$ direct + indirect costs). An application of this type proposing a budget higher than the maximum award will be deemed nonresponsive to the Request for Applications and will not be accepted for review.

- The maximum award for an Exploration project involving primary data collection is $\mathbf{\$ 1 , 6 0 0 , 0 0 0}$ (total cost $=$ direct + indirect costs). An application of this type proposing a budget higher than the maximum award will be deemed nonresponsive to the Request for Applications and will not be accepted for review. 


\section{Goal Two: Development and Innovation}

\section{a) Purpose}

The Development and Innovation goal (Development/Innovation) supports the development of new interventions and the further development of existing interventions that are intended to produce beneficial impacts on student education outcomes when implemented in authentic education settings. ${ }^{8}$

Projects under the Development/Innovation goal will result in the following:

- A fully-developed version of the proposed intervention.

- A well-specified theory of change for the intervention.

- Data that demonstrate that end users understand and can feasibly implement the intervention in an authentic education setting.

- A fidelity of implementation measure (or measures) to assess whether the intervention is delivered as intended by the end users in an authentic education setting.

- Pilot data regarding the intervention's promise for generating the intended beneficial student education outcomes and reaching the level of fidelity of implementation considered necessary to generate the intended beneficial student education outcomes.

\section{b) Requirements and Recommendations}

\section{Intervention}

The wide range of education curricula, instructional approaches, professional development, technology, and practices, programs, and policies that are implemented at

the student, classroom, school, district, state, or federal level to improve student education outcomes.

\section{Fully-developed intervention}

An intervention is fully developed when all materials and products required for its implementation by the end user are readily available for use

in authentic education settings.

Applications under the Development/Innovation goal must meet the requirements set out under (1) Project Narrative and (2) Awards in order to be responsive and sent forward for scientific peer review. The requirements are the minimum necessary for an application to be sent forward for peer review.

In order to improve the quality of your application, the Institute offers recommendations following each set of Project Narrative requirements.

\section{(1) Project Narrative}

The 25-page project narrative for a Development/Innovation project application must include four sections - Significance, Research Plan, Personnel, and Resources.

\footnotetext{
${ }^{8}$ The Institute will not accept applications under Development/Innovation that propose only minor development activities and are mainly focused on testing the intervention's impacts. Instead, if you have an intervention that is ready to be tested for efficacy you should apply to the Efficacy and Replication goal. 
a. Significance - The purpose of this section is to explain why it is important to develop this intervention.

Requirements: In order to be responsive and sent forward for peer review, applications under the Development/Innovation goal must include a Significance section that describes the following:

(i) The new or existing intervention that will be developed or revised.

(ii) A rationale for the proposed work.

Recommendations: In order to address the above requirements, the Institute recommends that you include the following in your Significance section to provide a compelling rationale for the proposed Development/Innovation work.

- Clearly describe the specific issue or problem your work will address including the overall importance of this issue/problem and how its resolution will contribute to the improvement of student education outcomes. Strong applications will discuss the importance of the issue or problem to education stakeholders, such as practitioners and policymakers.

- Clearly describe current typical practice to address this issue or problem and why current practice is not satisfactory.

- Clearly describe your proposed intervention, its key components, and how it is to be implemented. Contrast these with current typical practice and its identified shortcomings. Your description of the proposed intervention should show that it has the potential to produce substantially better student education outcomes because

- it is sufficiently different from current practice and does not suffer from the same shortcomings;

- it has key components that can be justified, using theoretical or empirical reasons, as powerful agents for improving the outcomes of interest; and

- its implementation appears feasible for teachers, other education personnel, and/or schools given their resource constraints (e.g., time, funds, personnel, schedules).

- Clearly describe the initial theory of change for your proposed intervention (Figure 1 provides an example of one way that you could conceptualize a simple theory of change), along with theoretical justifications and empirical evidence that support it. Keep in mind that you may need to revise your theory over the course of the project.

- Your theory of change should describe the component or components of the planned intervention that are to lead to changes in one or multiple underlying processes, which in turn will foster better student education outcomes directly or through intermediate outcomes (e.g., changed teacher practices). A more complete theory of change could include further details such as the sample representing the target population, level of exposure to the components of the intervention, key moderators (such as setting, context, student and their family characteristics), and the specific measures used for the outcomes.

- For interventions designed to directly affect the teaching and learning environment and, thereby, indirectly affect student education outcomes, be clear in your theory of change to identify any intermediate outcomes that the 
intervention is designed to affect (e.g., teacher practices) and how these outcomes impact the student education outcomes of interest.

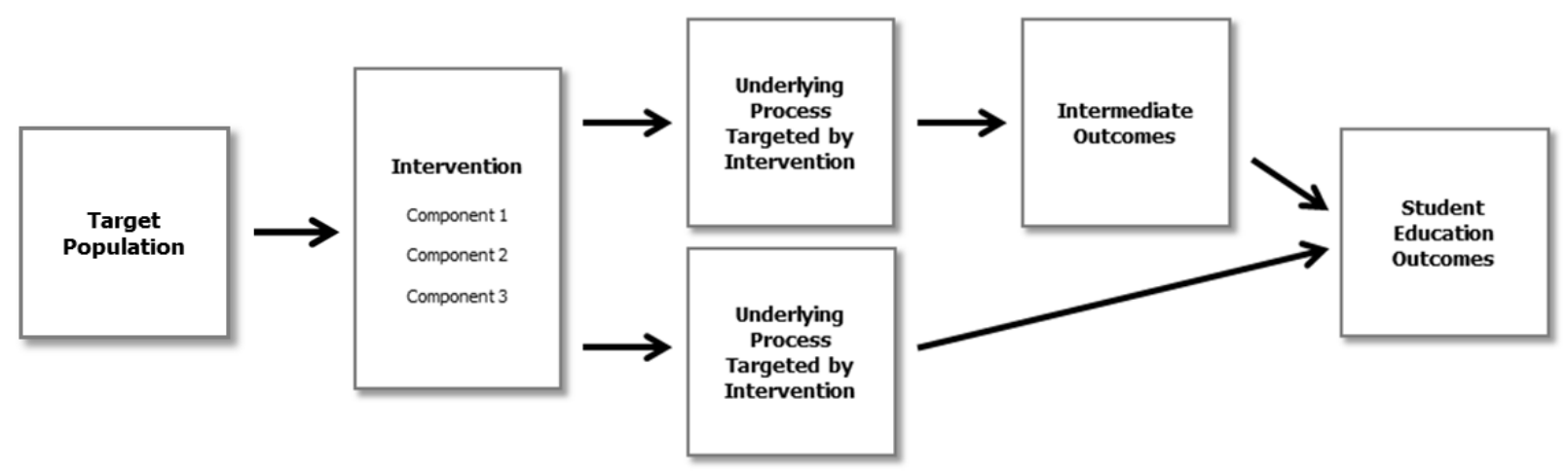

Figure 1. A diagram of a simple theory of change.

- Discuss the expected practicality of the intervention including why the intervention is likely to be accepted and implemented and how it could contribute to resolving the issue or problem that forms the basis of the project. You should also note the level of resources expected for the implementation of the intervention (e.g., teacher training, classroom time, materials).

- If you are applying for a Development/Innovation award to further develop an intervention that was the focus of a previous Development/Innovation or Efficacy/Replication project, you should (1) justify the need for another award, (2) describe the results and outcomes of prior or currently held awards to support the further development of the intervention (e.g., evidence that the intervention in its current form shows promise for improving education outcomes for students or evidence from a prior efficacy study indicates the need for further development), and (3) indicate whether what was developed has been (or is being) evaluated for efficacy and describe any available results from those efficacy evaluations and their implications for the proposed project. 
b. Research Plan - The purpose of this section is to describe the methodology you will use to develop your intervention, document its feasibility, determine its promise for improving the targeted student education outcomes and reaching the level of fidelity of implementation necessary to improve those outcomes, and describe your plan to disseminate the project's findings.

Requirements: In order to be responsive and sent forward for peer review, applications under the Development/Innovation goal must include a Research Plan section that describes:

(i) The sample, setting, and measures.

(ii) The method for developing the intervention (development process).

(iii) The method for collecting evidence of feasibility of implementation.

(iv) The method for developing a fidelity of implementation measure(s).

(v) A plan for a pilot study.

(vi) Data analysis procedures.

(vii) A plan for dissemination.

Recommendations: In order to address the above requirements, the Institute recommends that you include the following in your Research Plan section to strengthen the methodological rigor of the proposed Development/Innovation work and to optimize the dissemination plan.

\section{Development Process}

The method for developing the intervention to the point where it can be used by the intended end users.

\section{Pilot Study}

A study designed to provide evidence of the promise of the fully-developed intervention for achieving its intended outcomes when it is implemented in an authentic education setting.

Note that a pilot study is different from studies conducted during the development process. The latter are designed to inform the iterative development process (e.g., by identifying areas of further development, testing individual components of the intervention).

Measures:

- Your measures should address (a) usability, (b) feasibility, (c) fidelity of implementation, (d) student education outcomes, and (e) expected intermediate outcomes.

- Discuss the procedures for collecting the data for these measures. For pre-existing measures of student education outcomes or fidelity, discuss each measure's psychometric properties (e.g., reliability and validity). If you need to develop a measure, you should describe what will be developed, why it is necessary, how it will be developed, and, as appropriate, the process for checking its reliability and validity.

\section{Development Process:}

- As you describe the development process, make clear what will be developed, how it will be developed to ensure usability, and the chronological order of development (e.g., by providing a timeline either in the Project Narrative or Appendix B).

- Discuss how you will develop the initial version of the intervention or indicate that there is already an initial version that you intend to revise. 
- Discuss how you will refine and improve upon the initial version of the intervention by implementing it (or components of it), observing its functioning, and making necessary adjustments to ensure usability and feasibility. Lay out your plan for carrying out a systematic, iterative, development process. ${ }^{9}$

- You may propose to do some laboratory research during the development process as long as it adheres to the sample and outcome requirements outlined for the topic you select.

- Be clear about how that research will contribute to the development of an intervention that is intended to be implemented in authentic education settings by the proposed end user. In addition, the materials and procedures should allow for generalizability to authentic education settings.

\section{Usability}

The extent to which the intended user understands or can learn how to use the intervention effectively and efficiently, is physically able to use the intervention, and is willing to use the intervention.

\section{Feasibility}

The extent to which the intervention can be implemented within the requirements and constraints of an authentic education setting.

\section{Fidelity of implementation}

The extent to which the intervention is being delivered as it was designed to be by end users in an authentic education setting.

\section{Evidence of Feasibility of Implementation:}

- To determine whether the intervention can be implemented within the requirements and constraints of an authentic education setting (e.g., classroom, school, district), collect feasibility data both in the type of setting (e.g., classroom or school) and with the end users for which the intervention is intended.

- You can collect feasibility evidence at any point during the project.

\section{Fidelity of Implementation:}

- Discuss how you will develop the fidelity of implementation measures that will be used to monitor the implementation of the intervention. Information collected on the usability and feasibility of implementation can contribute to the development of fidelity of implementation measures. Prototype fidelity measures can be tested and refined in separate studies or in the pilot study.

- If your intervention includes a training component for end users, you should also develop a measure of the fidelity of implementation of the training.

\footnotetext{
${ }^{9}$ The development process often includes small-scale studies in which different components of or approaches to using the intervention are tried in order to obtain feedback for revision. The Institute does not require or endorse any specific model of iterative development and suggests that you review models that have been used to develop interventions (e.g., Fuchs \& Fuchs, 2001; Diamond \& Powell, 2011) to identify processes appropriate for your work. There is no ideal number of iterations (revise, implement, observe, revise). Identify and justify your proposed number of iterations based on the complexity of the intervention and its implementation. This process should continue until you determine that the intervention can be successfully used by the intended end users.
} 


\section{Pilot Study:}

- Describe the design of the pilot study, the data to be collected, the analyses to be done, and the criteria you will use to determine whether any change in student education outcomes is consistent with your underlying theory of change and is large enough to be considered a sign of promise of the intervention's success.

- To ensure that Development/Innovation projects focus on the development process, a maximum of 35 percent of project funds should be used for the pilot study (i.e., its implementation, data collection, and analysis of pilot data).

- The type of pilot study you propose will depend upon the intervention, the level at which the intervention is implemented (i.e., student, classroom, school), and the need to stay within the maximum 35 percent of grant funds that could be used for the pilot study. As a result, pilot studies may range along a continuum of rigor: ${ }^{10}$

- Efficacy studies (e.g., fully-powered, randomized controlled studies are possible especially when randomization occurs at the student level).

- Underpowered efficacy studies (e.g., randomized controlled trials with a small number of classrooms or schools that provide unbiased effect size estimates of practical consequence which can stand as evidence of promise while not statistically significant).

- Single-case studies that meet the design standards for individual single case studies set by the What Works Clearinghouse (Kratochwill et al., 2010).

- Quasi-experimental studies based on the use of comparison groups with additional adjustments to address potential differences between groups (i.e., use of pretests, control variables, matching procedures).

- Identify the measures to be used for all outcomes identified in your theory of change. Give careful consideration to the measures of student education outcomes used to determine the intervention's promise and consider the inclusion of both those sensitive to the intervention as well as those of practical interest to students, parents, education practitioners, and policymakers.

- Describe how you will measure fidelity of implementation during the pilot and how you will determine whether fidelity is high enough to expect beneficial student education outcomes. Discuss possible responses if you find lower than expected fidelity (e.g., efforts to increase fidelity). In addition, if a training component is included in the intervention, then evidence of promise should also address the fidelity of implementation of the training component and whether it is high enough to expect end users to implement the intervention as planned.

- Address whether the comparison group is implementing something similar to the intervention during the pilot and, if so, provide a determination of whether the treatment and comparison groups are different enough to expect the predicted student education outcomes.

\section{Dissemination Plan:}

- Identify the audiences that you expect will be most likely to benefit from your research (e.g., other researchers, federal or state policymakers, state and local school system administrators, principals, teachers, counselors, parents, students, and others).

\footnotetext{
${ }^{10}$ This list is meant to be illustrative and not exhaustive as other designs may be appropriate. 
- Discuss the ways in which you intend to reach these audiences through the major publications, presentations, and products you expect from your project.

- Be cognizant of the particular research goal of your project and how this affects the type and use of your findings. Development/Innovation projects are expected to develop new or revise existing interventions. For example, if the results of pilot study indicate the intervention is promising, dissemination efforts should focus on letting others know about the availability of the new intervention for testing and further adaptation. Dissemination efforts from these projects could also provide useful information on the design process, how intervention development can be accomplished in partnership with practitioners, and what type of new practices are feasible or not feasible for use by practitioners.

- Your pilot study will normally not provide evidence of the impact of the interventions, and the Institute does not expect dissemination efforts for broad implementation of interventions until such evidence is obtained.

\section{Timeline:}

- Provide a timeline for each step in your project including such actions as the development process, pilot study sample selection and assignment, data collection, data analysis, and dissemination.

- The timeline may be discussed in the project narrative and/or presented in $\underline{\text { Appendix } B}$.

c. Personnel - The purpose of this section is to describe the relevant expertise of your research team, the responsibilities of each team member, and each team member's time commitments.

Requirements: In order to be responsive and sent forward for peer review, applications under the Development/Innovation goal must include a Personnel section that describes the following:

(i) The research team at both the primary applicant institution and any subaward institutions.

Recommendations: In order to address the above requirements, the Institute recommends that you include the following in your Personnel section to demonstrate that your team possesses the appropriate training and experience and will commit sufficient time to competently implement the proposed research.

- Identify and briefly describe the following for all key personnel (i.e., Principal Investigator, co-Principal Investigators, co-Investigators) on the project team: qualifications to carry out the proposed work, roles and responsibilities within the project, percent of time and calendar months per year (academic plus summer) to be devoted to the project, and past success at disseminating research findings in peer-reviewed scientific journals and to policymaker or practitioner audiences.

- Identify the management structure and procedures that will be used to keep the project on track and ensure the quality of its work. This is especially important for projects involving multiple institutions carrying out different tasks that must be coordinated and/or integrated.

- Key personnel may be from for-profit entities. However, if these entities are to be involved in the commercial production or distribution of the intervention to be developed, include a plan describing how their involvement will not jeopardize the objectivity of the research. 
- If you have previously received an award from the Institute to develop an intervention and are applying for a grant to develop a new intervention, you should indicate whether the previous intervention has been evaluated for its efficacy (by yourself or another research team).

d. Resources - The purpose of this section is to describe both how you have the institutional capacity to complete a project of this size and complexity and your access to the resources you will need to successfully complete this project.

Requirements: In order to be responsive and sent forward for peer review, applications under the Development/Innovation goal must include a Resources section that describes the following:

(i) Access to and/or a plan to acquire the resources you will need to successfully complete this project at the primary applicant institution and any subaward institutions.

Recommendations: In order to address the above requirements, the Institute recommends that you include the following in your Resources section to demonstrate that your team has a plan for acquiring or accessing the facilities, equipment, supplies, and other resources required to support the proposed Development/Innovation work and the commitments of each partner for the implementation and success of the project.

- Describe your institutional capacity and experience to manage a grant of this size.

- Describe your access to resources available at the primary institution and any subaward institutions.

- Describe your plan for acquiring any resources that are not currently accessible, will require significant expenditures, and are necessary for the successful completion of the project (e.g., equipment, test materials, curriculum or training materials).

- Describe your access to the schools (or other authentic education settings) in which the research will take place. Include letters of agreement in Appendix D documenting the participation and cooperation of the schools. Convincing letters will convey that the organizations understand what their participation in the study will involve (e.g., annual student and teacher surveys, student assessments, classroom observations).

- Include information about teacher and school incentives, if applicable.

- Describe your access to any data sets that you will require. Include letters of agreement, data licenses, or existing Memoranda of Understanding in Appendix D to document that you will be able to access the data for your proposed use.

\section{(2) Awards}

A Development/Innovation project must conform to the following limits on duration and cost:

\section{Duration Maximums:}

- The maximum duration of a Development/Innovation project is 4 years. An application of this type proposing a project length of greater than 4 years will be deemed nonresponsive to the Request for Applications and will not be accepted for review.

- The development and piloting of an intervention may vary in time due to the complexity of the intervention, the length of its implementation period, and the time expected for its implementation to result in changed student outcomes. 
Your proposed project length should reflect these factors. For example, if you are proposing to develop a lengthy intervention (e.g., a year-long curriculum) or an intervention that requires a long pilot study because it is expected to take additional time to affect students (e.g., a principal training program that is intended to improve instruction), requesting a 4-year project would be appropriate.

\section{Cost Maximums:}

- The maximum award for a Development/Innovation project is $\$ \mathbf{1 , 5 0 0 , 0 0 0}$ (total cost $=$ direct costs $\boldsymbol{+}$ indirect costs). An application of this type proposing a budget higher than the maximum award will be deemed nonresponsive to the Request for Applications and will not be accepted for review.

- Your pilot study should require no more than 35 percent of your total budget. You should note the budgeted cost of the pilot study (i.e., its implementation, data collection, and analysis of pilot data) and its percentage of the total budget in your Narrative Budget Justification. 


\section{Goal Three: Efficacy and Replication}

\section{a) Purpose}

The Efficacy/Replication goal supports the evaluation of fully-developed education interventions to determine whether they produce a beneficial impact on student education outcomes relative to a counterfactual when they are implemented under ideal or routine conditions by the end user in authentic education settings.

Projects under the Efficacy/Replication goal will result in the following:

- Evidence regarding the impact of a fullydeveloped intervention on relevant student education outcomes relative to a comparison condition using a research design that meets the Institute's What Works Clearinghouse evidence standards (with or without reservations) (http://ies.ed.gov/ncee/wwc).

- Conclusions about and revisions to the theory of change that guides the intervention and a discussion of the broader contributions to the theoretical and practical understanding of education processes and procedures.

- Information needed for future research on the intervention.

- If a beneficial impact is found, the identification of the organizational supports, tools, and procedures needed for sufficient implementation of the core components of the intervention under a future Replication study or Effectiveness study.

- If no beneficial impact is found, a determination of whether and how to revise the intervention and/or its implementation under a future Development/Innovation project.

The Institute supports four types of studies under the Efficacy/Replication goal:

- Efficacy - A study that tests an intervention's beneficial impacts on student education outcomes in comparison to an alternative practice, program, or policy.

- $\quad$ Replication - An efficacy study designed to generate additional evidence that an intervention improves student education outcomes by testing an intervention that has been shown to have beneficial impacts on student education outcomes in a previous efficacy study.

\section{Intervention}

The wide range of education curricula, instructional approaches, professional development, technology, practices, programs, and policies that are implemented at the student, classroom, school, district, state, or federal level to improve student education outcomes.

\section{Fully-developed intervention}

An intervention is fully developed when all materials and products required for its implementation by the end user are readily available for use in authentic education settings.

\section{Ideal conditions}

Conditions that provide a more controlled setting, such as greater implementation support or a more homogeneous sample, under which the intervention may be more likely to have beneficial impacts.

\section{Routine conditions}

Conditions under which an intervention is implemented that reflect 1 ) the everyday practice occurring in homes, childcare, natural settings for infants and toddlers, classrooms, schools, and districts and 2) the heterogeneity of the target population.

\section{End user}

The person intended to be responsible for the implementation of the intervention. 
- Efficacy Follow-Up - An efficacy study that tests the longer-term impacts of an intervention that has been shown to have beneficial impacts on student education outcomes in a previous or ongoing efficacy study.

- $\quad$ Retrospective - An efficacy study that analyzes retrospective (historical) secondary data to test an intervention implemented in the past, and, as a result, may not be able meet the requirements for Efficacy/Replication projects regarding fidelity of implementation and comparison group practice.

\section{b) Requirements and Recommendations and Data Management Plan}

Applications under the Efficacy/Replication goal must meet the requirements set out under (1) Project Narrative and (2) Awards in order to be responsive and sent forward for scientific peer review. The requirements are the minimum necessary for an application to be sent forward for peer review.

In order to improve the quality of your application, the Institute offers recommendations following each set of Project Narrative requirements.

Applications under the Efficacy/Replication goal are to include a Data Management Plan as described in (3) Data Management Plan in anticipation of forthcoming federal policy changes regarding data access.

\section{(1) Project Narrative}

The 25-page project narrative for an Efficacy/Replication project application must include four sections - Significance, Research Plan, Personnel, and Resources.

a. Significance - The purpose of this section is to explain why it is important to test the impact of the intervention on student education outcomes under the proposed conditions and sample.

Requirement: In order to be responsive and sent forward for peer review, applications under the Efficacy/Replication goal must include a Significance section that describes the following:

(i) A rationale for testing the impact of the intervention on student education outcomes in the proposed manner.

Recommendations: In order to address the above requirement, the Institute recommends that you include the following in your Significance section to justify the significance of the proposed work.

- Note the type of study proposed (Efficacy, Replication, Follow-Up, or Retrospective) early in the Significance section.

- Describe the fully-developed intervention that you propose to evaluate: ${ }^{11}$

○ The intervention's components.

- Processes and materials (e.g., manuals, websites, training, coaching) that will be used to support implementation of the intervention.

\footnotetext{
${ }^{11}$ If the intervention you wish to test and/or its implementation processes and materials are not yet fully developed, you should apply under Development/Innovation to complete it. 
- Evidence that the intervention is fully developed and ready for implementation in authentic education settings (e.g., all materials and implementation supports such as professional development are available). ${ }^{12}$

- Describe the intervention's implementation:

- Identify the target population and where implementation will take place.

- Identify who the end users of the intervention are and describe how implementation will be carried out by them.

- Describe the ideal or routine conditions under which the intervention will be implemented.

- Ideal conditions provide a more controlled setting under which the intervention may be more likely to have beneficial impacts. For example, ideal conditions could include more implementation support than would be provided under routine practice in order to ensure adequate fidelity of implementation. Ideal conditions could also include a more homogeneous sample of students, teachers, schools, and/or districts than would be expected under routine practice in order to reduce other sources of variation that may contribute to outcomes.

- Routine conditions reflect the everyday practice occurring in homes, childcare, natural settings for infants and toddlers, classrooms, schools, and districts including the expected level of implementation that would take place if no study was being done and a sample that represents the heterogeneity of the students, teachers, schools, and districts being studied.

- Describe the measures you will use to assess the fidelity of implementation of the intervention and to determine what the comparison group is receiving.

- If needed, you can propose devoting a short period of time (e.g., 2-6 months) to develop a measure of fidelity of implementation or comparison group practice; however, the intervention itself and its accompanying materials (e.g., professional development materials) must be fully developed before applying to Efficacy/Replication.

- Clearly describe the initial theory of change for your proposed intervention (Figure 1 provides an example of one way that you could conceptualize a simple theory of change), along with theoretical justifications and empirical evidence that support it. Keep in mind that you may need to revise your theory over the course of the project.

- Your theory of change should describe the component or components of the planned intervention that are to lead to changes in one or multiple underlying processes, which in turn will foster better student education outcomes directly or through intermediate outcomes (e.g., changed teacher practices). A more complete theory of change could include further details such as the sample representing the target population, level of exposure to the components of the intervention, key moderators (such as setting, context, student and their family characteristics), and the specific measures used for the outcomes.

\footnotetext{
${ }^{12}$ Applications to evaluate newly developed and non-widely used interventions often require more of this type of evidence than those evaluating widely-used interventions.
} 
- For interventions designed to directly affect the teaching and learning environment and, thereby, indirectly affect student education outcomes, in your theory of change clearly identify any intermediate outcomes that the intervention is designed to affect (e.g., teacher practices) and how these outcomes impact the student education outcomes of interest.

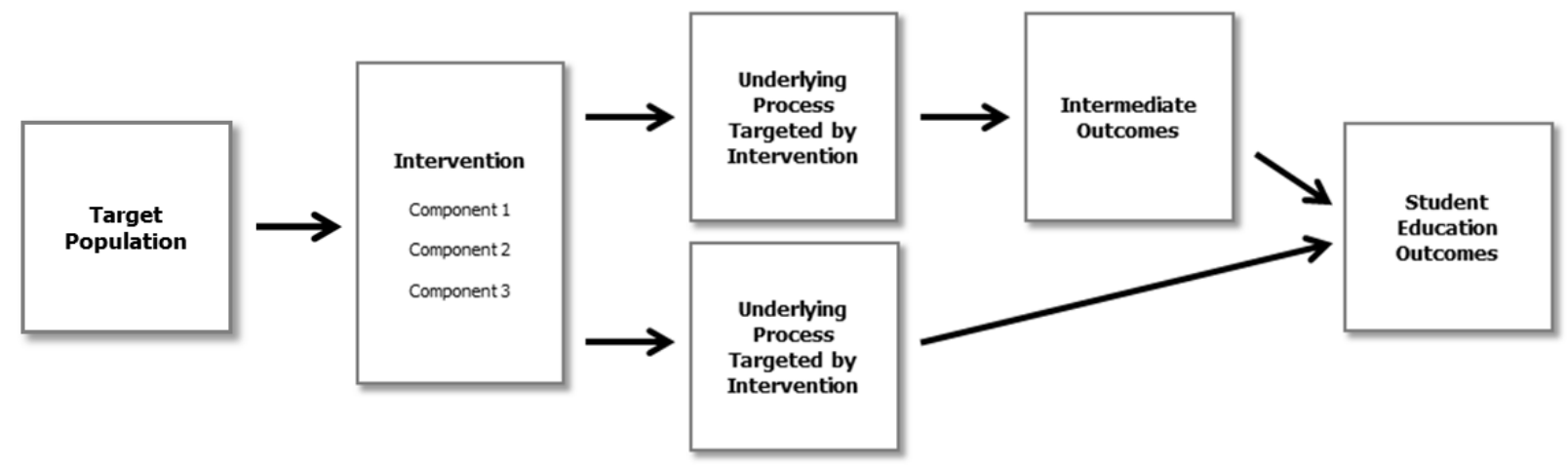

Figure 1. A diagram of a simple theory of change.

- To provide a compelling rationale for testing the impact of the intervention on student education outcomes in the proposed manner, address why the intervention is likely to produce better student outcomes relative to current practice (or argue that the intervention is current practice if widely used) and discuss the overall practical importance of the intervention (i.e., why education practitioners or policymakers should care about the results of the proposed evaluation). The specifics of your rationale will differ by the type of study you propose:

- For an efficacy study of a widely-used intervention that has not been rigorously evaluated (e.g., a commercial curriculum or a specific state program), provide evidence of its widespread use (across the country or within a state, large district, or multiple districts) and if available, information about the fidelity of its implementation. In addition, describe any prior studies that have attempted to evaluate the intervention, note their findings, and discuss why your proposed study would improve on past work. Widely-used interventions are not required to have evidence of impact or promise of impact on student education outcomes if their use is so widespread that their evaluation could have important implications for practice and policy.

- For an efficacy study of a not widely-used intervention that has not been rigorously evaluated (e.g., an intervention produced by a Development/Innovation project), focus more on the intervention's potential versus its current practical importance. Also focus on the evidence showing the intervention's readiness for implementation, feasibility, fidelity of implementation, and promise for achieving its intended outcomes (as described under Development/Innovation).

- For a replication study, describe the existing evidence of the intervention's fidelity of implementation and beneficial impact on student outcomes from at least one prior study that would meet the methodological requirements of the Institute's Efficacy/Replication goal. To this end, clearly describe the prior efficacy study (or studies), including the sample, design, measures, fidelity of 
implementation, analyses, and results so that reviewers have sufficient information to judge its quality. Also, justify why the impact found in the prior study would be considered of practical importance. Second, describe the practical and theoretical importance of carrying out another efficacy study on the intervention, distinguish your study from prior efficacy studies, and describe the additional contribution your study will make. Replication studies are intended to generate additional evidence that an intervention improves student education outcomes but also may identify ways to increase the impact of the intervention, improve its efficiency, or reduce its cost in comparison to what was done in the prior efficacy study. For example, your study may address the following:

- Different populations of students (e.g., differences in socio-economic status, race/ethnicity, prior achievement level), teachers (e.g., specialists vs. generalists), and/or schools (e.g., those in State improvement programs vs. those not, rural vs. urban).

- Modifications of the intervention (e.g., adding supportive components, varying emphases among the components, changes in the ordering of the components) to determine if the intervention can be improved. ${ }^{13}$

- Differences in implementation of an intervention (e.g., changing the level of support, providing support in alternative ways such as in-person vs. online).

- For an efficacy follow-up study, describe the existing evidence of the intervention's beneficial impact on student outcomes from a previous efficacy study (either completed or ongoing) that would meet the methodological requirements of the Institute's Efficacy/Replication goal. To this end, clearly describe the completed or ongoing efficacy study, including the sample, design, measures, fidelity of implementation, analyses, and results so that reviewers have sufficient information to judge its quality. Explain why the original impacts would be expected to continue into the future (this may require revising the original theory of change), and why the impacts found would be considered of practical importance. In addition, provide evidence that you have access to research participants for successful follow up (e.g., letters of agreement from schools or districts to be included in Appendix D). ${ }^{14}$ Efficacy Follow-up studies take one of two forms:

- Following Students: You may follow students who took part in the original study as they enter later grades (or different places), where they do not continue to receive the intervention, in order to determine if the beneficial effects are maintained. ${ }^{15}$ Student attrition during the prior study and the ability to follow students into later grades (especially at key transition points that entail changing schools) are key factors in the success of such follow-up studies. Include a CONSORT flow diagram ${ }^{16}$ showing the numbers of participants at each stage of the prior study.

\footnotetext{
${ }^{13}$ Testing modifications of the intervention should not require further development of the intervention (such work is supported under Development and Innovation). If you intend to evaluate an intervention that has been significantly changed from an earlier efficacy study, you should propose another efficacy study, rather than a replication study, and discuss the reasons for the changes. ${ }^{14}$ Grant funds should not be used to support implementation of the intervention in an efficacy follow-up project. However, districts and schools can support implementation through their own funds.

15 These studies examine the sustainability of the intervention's implementation and impacts after the additional resources provided by the original study are withdrawn. If the students will continue to receive the intervention in the later grades, you should propose a replication study, rather than a follow-up study.

${ }^{16}$ The Consort flow diagram that provides a structure for tracking participants at each study stage can be found at http://www.consort-statement.org/consort-statement/overview0/. 
Also discuss expected levels of attrition in the follow-up study, how it will be reduced, and its impact on the interpretation of the results.

- Following Education Personnel: You may follow the education personnel who implemented the intervention under the original efficacy study to determine if their continued implementation of the intervention will benefit a new group of students. Include a CONSORT flow diagram showing the numbers of education personnel at each stage of the prior study in both treatment and control groups, and show that you will have enough personnel to maintain the intervention's fidelity of implementation. Discuss expected attrition in the follow-up study, how it will be reduced, and its impact on the interpretation of the results. Also describe how you plan to address differential attrition if it occurs. In addition, discuss how you will determine whether the incoming cohort of students is similar to the original student cohort, whether the incoming cohort of treatment and control students are similar enough to compare to the prior cohort (e.g., schools or parents aren't selecting specific students to receive the treatment in a manner that could impact the student outcomes), and what you will do if they are not similar in either way.

- For a retrospective study relying on secondary analysis of historical data, discuss how widespread the intervention's use was and provide conceptual arguments for the importance of evaluating the intervention including the intervention's relevance to current education practice and policy. If the intervention is ongoing, discuss why a historical evaluation would be relevant compared to an evaluation using prospective data. If the intervention is no longer in use, address how the results of your evaluation would be useful for improving today's practice and policy. Be clear on what the existing data will allow you to examine and what issues you will not be able to address due to a lack of information. This discussion should include what is known or could be determined about the intervention's fidelity of implementation and comparison group practice. Discuss the implications for interpreting your results due to a lack or absence of such information.

b. Research Plan - The purpose of this section is to describe the evaluation of the intervention and the dissemination of the results.

Requirements: In order to be responsive and sent forward for peer review, applications under the Efficacy/Replication goal must include a Research Plan section that describes the following:

(i) A research design for the study of the intervention's impact on student education outcomes (including the sample, setting, and measures).

(ii) A power analysis.

(iii) Data analysis procedures.

(iv) A cost analysis.

(v) A plan for dissemination. 
Recommendations: In order to address the above requirements, the Institute recommends that you include the following in your Research Plan section to strengthen the methodological rigor of the proposed Efficacy/Replication work and optimize the dissemination plan. If you propose a single-case experimental design as the primary means for establishing efficacy, please see additional recommendations outlined below in Additional Recommendations for Single-Case Experimental Designs Proposed as the Primary Design for Efficacy Studies.

\section{Sample and Setting:}

- Discuss the population you intend to study and how your sample and sampling procedures will allow you to draw inferences for this population.

- Define your sample and sampling procedures for the proposed study, including justification for exclusion and inclusion criteria.

- Describe strategies to increase the likelihood that participants (e.g., schools, teachers, and/or students) will join the study and remain in the study over the course of the evaluation.

- Describe the setting in which the study will take place (e.g., the size and characteristics of the intervention setting, classroom, school and/or the surrounding community), and how this may affect the generalizability of your study.

\section{Research Design:}

- Describe how you will be able to make causal inferences based on the results from your design and how potential threats to internal validity will be addressed. Typical designs for Efficacy/Replication projects include the following:

- Randomized controlled trials (using random assignment to intervention and comparison conditions) - Randomized controlled trials have the strongest internal validity for causal conclusions and, thus, are preferred whenever feasible. Clearly identify and present a convincing rationale for the unit of randomization (e.g., student, classroom, teacher, or school) and explain the procedures for random assignment, including how the integrity of the assignment process will be ensured.

- Regression discontinuity designs - Regression discontinuity designs can also provide unbiased estimates of the effects of education interventions. Explain the appropriateness of the assignment variable, show that there is a true discontinuity, document that no manipulation of the assignment variable has occurred and that the composition of the treatment and comparison group does not differ in ways that would indicate selection bias, and include sensitivity analyses to assess the influence of key procedural or analytic decisions on the results.

- Single-Case experimental designs - Single-case experimental designs are intended to demonstrate a causal or functional relationship between two variables using a small number of cases ${ }^{17}$. Single-case experimental designs are not descriptive case studies. For single-case designs, describe the repeated, systematic measurement of a dependent variable before, during, and after the active manipulation of an independent variable (i.e., intervention).

- Single-case experimental designs can also be used as a complementary method to further understand the results of randomized controlled trials

${ }^{17} \mathrm{~A}$ case is a unit of intervention administration and data analysis. A case may be a single participant or a cluster of participants (e.g., a classroom or community). 
in efficacy studies. For example, you could implement a complementary study using single-case designs to determine how manipulation of intervention components may affect outcomes for children who were nonresponsive to the intervention tested in the randomized controlled trial.

- Quasi-experimental designs (other than a regression discontinuity design) Quasi-experimental designs can be proposed when randomization is not possible. Justify how the proposed design permits drawing causal conclusions about the effect of the intervention on the intended outcomes, explain how selection bias will be minimized or modeled, ${ }^{18}$ and discuss those threats to internal validity that are not addressed convincingly by the design and how conclusions from the research will be tempered in light of these threats. Because quasi-experimental designs can meet the WWC's standards for evidence with reservations only, it is also important to detail how you will ensure that the study meets these standards (e.g., by establishing baseline equivalence between treatment and comparison groups and preventing high and/or non-equivalent attrition).

- For all types of research designs, including those using random assignment, explain how you will document that the intervention and comparison conditions are equivalent at the outset of the study and how you will document the level of bias occurring from overall and differential attrition rates.

- Describe and justify the counterfactual. In evaluations of education interventions, individuals in the comparison group typically receive some kind of treatment. It may be a well-defined alternative treatment or a less well-defined standard or frequent practice across the district or region. A clear description of the intervention and the counterfactual helps reviewers decide whether the intervention is sufficiently different from what the comparison group receives to produce different student education outcomes.

- Describe strategies or existing conditions that will reduce potential contamination between treatment and comparison groups.

Power Analysis ${ }^{19}$ :

- Discuss the statistical power of the research design to detect a reasonably expected and minimally important effect of the intervention on the student education outcomes and consider how the clustering of participants (e.g., students in classrooms and/or schools) will affect statistical power.

- Identify the minimum effect of the intervention that you will be able to detect, justify why this level of effect would be expected from the intervention, and explain why this would be a practically important effect.

- Detail the procedure used to calculate either the power for detecting the minimum effect or the minimum detectable effect size. Include the following:

- The statistical formula you used.

\section{Include power analyses for all proposed causal analyses. \\ Include enough information so that reviewers can duplicate your power analysis.}

\footnotetext{
${ }^{18}$ For more information, see Shadish, W. R., Cook, T. D., \& Campbell, D. T. (2002). Experimental and quasi-experimental designs for generalized causal inference. Boston, MA: Houghton Mifflin Company.

${ }^{19}$ Power analysis is not necessary for applicants proposing single-case designs. 
- The parameters with known values used in the formula (e.g., number of clusters, number of participants within the clusters).

- The parameters whose values are estimated and how those estimates were made (e.g., intraclass correlations, role of covariates).

- Other aspects of the design and how they may affect power (e.g., stratified sampling/blocking, repeated observations).

- Predicted attrition and how it was addressed in the power analysis.

- Provide a similar discussion regarding power for any causal analyses to be done using subgroups of the proposed sample.

\section{Outcome Measures:}

- Include student education outcome measures that will be sensitive to the change in performance that the intervention is intended to bring about (e.g., researcher-developed measures that are aligned with the experiences of the treatment group); outcome measures that are not strictly aligned with the intervention and that therefore could capture change in the control group; and measures of student outcomes that are of practical interest to students, parents, and educators. For example, applications to evaluate interventions to improve academic outcomes should include measures of achievement and/or measures of progress. Applications to evaluate interventions designed to improve behavioral outcomes should include practical measures of behaviors that are relevant to schools, such as academic engaged time, attendance, tardiness, drop-out rates, disciplinary actions, or graduation rates.

- For interventions designed to directly change the teaching and learning environment and, in doing so, indirectly affect student outcomes, provide measures of student education outcomes, as well as measures of the intermediate outcomes (e.g., teacher or leader behaviors) that are hypothesized to be directly linked to the intervention.

- Describe the psychometric properties (reliability and validity) of your student education outcome measures.

\section{Moderators and Mediators:}

- While not required, the analysis of moderators and mediators can strengthen your application. Such analyses can make your research more useful to policymakers and practitioners by helping to explain how or under what conditions a program or policy improves student education outcomes. Such analyses can also improve the quality and usefulness of future research syntheses or meta-analyses that may draw upon your work.

- Focus on a small set of moderators for which there is a strong theoretical and/or empirical base to expect they will moderate the impact of the intervention on the student education outcomes measured. Give consideration to factors that may affect the generalizability of the study (e.g., whether the intervention works for some groups of students but not others, or in intervention settings, schools, or neighborhoods with particular characteristics).

- Conduct exploratory analyses of potential mediators of the intervention. Most Efficacy/Replication studies are not designed or powered to rigorously test the effects of specific mediating variables; however, exploratory analyses can be used to better understand potential mediators of the intervention. 
- Describe the measures for the moderators and mediators you will examine, how they will be collected, and how they will be analyzed.

\section{Determining Fidelity of Implementation and Comparison Group Practice:}

- Identify the measures of the fidelity of implementation of the intervention and describe how they capture the core components of the intervention. If the intervention includes training of district personnel, you should also identify the measures of fidelity of implementation of the training being provided.

- Identify the measures of comparison group practices so that you can compare intervention and comparison groups on the implementation of critical features of the intervention

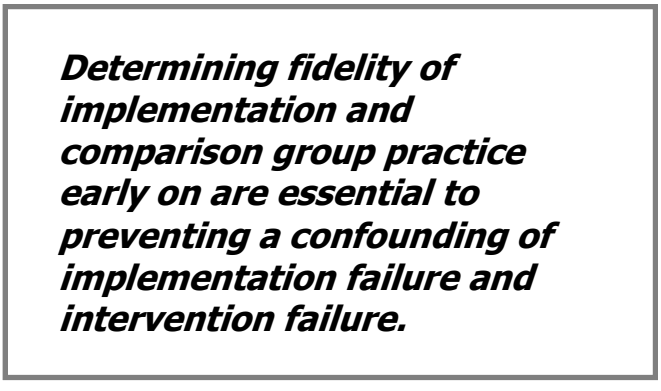
and determine whether there was clear distinction in what the groups received or whether both groups received key elements of the intervention.

- Show that these two sets of measures are sufficiently comprehensive and sensitive to identify and document critical differences between what the intervention and comparison groups receive.

- Describe your plan for determining the fidelity of implementation of the intervention within the treatment group and the identification of practice (especially practices that are similar to the treatment) in the comparison group.

- Include initial studies of fidelity of implementation and comparison group practice to be completed within the first year that end users are to implement the intervention.

- Include a plan for how you would respond if either low-fidelity or similar comparison group practice is found in the initial studies. ${ }^{20}$

- Retrospective studies may, but are not required to, include information on fidelity of implementation and comparison group practices. If available, the inclusion of this information strengthens the application.

Data Analysis:

- Detail your data analysis procedures for all analyses (e.g., impact study, subgroup analyses, fidelity of implementation study), including both quantitative and qualitative methods.

- Make clear how the data analyses directly answer your research questions.

- Address any clustering of students in classes and schools.

- Discuss how exclusion from testing and missing data will be handled in your analysis.

\footnotetext{
${ }^{20}$ As Efficacy studies may take place under ideal conditions, an early finding of low fidelity during the first year of implementation can be addressed (e.g., by increasing implementation support and monitoring activities, addressing obstacles to implementation, replacing or supplementing the sample in ways that preserve the design). Findings of unexpected similar practice in the comparison group may also be addressed (e.g., by further differentiation of the intervention or additional data collection to determine how similar practice is in both groups). Such actions are to prevent studies that find no impacts of an intervention but cannot determine whether the finding was due to the intervention or its implementation. 
- If you intend to link multiple data sets, provide sufficient detail for reviewers to judge the feasibility of the linking plan.

\section{Cost Analysis:}

- The cost analysis should help schools and districts understand the monetary costs of implementing the intervention (e.g., expenditures for personnel, facilities, equipment, materials, training, and other relevant inputs). Annual costs should be assessed to adequately reflect expenditures across the lifespan of the program (e.g., start-up costs and maintenance costs). Intervention costs can be contrasted with the costs of comparison group practice to reflect the difference between them. The Institute is not asking for an economic evaluation of the program (e.g., cost-benefit, cost-utility, or costeffectiveness analyses), although such analyses can be proposed.

\section{Dissemination Plan:}

- Identify the audiences that you expect will be most likely to benefit from your research (e.g., other researchers, federal or state policymakers, state and local school system administrators, principals, teachers, counselors, parents, students, and others).

- Discuss the ways in which you intend to reach these audiences through the major publications, presentations, and products you expect from your project. These should include:

- Publication in scientific, peer-reviewed journals and presentations at academic conferences

- Reporting findings to any

\section{Disseminate findings of impact} and findings of no impact. education agencies and schools that provided the project with data and data-collection opportunities

- Publications and presentations in venues designed for policymakers, practitioners, and the general public including electronic venues (e.g., websites, webinars, podcasts, videos)

- Be cognizant of the particular research goal of your project and how this affects the type and use of your findings. Efficacy/Replication projects are to causally evaluate the impact of intervention on student outcomes. The Institute considers all types of findings from these projects to be potentially useful to researchers, policymakers, and practitioners.

- Findings of a beneficial impact on student outcomes could support the wider use of the intervention, given the availability of any ideal conditions if used, and the further adaptation of the intervention to conditions that are less ideal or quite different.

- Findings of no impacts on student outcomes (with or without impacts on more intermediate outcomes such as a change in teacher instruction) are important for decisions regarding the ongoing use and wider dissemination of the intervention, further revision of the intervention and its implementation, and revision of the theory of change underlying the intervention. 


\section{Timeline:}

- Provide a timeline for each step in your evaluation including such actions as sample selection and assignment, baseline data collection, intervention implementation, ongoing data collections, fidelity of implementation and comparison group practice study, impact analysis, and dissemination.

- Indicate procedures to guard against bias entering into the data collection process (e.g., pretests occurring after the intervention has been implemented or differential timing of assessments for treatment and control groups).

- The timeline may be discussed in the project narrative and/or presented in Appendix B.

\section{Additional Recommendations for Single-Case Experimental Designs Proposed as the Primary Design for Efficacy Studies}

Recommendations: The Institute recommends that you include the following in your Research Plan to strengthen the methodological rigor of the proposed Single-Case research.

- Describe a research design plan that meets WWC evidence standards without or with reservations $^{21}$

- Provide a strong argument supporting the use of a single-case experimental design as opposed to a randomized controlled trial (e.g., focusing on a low-incidence condition).

- Describe any randomization procedures planned to strengthen the internal validity of your single-case experimental design. ${ }^{22}$

- Include outcome measures that are not strictly aligned with the intervention.

- Describe quantitative analyses, in addition to visual analysis, for analyzing the resulting data.

c. Personnel - The purpose of this section is to describe the relevant expertise of your research team, the responsibilities of each team member, and each team member's time commitments.

Requirements: In order to be responsive and sent forward for peer review, applications under the Efficacy/Replication goal must include a Personnel section that describes the following:

(i) The research team at both the primary applicant institution and any subaward institutions.

Recommendations: The Institute recommends that, in order to address the above requirements, you include the following in your Personnel section to demonstrate that your team possesses the appropriate training and experience and will commit sufficient time to competently implement the proposed research.

- Identify and briefly describe the following for all key personnel (i.e., Principal Investigator, co-Principal Investigators, co-Investigators) on the project team: qualifications to carry out the proposed work, roles and responsibilities within the project, percent of time and calendar months per year (academic plus summer) to be devoted to the project, and past success at disseminating research findings in peer-reviewed scientific journals and other venues targeting policymakers and practitioners.

\footnotetext{
${ }^{21}$ See the WWC's Procedures and Standards Handbook, Version 3.0 at http: //ies.ed.gov/ncee/wwc/documentsum.aspx?sid=19 (primarily Appendix E).

${ }^{22}$ See Kratochwill, \& Levin, 2010; Koehler \& Levin, 1998; Levin \& Wampold, 1999 
- Identify the management structure and procedures that will be used to keep the project on track and ensure the quality of its work. This is especially important for projects involving multiple institutions carrying out different tasks that must be coordinated and/or integrated.

- Include a plan to ensure the objectivity of the research if key personnel were involved in the development of the intervention, are from for-profit entities (including those involved in the commercial production or distribution of the intervention), or have a financial interest in the outcome of the research. Such a plan might include how assignment of units to treatment and comparison conditions, supervision of outcome data collection and coding, and data analysis are assigned to persons who were not involved in the development of the intervention and have no financial interest in the outcome of the evaluation.

- If you have previously received an award from any source to evaluate an intervention, discuss any theoretical and practical contributions made by your previous work. By demonstrating that your previous evaluation was successful, you provide a stronger case for your evaluation of another intervention.

d. Resources - The purpose of this section is to describe both how you have the institutional capacity to complete a project of this size and complexity and your access to the resources you will need to successfully complete this project.

Requirements: In order to be responsive and sent forward for peer review, applications under the Efficacy/Replication goal must include a Resources section that describes the following:

(i) Access to and/or a plan to acquire the resources you will need to successfully complete this project at the primary applicant institution and any subaward institutions.

Recommendations: In order to address the above requirements, the Institute recommends that you include the following in your Resources section to demonstrate that your team has a plan for acquiring or accessing the facilities, equipment, supplies, and other resources required to support the proposed Efficacy/Replication work and the commitments of each partner for the implementation and success of the project.

- Describe your institutional capacity and experience to manage a grant of this size.

- Describe your access to resources available at the primary institution and any subaward institutions.

- Describe your plan for acquiring any resources that are not currently accessible, will require significant expenditures, and are necessary for the successful completion of the project (e.g., equipment, test materials, curriculum or training materials).

- Describe your access to the schools (or other authentic education settings) in which the research will take place. Include letters of agreement in Appendix D documenting the participation and cooperation of the schools. Convincing letters will convey that the organizations understand what their participation in the study will involve (e.g., annual student and teacher surveys, student assessments, classroom observations).

- Include information about student, teacher and school incentives, if applicable.

- Describe your access to any data sets that you will require. Include letters of agreement, data licenses, or existing Memoranda of Understanding in Appendix D to document that you will be able to access the data for your proposed use. 


\section{(2) Awards}

An Efficacy/Replication project must conform to the following limits on duration and cost:

\section{Duration Maximums:}

- The maximum duration of an Efficacy or a Replication project is $\mathbf{4}$ years. An application of either type proposing a project length of greater than 4 years will be deemed nonresponsive to the Request for Applications and will not be accepted for review.

- The maximum duration of an Efficacy Follow-Up or a Retrospective project is 3 years. An application of either type proposing a project length of greater than 3 years will be deemed nonresponsive to the Request for Applications and will not be accepted for review.

\section{Cost Maximums:}

- The maximum award for an Efficacy or a Replication project is $\$ 3,500,000$ (total cost $=$ direct costs + indirect costs). An application of either type proposing a budget higher than the maximum award will be deemed nonresponsive to the Request for Applications and will not be accepted for review.

- The maximum award for an Efficacy Follow-Up project is $\$ 1,300,000$ (total cost $=$ direct costs + indirect costs). An application of this type proposing a budget higher than the maximum award will be deemed nonresponsive to the Request for Applications and will not be accepted for review.

- Grant funds should not be used for implementation of the intervention.

- The maximum award for a Retrospective project is $\$ \mathbf{8 0 0 , 0 0 0}$ (total cost $=$ direct costs + indirect costs). An application of this type proposing a budget higher than the maximum award will be deemed nonresponsive to the Request for Applications and will not be accepted for review.

\section{(3) Data Management Plan}

In anticipation of forthcoming federal policy changes regarding data access, applications under the Efficacy/Replication goal are to include a Data Management Plan (DMP, no more than five pages in Appendix E) that describes your plans for making the final research data from the proposed project accessible to others. DMPs are expected to differ depending on the nature of the project and the data collected. By addressing the items identified below, your DMP describes how you will meet the requirements of the U.S. Department of Education's forthcoming public access plan for final research data. The DMP should include the following:

- Type of data to be shared.

- Procedures for managing and for maintaining the confidentiality of the data to be shared.

- Roles and responsibilities of project or institutional staff in the management and retention of research data, including a discussion of any changes to the roles and responsibilities that will occur should the Project Director/Principal Investigator and/or Co-Project Directors/Co-Principal Investigators leave the project or their institution.

- Expected schedule for data access, including how long the data will remain accessible (at least 10 years) and acknowledgement that the timeframe of data accessibility will be reviewed at the annual progress reviews and revised as necessary.

- $\quad$ Format of the final data set. 
- Data set documentation to be provided.

- Method of data access (e.g., provided by the Project Director/Principal Investigator, through a data archive) and how those interested in using the data can locate and access them.

- Whether or not a data agreement that specifies conditions under which the data will be shared will be required.

- Any circumstances that prevent all or some of the data from being made accessible. This includes data that may fall under multiple statutes and, hence, must meet the confidentiality requirements for each applicable statute (e.g., data covered by Common Rule for Protection of Human Subjects, FERPA and HIPAA).

The costs of the DMP can be covered by the grant and should be included in the budget and explained in the budget narrative. The peer-review process will not include the DMP in the scoring of the scientific merit of the application. The Institute's program officers will be responsible for reviewing the completeness of the proposed DMP. If your application is being considered for funding based on the scores received during the peer-review process but your DMP is determined incomplete, you will have to complete your DMP before an award will be made. 


\section{Goal Four: Effectiveness}

\section{a) Purpose}

The Effectiveness goal supports the independent evaluation of fully-developed education interventions with prior evidence of efficacy to determine whether they produce a beneficial impact on student education outcomes relative to a counterfactual when they are implemented by the end user under routine conditions in authentic education settings. Unlike Efficacy/Replication, Effectiveness projects evaluate only interventions with prior evidence of efficacy when implemented without special support. ${ }^{23}$

Projects under the Effectiveness goal will result in the following:

- Evidence regarding the impact of a fullydeveloped intervention on relevant student education outcomes relative to a comparison condition using a research design that meets the Institute's What Works Clearinghouse evidence standards (with or without reservations) (http://ies.ed.gov/ncee/wwc).

- Conclusions on and revisions to the theory of change that guides the intervention and a discussion of the broader contributions to the theoretical and practical understanding of education processes and procedures.

- Information needed for future research on the intervention.

- If a beneficial impact is found, the identification of the organizational supports, tools, and procedures needed for sufficient implementation of the core components of the intervention under routine conditions.

- If no beneficial impact is found, an examination of why the findings differed from those of the previous efficacy studies on the intervention and a determination of whether and what type of further research would be useful to revise the intervention and/or its implementation.

\section{Intervention}

The wide range of education curricula, instructional approaches, professional development, technology, and practices, programs, and policies that are implemented at the student, classroom, school, district, state, or federal level to improve student education outcomes.

\section{Fully-developed intervention}

An intervention is fully-developed when all materials and products required for its implementation by the end user are readily available for use in authentic education settings.

\section{End user}

The person intended to be responsible for the implementation of the intervention.

\section{Routine conditions}

Conditions under which an intervention is implemented that reflect 1 ) the everyday practice occurring in homes, childcare, natural settings for infants and toddlers, classrooms, schools, and districts and 2) the heterogeneity of the target population.

\section{Independent evaluation}

An evaluation carried out by individuals who did not and do not participate in the development or distribution of the intervention and have no financial interest in the outcome of the evaluation.

\footnotetext{
${ }^{23}$ Effectiveness studies differ from Efficacy/Replication studies in several ways: (1) the intervention must already have been found to have beneficial impacts on student education outcomes by at least two prior efficacy studies; (2) the intervention must be implemented under routine conditions; (3) retrospective studies based on secondary data analyses are not allowed; (4) the project team involved in the evaluation activities must be independent of the intervention; and (5) the award duration is longer, cost maximums are higher, and a limit is placed on the percent of funds that can be used for implementing the intervention. 
The Effectiveness goal also supports Effectiveness Follow-Up studies to determine the long-term impacts of an intervention for students who showed beneficial results during an Effectiveness study as they enter later grades (or different authentic education settings) in which they do not continue to receive the intervention.

Retrospective studies based on secondary analysis of historical data are not allowed under the Effectiveness goal and should be submitted under Efficacy/Replication. However, applications under Effectiveness may include secondary analysis of historical data to supplement the primary analysis.

\section{b) Requirements and Recommendations and Data Management Plan}

Applications under the Effectiveness goal must meet the requirements set out under (1) Project Narrative and (2) Awards in order to be responsive and sent forward for scientific peer review. The requirements are the minimum necessary for an application to be sent forward for peer review.

In order to improve the quality of your application, the Institute offers recommendations following each set of Project Narrative requirements.

Applications under the Efficacy/Replication goal are to include a Data Management Plan as described in (3) Data Management Plan in anticipation of forthcoming federal policy changes regarding data access.

\section{(1) Project Narrative}

The 25-page project narrative for an Effectiveness project application must include four sections Significance, Research Plan, Personnel, and Resources.

a. Significance - The purpose of this section is to explain why it is important to independently test the impact of the intervention on student education outcomes under the proposed routine conditions and with the proposed sample.

Requirements: In order to be responsive and sent forward for peer review, applications under the Effectiveness goal must include a Significance section that describes the following:

(i) Evidence of the intervention's impact on student education outcomes.

a. For an Effectiveness study, the evidence includes at least two prior studies that meet the criteria for Efficacy/Replication studies.

b. For a Follow-Up study, the evidence comes from the original Effectiveness study.

(ii) A rationale for testing the impact of the intervention on student education outcomes in the proposed manner.

Recommendations: In order to address the above requirements, the Institute recommends that you include the following in your Significance section to justify the significance of the proposed work.

- Note the type of study proposed (Effectiveness or Follow-up) early in the Significance section.

- Describe the fully-developed intervention:

○ The intervention's components.

- Processes and materials (e.g., manuals, websites, training, coaching) that will be used to support implementation of the intervention. 
- Evidence that the intervention is fully developed and ready for implementation in authentic education settings (e.g., all materials and implementation supports such as professional development are available, the intervention is being implemented).

- Describe the intervention's implementation:

- Identify the target population and where implementation will take place.

- Identify who the end users of the intervention are and describe how implementation will be carried out by them.

- Describe the routine conditions under which the Effectiveness study will take place, including the following details:

- The implementation of the intervention, making clear that it would be the same as for any similar school or district intending to use the intervention.

- The heterogeneity of the sample in comparison with that of the target population.

- Explain how fidelity of implementation will be maintained in the Effectiveness study at least at the same levels found in the prior evaluations.

- Identify the implementation supports to be used in this project compared to those used under the previous efficacy evaluations of the intervention.

- Describe the measures you will use to assess the fidelity of implementation of the intervention and to determine what the comparison group is receiving.

- Clearly describe the initial theory of change for your proposed intervention (Figure 1 provides an example of one way that you could conceptualize a simple theory of change), along with theoretical justifications and empirical evidence that support it, keeping in mind that you may need to revise your theory over the course of the project.

- Your theory of change should describe the component or components of the planned intervention that are to lead to changes in one or multiple underlying processes, which in turn will foster better student education outcomes directly or through intermediate outcomes (e.g., changed teacher practices). A more complete theory of change could include further details such as the sample representing the target population, level of exposure to the components of the intervention, key moderators (such as setting, context, student and their family characteristics), and the specific measures used for the outcomes.

- For interventions designed to directly affect the teaching and learning environment and, thereby, indirectly affect student education outcomes, be clear in your theory of change to identify any intermediate outcomes that the intervention is designed to affect (e.g., teacher practices) and how these outcomes impact the student education outcomes of interest. 


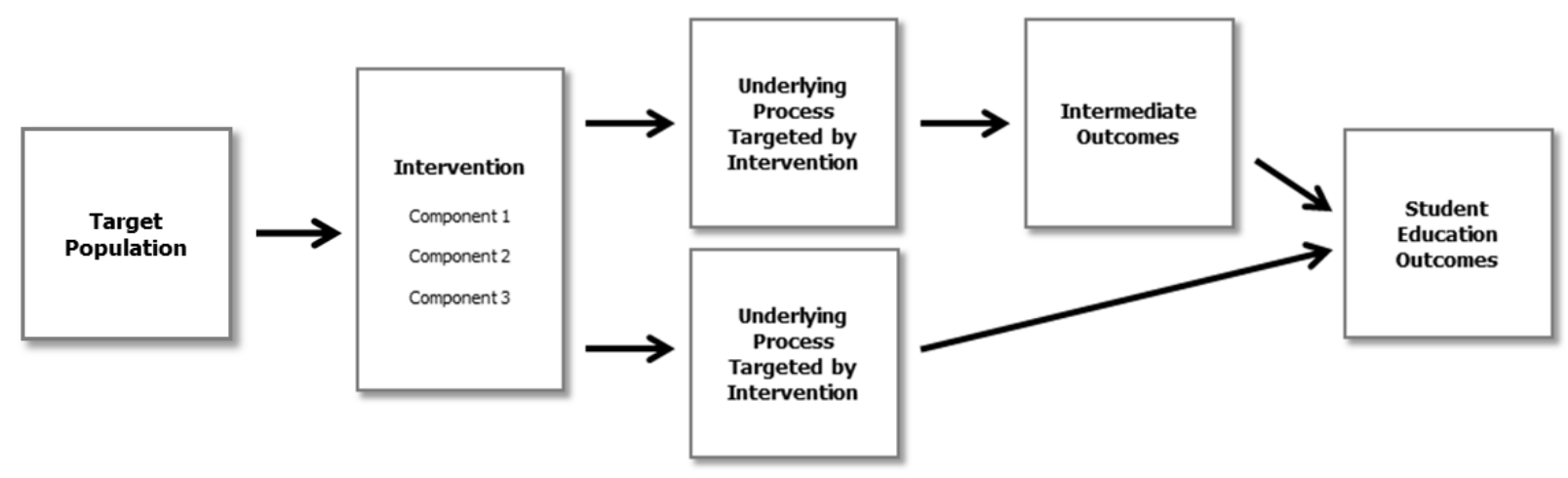

Figure 1. A diagram of a simple theory of change.

- When describing the two or more prior studies that provide evidence of the intervention's efficacy for an Effectiveness study, detail the conditions under which the intervention was implemented, the sample, research design, measures, fidelity of implementation, analysis, and results of the studies. In addition, describe the size and statistical significance of the effects that were found, indicate how any reported effect sizes were calculated, and discuss how the results show a practically important impact on student outcomes large enough to justify an Effectiveness study. ${ }^{24}$

- For an Effectiveness Follow-Up study, describe the existing evidence of the intervention's beneficial impact on student outcomes from a previous evaluation (either completed or ongoing) that would meet the requirements of the Institute's Effectiveness goal. To this end, clearly describe the Effectiveness study, including the sample, research design, measures, analyses, and results (including the size and significance of the effects and their practical importance).

- Student attrition during the prior study and the ability to follow students into later grades (especially at key transition points that entail moving schools) are key factors in the success of Follow-Up studies. Show that you have access to research participants for successful follow up (e.g., letters of agreement from schools or districts to be included in Appendix D). Discuss attrition during the Effectiveness study (a CONSORT flow diagram is recommended ${ }^{25}$ ) and how it will be addressed in the Follow-Up study.

- To provide a compelling rationale for testing the impact of the intervention on student education outcomes in the proposed manner, address why the intervention is likely to produce better student outcomes relative to current practice under routine conditions and the overall practical importance of the intervention (i.e., why education practitioners or policymakers should care about the results of the proposed evaluation).

- For Follow-Up studies, also discuss why those students who received the intervention would be expected to continue having beneficial impacts in future grades/sites when they no longer receive it.

\footnotetext{
${ }^{24}$ The prior studies are not required to have been from Institute-funded projects. Prior studies may have taken place under ideal or routine conditions.

${ }^{25}$ The Consort flow diagram that provides a structure for tracking participants at each study stage can be found at http://www.consort-statement.org/consort-statement/overview0/. 
b. Research Plan - The purpose of this section is to describe the independent evaluation of the intervention and the dissemination of the results. The Requirements and Recommendations for the Research Plan are the same as those for Efficacy/Replication except for Single-Case Experimental Design. For Effectiveness projects, Single-Case Experimental Designs are not allowed as your primary research design.

c. Personnel - The purpose of this section is to describe the relevant expertise of your research team, the responsibilities of each team member, and each team member's time commitments.

Requirements: In order to be responsive and sent forward for peer review, applications under the Effectiveness goal must include a Personnel section that describes the following:

\section{Effectiveness Research Plan}

The requirements and recommendations for the Research Plan are the same as those for the Efficacy and Replication goal.

(i) The research team at both the primary applicant institution and any subaward institutions.

(ii) The independence of the PI and key personnel involved in evaluation tasks from the intervention.

Recommendations: In order to address the above requirements, the Institute recommends that you include the following in your Personnel section to demonstrate that your team possesses the appropriate training and experience and will commit sufficient time to competently implement the proposed research.

- Identify and briefly describe the following for all key personnel (i.e., Principal Investigator, co-Principal Investigators, co-Investigators) on the project team: qualifications to carry out the proposed work, roles and responsibilities within the project, percent of time and calendar months per year (academic plus summer) to be devoted to the project, and past success at disseminating research findings in peer-reviewed scientific journals and other venues targeting policymakers and practitioners.

- Identify the management structure and procedures that will be used to keep the project on track and ensure the quality of its work. This is especially important for projects involving multiple institutions carrying out different tasks that must be coordinated and/or integrated.

- Show that the PI and key personnel involved in the design of the evaluation, the assignment to treatment and comparison groups, and the data analysis did not and do not participate in the development or distribution of the intervention and do not have a financial interest in the intervention.

- The developer or distributor of the intervention may provide the typical implementation support they would provide under the routine adoption of the intervention (e.g., professional development). If included, discuss how their involvement will not jeopardize the objectivity of the research.

- If you have previously received an award from any source to evaluate an intervention, discuss any theoretical and practical contributions made by your previous work. By 
demonstrating that your previous evaluation was successful, you provide a stronger case for your evaluation of another intervention.

d. Resources - The purpose of this section is to describe both how you have the institutional capacity to complete a project of this size and complexity and your access to the resources you will need to successfully complete this project.

Requirements: In order to be responsive and sent forward for peer review, applications under the Effectiveness goal must include a Resources section that describes the following:

(i) Access to and/or a plan to acquire the resources you will need to successfully complete this project at the primary applicant institution and any subaward institutions.

Recommendations: In order to address the above requirements, the Institute recommends that you include the following in your Resources section to demonstrate that your team has a plan for acquiring or accessing the facilities, equipment, supplies, and other resources required to support the proposed Effectiveness work and the commitments of each partner for the implementation and success of the project.

- Describe your institutional capacity and experience to manage a grant of this size.

- Describe your access to resources available at the primary institution and any subaward institutions.

- Describe your plan for acquiring any resources that are not currently accessible, will require significant expenditures, and are necessary for the successful completion of the project (e.g., equipment, test materials, curriculum or training materials).

- Describe your access to the schools (or other authentic education settings) in which the research will take place. Include letters of agreement in Appendix D documenting the participation and cooperation of the schools. Convincing letters will convey that the organizations understand what their participation in the study will involve (e.g., annual student and teacher surveys, student assessments, classroom observations).

- Include information about student, teacher and school incentives, if applicable.

- Describe your access to any data sets that you will require. Include letters of agreement, data licenses, or existing Memoranda of Understanding in Appendix D to document that you will be able to access the data for your proposed use.

\section{(2) Awards}

An Effectiveness project must conform to the following limits on duration and cost:

\section{Duration Maximums:}

- The maximum duration of an Effectiveness project is $\mathbf{5}$ years. An application of this type proposing a project length of greater than 5 years will be deemed nonresponsive to the Request for Applications and will not be accepted for review.

- The maximum duration of an Effectiveness Follow-Up project is $\mathbf{3}$ years. An application of this type proposing a project length of greater than 3 years will be deemed nonresponsive to the Request for Applications and will not be accepted for review. 


\section{Cost Maximums:}

- The maximum award for an Effectiveness project is $\$ 5,000,000$ (total cost = direct costs + indirect costs). An application of this type proposing a budget higher than the maximum award will be deemed nonresponsive to the Request for Applications and will not be accepted for review.

- No more than 25 percent of the award may be allocated to the cost of the intervention. The cost of the intervention includes any materials, textbooks, software, computers, or training required to implement the intervention. When calculating the cost of the intervention, you should not include salaries for school or district staff who implement the intervention as part of their regular duties or funds allocated to pay teachers or other participants for time involved in completing questionnaires, surveys, or any other assessments that are part of the evaluation. Note the budgeted cost of the intervention and the percentage of the project's total funding represented by the cost of the intervention in your budget narrative.

- The maximum award for an Effectiveness Follow-Up project is $\$ 1,600,000$ (total cost $=$ direct costs + indirect costs). An application of this type proposing a budget higher than the maximum award will be deemed nonresponsive to the Request for Applications and will not be accepted for review.

- Grant funds should not be used for purchase or implementation of the intervention.

\section{(3) Data Management Plan}

In your Effectiveness application, include a Data Management Plan (DMP) in Appendix E that is no more than five pages. The DMP describes how you will meet the requirements of the U.S. Department of Education's forthcoming public access plan for final research data. The items to be described under your DMP are the same as those listed for Efficacy/Replication.

Effectiveness Data Management Plan

The requirements and recommendations for the DPM are the same as those for the Efficacy/Replication goal. 


\section{Goal Five: Measurement}

\section{a) Purpose}

The Measurement goal supports 1) the development of new assessments or refinement of existing assessments (Development/Refinement Projects) or 2) the validation of existing assessments for specific purposes, contexts, and populations (Validation Projects). Measurement projects can address a wide variety of measures, depending on the topic, such as academic tests, behavioral measures, observational tools, informal assessments, and school quality indicators. Measurement projects can address a range of purposes, such as measuring knowledge, skills, and abilities; guiding instruction; improving educator practice; evaluating educator job performance; or assessing the effectiveness of schools or school systems. All measurement projects must link the assessment to student education outcomes.

Development/Refinement Projects will result in the following:

- A fully-developed version of the proposed assessment or refinement.

- A detailed description of the assessment or refinements and their intended use.

- A detailed description of the iterative development processes used to develop or refine the assessment, including field-testing procedures and processes for item revision.

All projects under the Measurement goal will result in the following:

- A well-specified assessment framework that provides the rationale for the assessment, the theoretical basis that underlies its design, and its validation activities.

- A detailed description of the validation activities.

- Evidence of the reliability and validity of the assessment for the specified purpose(s), populations, and contexts.

\section{b) Requirements and Recommendations}

Applications under the Measurement goal must meet

the requirements set out under (1) Project Narrative and (2) Awards in order to be responsive and sent forward for scientific peer review. The requirements are the minimum necessary for an application to be sent forward for peer review.

In order to improve the quality of your application, the Institute offers recommendations following each set of Project Narrative requirements.

\section{(1) Project Narrative}

The 25-page project narrative for a Measurement project application must include four sections Significance, Research Plan, Personnel, and Resources. 
a. Significance - The purpose of this section is to explain why it is important either to develop/refine this assessment or to validate the assessment for a specific purpose and/or population.

Requirements: In order to be responsive and sent forward for peer review, applications under the Measurement goal must include a Significance section that describes the following:

Development/Refinement Projects:

(i) The new assessment or refinement for an existing assessment.

(ii) A rationale for the need for the new assessment or refinement.

Validation Projects:

(i) A rationale for collecting additional evidence of validity.

Recommendations: In order to address the above requirements, the Institute recommends that you include the following in your Significance section to provide a compelling rationale for the proposed measurement work.

Development/Refinement Projects:

- Describe the specific need for developing or refining the assessment. Discuss how the results of this work will be important both to the field of special education research and to education practice and education stakeholders (e.g., practitioners and policymakers).

- Identify any current assessments that address this need and explain why they are not satisfactory. Contrast the new assessment with current typical assessment practice and its identified shortcomings. A detailed description of the assessment will clearly show that it has the potential to provide a better measure of the intended construct(s) because 1 ) it is sufficiently different from current assessments practice and does not

The assessment framework includes the following:

- Operational definition(s) of the construct(s) of measurement.

- Theoretical model showing how construct(s) are related to each other and/or external variables.

- Description of how the assessment provides evidence of the construct(s) identified in the rationale.

- Description of the processes for reasoning from assessment items and scores to the intended inferences regarding the construct(s) of measurement.

- Description of the intended use(s) and population(s) for which the assessment is meant to provide valid inferences. suffer from the same shortcomings,

2) it has a strong theoretical or empirical basis, and 3) its implementation appears feasible for researchers, teachers and schools given their resource constraints (e.g., time, funds, personnel, schedules). 


\section{Validation Projects:}

- Describe the specific need for validating an existing assessment. Discuss how the results of this work will be important both to the field of special education research and to education practice and education stakeholders (e.g., practitioners, policymakers).

- Identify current validation evidence for this assessment and explain why it is not satisfactory for the proposed purpose(s).

\section{All Measurement Projects:}

- Describe the assessment framework and the fit between validation activities and the assessment framework.

- If you are applying for a second Measurement award to further develop or validate an assessment that was the focus of a previous Measurement award, justify the need for a second award and describe the results and outcomes of the previous award (e.g., the status of the assessment and its validation).

b. Research Plan - The purpose of this section is to describe the methodology you will use to develop, refine, and/or establish the validity of your assessment and disseminate the project's findings.

Requirements: In order to be responsive and sent forward for peer review, applications under the Measurement goal must include a Research Plan section that describes the following:

\section{Development/Refinement Projects:}

(i) The method for developing, field testing, and refining the assessment.

\section{All measurement projects:}

(ii) The method for collecting evidence of reliability and validity.

(iii) Data analysis procedures.

(iv) The sample for the studies.

(v) A plan for dissemination.

Recommendations: In order to address the above requirements, the Institute recommends that you include the following in your Research Plan section to strengthen the methodological rigor of the proposed measurement project and to optimize the dissemination plan.

\section{Development/Refinement Projects:}

- Describe the iterative procedures for developing, field testing, and selecting items to be used in the assessment and for obtaining representative responses to items.

- Describe the procedures for scoring the assessment, including justification for the scaling model that will be used to create scores. For example, if item response theory will be used to create scores, describe the model that will be applied.

- Describe the procedures for demonstrating adequate construct coverage and minimizing the influence of factors irrelevant to the construct.

- Provide the plans for establishing the fairness of the test for all members of the intended population (e.g., differential item functioning). 
- Describe the procedures for determining the administrative procedures for conducting the assessment (e.g., mode of administration, inclusion/exclusion of individual test takers, accommodations, and whether make-ups or alternative administrative conditions will be allowed).

- Describe the plans for examining the feasibility of use of the assessment for the intended purpose.

- If alternate forms will be developed, describe the procedures for establishing the equivalency of the forms (i.e., horizontal equating).

- If the proposed assessment is used to measure growth, describe the procedures for establishing a developmental scale (i.e., vertical equating).

\section{All Measurement Projects.}

- Identify the theoretical and analytic steps that you will undertake to provide evidence that an assessment measures the intended construct for a given purpose and population.

- Describe the procedures for determining the reliability of the assessment for the intended purpose and population.

- Identify the types of validity evidence that will be used and provide justification for the adequacy of the selected types of evidence to support use of the assessment (e.g., predictive, concurrent, convergent, discriminant).

- You may propose to do some laboratory research as long as it adheres to the sample and outcome requirements outlined for the topic you select.

- Justify the amount of laboratory research that you are choosing to do and describe how it will provide relevant evidence for the validation or development/refinement of the assessment and how it will improve use of the assessment in authentic education settings. In addition, the materials and procedures should allow for generalizability to authentic education settings.

- Describe the statistical models and analyses that will be used (e.g., structural equation modeling; type of IRT model).

\section{Dissemination Plan for All Measurement Projects:}

- Identify the audiences that you expect will be most likely to benefit from your research (e.g., other researchers, federal or state policymakers, state and local school system administrators, principals, teachers, counselors, parents, students, and others).

- Discuss the ways in which you intend to reach these audiences through the major publications, presentations, and products you expect from your project.

- Be cognizant of the particular research goal of your project and how this affects the type and use of your findings. The Institute expects that the dissemination of Development/Refinement Projects would clearly specify the validity evidence for the appropriate users. Validation Projects should be tied to wider use for an existing or new purpose and/or population.

- Findings that assessments are not validated for specific uses or populations should be disseminated to support decision-making regarding those assessments. 


\section{Timeline:}

- Provide a timeline for each step in your project including such actions as measurement development (if applicable), sample selection and assignment, data collection, validation activities, data analysis, and dissemination.

- The timeline may be discussed in the project narrative and/or presented in Appendix B.

c. Personnel - The purpose of this section is to describe the relevant expertise of your research team, the responsibilities of each team member, and each team member's time commitments.

Requirements: In order to be responsive and sent forward for peer review, applications under the Measurement goal must include a Personnel section that describes the following:

(i) The research team at both the primary applicant institution and any subaward institutions.

Recommendations: In order to address the above requirements, the Institute recommends that you include the following in your Personnel section to demonstrate that your team possesses the appropriate training and experience and will commit sufficient time to competently implement the proposed research.

- You will need to describe a research team that collectively demonstrates the expertise in content domain(s), assessment development and administration, psychometrics, and statistical analysis as appropriate to support your scope of work. In many projects it will also be important to include staff with expertise working with teachers, in schools, or in other education delivery settings in which the proposed assessment is intended to be used.

- Identify and briefly describe the following for all key personnel (i.e., Principal Investigator, co-Principal Investigators, co-Investigators) on the project team: qualifications to carry out the proposed work, roles and responsibilities within the project, percent of time and calendar months per year (academic plus summer) to be devoted to the project, and past success at disseminating research findings in peer-reviewed scientific journals.

- Identify the management structure and procedures that will be used to keep the project on track and ensure the quality of its work. This is especially important for projects involving multiple institutions carrying out different tasks that must be coordinated and/or integrated.

- Key personnel may be from for-profit entities. However, if these entities are to be involved in the commercial production or distribution of the assessment being developed and/or validated, include a plan describing how their involvement will not jeopardize the objectivity of the research.

- If you have previously received a Measurement award and are applying for a grant to develop/refine and/or validate a new assessment, indicate the status of the previous assessment, its current use in education research, and/or the citing of your validation work in studies that use the assessment. 
d. Resources - The purpose of this section is to describe both how you have the institutional capacity to complete a project of this size and complexity and your access to the resources you will need to successfully complete this project.

Requirements: In order to be responsive and sent forward for peer review, applications under the Measurement goal must include a Resources section that describes the following:

(i) Access to and/or a plan to acquire the resources you will need to successfully complete this project at the primary applicant institution and any subaward institutions.

Recommendations: In order to address the above requirements, the Institute recommends that you include the following in your Resources section to demonstrate that your team has a plan for acquiring or accessing the facilities, equipment, supplies, and other resources required to support the proposed Measurement work and the commitments of each partner for the implementation and success of the project.

- Describe your institutional capacity and experience to manage a grant of this size.

- Describe your access to resources available at the primary institution and any subaward institutions.

- Describe your plan for acquiring any resources that are not currently accessible, will require significant expenditures, and are necessary for the successful completion of the project (e.g., equipment, test materials, curriculum or training materials).

- Describe your access to the schools (or other authentic education settings) in which the research will take place. Include letters of agreement in Appendix D documenting the participation and cooperation of the schools. Convincing letters will convey that the organizations understand what their participation in the study will involve (e.g., annual student and teacher surveys, student assessments, classroom observations).

- Include information about teacher and school incentives, if applicable.

- Describe your access to any data sets that you will require. Include letters of agreement, data licenses, or existing Memoranda of Understanding in Appendix D to document that you will be able to access the data for your proposed use.

(2) Awards

A Measurement project must conform to the following limits on duration and cost:

\section{Duration Maximums:}

- The maximum duration of a Measurement project is $\mathbf{4}$ years. An application of this type proposing a project length of greater than 4 years will be deemed nonresponsive to the Request for Applications and will not be accepted for review.

\section{Cost Maximums:}

- The maximum award for a Measurement project is $\$ 1,600,000$ (total cost = direct costs + indirect costs). An application of this type proposing a budget higher than the maximum award will be deemed nonresponsive to the Request for Applications and will not be accepted for review. 


\section{PART IV: COMPETITION REGULATIONS AND REVIEW CRITERIA}

\section{A. FUNDING MECHANISMS AND RESTRICTIONS}

\section{Mechanism of Support}

The Institute intends to award grants pursuant to this Request for Applications.

\section{Funding Available}

Although the Institute intends to support the research topics and goals described in this announcement, all awards pursuant to this Request for Applications are contingent upon the availability of funds and the receipt of meritorious applications. The Institute makes its awards to the highest quality applications, as determined through scientific peer review, regardless of topic or goal.

The size of the award depends on the research goal and scope of the project. Please attend to the duration and budget maximums set for each goal in Part III Goal Requirements. If you request a project length longer than the maximum or a budget higher than the maximum, your application will be deemed nonresponsive and will not be reviewed.

\section{Special Considerations for Budget Expenses}

\section{Indirect Cost Rate}

When calculating your expenses for research conducted in field settings, you should apply your institution's negotiated off-campus indirect cost rate, as directed by the terms of your institution's negotiated agreement with the federal government. Questions about indirect cost rates should be directed to the U.S. Department of Education's Indirect Cost Group http://www2.ed.gov/about/offices/list/ocfo/fipao/icgindex.html.

Institutions, both primary grantees and sub-awardees, not located in the territorial U.S. cannot charge indirect costs.

\section{Meetings and Conferences}

If you are requesting funds to cover expenses for hosting meetings or conferences, please note that there are statutory and regulatory requirements in determining whether costs are reasonable and necessary. Please refer to OMB's new Uniform Administrative Requirements, Cost Principles, and Audit Requirements for Federal Awards https://federalregister.gov/a/2013-30465 for more information.

In particular, federal grant funds cannot be used to pay for alcoholic beverages or entertainment, which includes costs for amusement, diversion, and social activities. In general, federal funds may not be used to pay for food. A grantee hosting a meeting or conference may not use grant funds to pay for food for conference attendees unless doing so is necessary to accomplish legitimate meeting or conference business. You may request funds to cover expenses for working meetings (e.g., working lunches); however, the Institute will determine whether these costs are allowable in keeping with the new OMB Uniform Cost Principles. Grantees are responsible for the proper use of their grant awards and may have to repay funds to the Department if they violate the rules for meeting- and conference-related expenses. 


\section{Program Authority}

20 U.S.C. 9501 et seq., the "Education Sciences Reform Act of 2002," Title I of Public Law 107-279, November 5, 2002. This program is not subject to the intergovernmental review requirements of Executive Order 12372.

\section{Applicable Regulations}

The Education Department General Administrative Regulations (EDGAR) in 34 CFR parts 74, 77, 80, 81, $82,84,85,86$ (part 86 applies only to institutions of higher education), 97, 98, and 99. In addition 34 CFR part 75 is applicable, except for the provisions in 34 CFR 75.100, 75.101(b), 75.102, 75.103, 75.105, 75.109(a), 75.200, 75.201, 75.209, 75.210, 75.211, 75.217, 75.219, 75.220, 75.221, 75.222, and 75.230.

\section{B. ADDITIONAL AWARD REQUIREMENTS}

1. Public Availability of Data and Results

Include a Data Management Plan (DMP) in Appendix E if you are submitting an Efficacy and Replication application or an Effectiveness application. The peer-review process will not include the DMP in the scoring of the scientific merit of the application. Instead, the Institute's program officers will be responsible for reviewing the completeness of the proposed DMP. If your application is being considered for funding based on the scores received during the peer-review process but your DMP is missing or determined incomplete, you will have to complete your DMP before an award will be made. The costs of the DMP can be covered by the grant and should be included in the budget and explained in the budget narrative.

Recipients of awards are expected to publish or otherwise make publicly available the results of the work supported through this program. Institute-funded investigators must submit final manuscripts resulting from research supported in whole or in part by the Institute to the Educational Resources Information Center (ERIC, http://eric.ed.gov) upon acceptance for publication. An author's final manuscript is defined as the final version accepted for journal publication and includes all graphics and supplemental materials that are associated with the article. The Institute will make the manuscript available to the public through ERIC no later than 12 months after the official date of publication. Investigators and their institutions are responsible for ensuring that any publishing or copyright agreements concerning submitted articles fully comply with this requirement.

\section{Special Conditions on Grants}

The Institute may impose special conditions on a grant if the grantee is not financially stable, has a history of unsatisfactory performance, has an unsatisfactory financial or other management system, has not fulfilled the conditions of a prior grant, or is otherwise not responsible.

\section{Demonstrating Access to Data and Authentic Education Settings}

The research you propose to do under a specific topic and goal will most likely require that you have (or will obtain) access to authentic education settings (e.g., classrooms, schools, districts), secondary data sets, or studies currently under way. In such cases, you will need to provide evidence that you have access to these resources prior to receiving funding. Whenever possible, include letters of agreement in Appendix $D$ from those who have responsibility for or access to the data or settings you wish to incorporate when you submit your application. Even in circumstances where you have included such letters with your application, the Institute may require additional supporting evidence prior to the release of funds. If you cannot provide such documentation, the Institute may not award the grant or may withhold funds.

You will need supporting evidence of partnership or access if you are: 
- Conducting research in or with authentic education settings - If your application is being considered for funding based on scientific merit scores from the peer-review panel and your research relies on access to authentic education settings (e.g., schools), you will need to provide documentation that you have access to the necessary settings in order to receive the grant. This means that if you do not have permission to conduct the proposed project in the necessary number of settings at the time of application, you will need to provide documentation to the Institute indicating that you have successfully recruited the necessary number of settings for the proposed research before the full first-year costs will be awarded. If you recruited sufficient numbers of settings prior to the application, the Institute may ask you to provide documentation that the settings originally recruited for the application are still willing to partner in the research.

- Using secondary data sets - If your application is being considered for funding based on scientific merit scores from the peer-review panel and your research relies on access to secondary data sets (such as federally-collected data sets, state or district administrative data, or data collected by you or other researchers), you will need to provide documentation that you have access to the necessary data sets in order to receive the grant. This means that if you do not have permission to use the proposed data sets at the time of application, you must provide documentation to the Institute from the entity controlling the data set(s) before the grant will be awarded. This documentation must indicate that you have permission to use the data for the proposed research for the time period discussed in the application. If you obtained permission to use a proposed data set prior to submitting your application, the Institute may ask you to provide updated documentation indicating that you still have permission to use the data set to conduct the proposed research during the project period.

- Building off of existing studies - You may propose studies that piggyback onto an ongoing study (i.e., that require access to subjects and data from another study). In such cases, the Principal Investigator of the existing study should be one of the members of the research team applying for the grant to conduct the new project.

In addition to obtaining evidence of access, the Institute strongly advises applicants to establish a written agreement, within 3 months of receipt of an award, among all key collaborators and their institutions (e.g., Principal and Co-Principal Investigators) regarding roles, responsibilities, access to data, publication rights, and decision-making procedures.

\section{OVERVIEW OF APPLICATION AND PEER REVIEW PROCESS}

1. Submitting a Letter of Intent

Institute strongly encourages potential applicants to submit a Letter of Intent by June 5, 2014. Letters of Intent are optional, non-binding, and not used in the peer review of a subsequent application. However, when you submit a Letter of Intent, one of the Institute's Program Officers will contact you regarding your proposed research to offer assistance. The Institute also uses the Letter of Intent to identify the expertise needed for the scientific peer-review panels and to secure a sufficient number of reviewers to handle the anticipated number of applications. Should you miss the deadline for submitting a Letter of Intent, you still may submit an application. If you miss the Letter of Intent deadline, the Institute asks that you inform the relevant program officer of your intention to submit an application.

Letters of Intent are submitted online at (https://iesreview.ed.gov). Select the Letter of Intent form for the topic under which you plan to submit your application. The online submission form contains fields for each of the seven content areas listed below. Use these fields to provide the requested information. The project description should be single-spaced and should not exceed one page (about 3,500 characters).

For awards beginning in FY 2015

Posted April 16, 2014

Special Education Research, p. 79 
- Descriptive title

- Topic and goal that you will address

- Brief description of the proposed project

- Name, institutional affiliation, address, telephone number and e-mail address of the Principal Investigator and any Co-Principal Investigators

- Name and institutional affiliation of any key collaborators and contractors

- Duration of the proposed project (attend to the Duration maximums for each goal)

- Estimated total budget request (attend to the Budget maximums for each goal)

\section{Resubmissions and Multiple Submissions}

If you intend to revise and resubmit an application that was submitted to one of the Institute's previous competitions but that was not funded, you must indicate on the SF-424 Form of the Application Package (Items 4a and 8) (see Part VI.E.1.) that the FY 2015 application is a resubmission (Item 8) and include the application number of the previous application (an 11-character alphanumeric identifier beginning "R305" or "R324" entered in Item 4a). The prior reviews will be sent to this year's reviewers along with the resubmitted application. You must describe your response to the prior reviews using Appendix A (see Part V.D.3.). Revised and resubmitted applications will be reviewed according to this FY 2015 Request for Applications.

If you submitted a somewhat similar application in the past and did not receive an award but are submitting the current application as a new application, you should indicate on the application form that the FY 2015 application is a new application. You must provide a rationale explaining why the FY 2015 application should be considered a new application rather than a revision using Appendix A (see Part

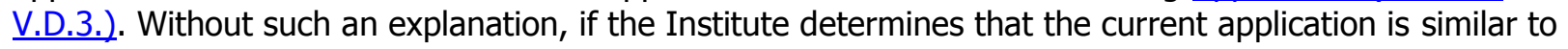
a previously unfunded application, the Institute may send the reviews of the prior unfunded application to this year's reviewers along with the current application.

You may submit applications to more than one of the Institute's FY 2015 grant programs and to multiple topics within the Special Education Research Grants program. In addition, within a particular grant program or topic, you may submit multiple applications. However, you may submit a given application only once for the FY 2015 grant competitions (i.e., you may not submit the same application or similar applications to multiple grant programs, multiple topics, or multiple times within the same topic). If you submit the same or similar applications, the Institute will determine whether and which applications will be accepted for review and/or will be eligible for funding.

\section{Application Processing}

Applications must be submitted electronically and received by 4:30:00 p.m., Washington, DC time on August 7, 2014. Grant applications are submitted through the Internet using the software provided on the Grants.gov website: http://www.grants.gov/. You must follow the application procedures and submission requirements described in Part V Preparing Your Application and Part VI Submitting Your Application and the instructions in the User Guides provided by Grants.gov (http://www.grants.gov/web/grants/applicants/applicant-resources.html).

After receiving the applications, Institute staff will review each application for compliance and responsiveness to this Request for Applications. Applications that do not address specific requirements of this request will be returned to the applicant without further consideration.

Once you formally submit an application, Institute staff will not comment on its status until the award decisions are announced (no later than July 1,2015 ) except with respect to issues of compliance and responsiveness. 
Once an application has been submitted and the application deadline has passed, you may not submit additional materials for inclusion with your application.

\section{Peer Review Process}

The Institute will forward all applications that are compliant and responsive to this Request for Applications to be evaluated for scientific and technical merit. Scientific reviews are conducted in accordance with the review criteria stated below and the review procedures posted on the Institute's website, http://ies.ed.gov/director/sro/peer review/application review.asp, by a panel of scientists who have substantive and methodological expertise appropriate to the program of research and Request for Applications.

Each compliant and responsive application is assigned to one of the Institute's scientific review panels. At least two primary reviewers will complete written evaluations of the application, identifying strengths and weaknesses related to each of the review criteria. Primary reviewers will independently assign a score for each criterion, as well as an overall score, for each application they review. Based on the overall scores assigned by primary reviewers, the Institute calculates an average overall score for each application and prepares a preliminary rank order of applications before the full peer-review panel convenes to complete the review of applications.

The full panel will consider and score only those applications deemed to be the most competitive and to have the highest merit, as reflected by the preliminary rank order. A panel member may nominate for consideration by the full panel any application that he or she believes merits full panel review but that would not have been included in the full panel meeting based on its preliminary rank order.

\section{Review Criteria for Scientific Merit}

The purpose of Institute-supported research is to contribute to solving education problems and to provide reliable information about the education practices that support learning and improve academic achievement and access to education for all students. The Institute expects reviewers for all applications to assess the following aspects of an application in order to judge the likelihood that the proposed research will have a substantial impact on the pursuit of that goal. Information pertinent to each of these criteria is described in Part III Goal Requirements and in the section describing the relevant research grant topic within Part II Topic Requirements.

\section{a) Significance}

Does the applicant provide a compelling rationale for the significance of the project as defined in the Significance section for the goal under which the applicant is submitting the application?

\section{b) Research Plan}

Does the applicant meet the methodological requirements described in the Research Plan section for the goal under which the applicant is submitting the application? Does the dissemination plan address a range of audiences in ways that are useful to them and reflective of the type of research done (e.g., the research goal)?

\section{c) Personnel}

Does the description of the personnel make it apparent that the Principal Investigator and other key personnel possess appropriate training and experience and will commit sufficient time to competently implement the proposed research?

\section{d) Resources}

Does the applicant have the facilities, equipment, supplies, and other resources required to support the proposed activities? Do the commitments of each partner show support for the implementation and success of the project? 


\section{Award Decisions}

The following will be considered in making award decisions for responsive and compliant applications:

- Scientific merit as determined by peer review,

- Performance and use of funds under a previous Federal award,

- Contribution to the overall program of research described in this Request for Applications, and

- Availability of funds. 


\section{PART V: PREPARING YOUR APPLICATION}

\section{A. OVERVIEW}

The application contents - individual forms and their PDF attachments -represent the body of an application to the Institute. All applications for Institute funding must be self-contained. As an example, reviewers are under no obligation to view an Internet website if you include the site address (URL) in the application. In addition, you may not submit additional materials directly to the Institute after the application package is submitted.

\section{B. GRANT APPLICATION PACKAGE}

The Application Package for this competition (84-324A2015) provides all of the forms that you must complete and submit. The application form approved for use in the competition specified in this Request for Applications is the government-wide SF-424 Research and Related (R\&R) Form (OMB Number 40400001).

\section{Date Application Package is Available on Grants.gov}

The Application Package will be available on http://www.grants.gov/ by June 5, 2014.

\section{How to Download the Correct Application Package}

To find the correct downloadable Application Package, you must first search by the CFDA number for this research competition without the alpha suffix. To submit an application to the Special Education Research Grants program, you must search on: CFDA 84.324.

The Grants.gov search on CFDA 84.324 will yield more than one Application Package. For the Special Education Research Grants program, you must download the Application Package marked:

- $\quad$ Special Education Research CFDA 84.324A

You must download the Application Package that is designated for this grant competition. If you use a different Application Package, even if it is for another Institute competition, the application will be submitted to the wrong competition. Applications submitted using the incorrect application package run the risk of not being reviewed according to the requirements and recommendations for the Special Education Research Grants competition.

See Part VI: Submitting Your Application, for a complete description of the forms that make up the application package and directions for filling out these forms.

\section{GENERAL FORMATTING}

For a complete application, you must submit the following as individual attachments to the R\&R forms that are contained in the application package for this competition in Adobe Portable Document Format (PDF):

- Project Summary/Abstract;

- Project Narrative and, if applicable, Appendix A, Appendix B, Appendix C, Appendix D, and Appendix E (all together as one PDF file);

- Bibliography and References Cited;

- Research on Human Subjects Narrative (i.e., Exempt or Non-Exempt Research Narrative);

- A Biographical Sketch for each senior/key person;

- A List of Current and Pending Support for each senior/key person; 
- A Narrative Budget Justification for the total Project budget; and

- Subaward Budget(s) that has (have) been extracted from the R\&R Subaward Budget (Fed/NonFed) Attachment(s) Form, if applicable.

Information about the formatting requirements for all of these documents except the Subaward budget attachment (see Part VI.E.6.) is provided below.

\section{Page and Margin Specifications}

For all Institute research grant applications, a "page" is 8.5 in. $x 11$ in., on one side only, with 1 inch margins at the top, bottom, and both sides.

\section{Page Numbering}

Add page numbers using the header or footer function, and place them at the bottom or upper right corner for ease of reading.

\section{Spacing}

Text must be single spaced.

\section{Type Size (Font Size)}

Type must conform to the following three requirements:

- The height of the letters must not be smaller than a type size of 12 point.

- Type density, including characters and spaces, must be no more than 15 characters per inch (cpi). For proportional spacing, the average for any representative section of text must not exceed 15 cpi.

- Type size must yield no more than six lines of type within a vertical inch.

You should check the type size using a standard device for measuring type size, rather than relying on the font selected for a particular word processing/printer combination. The type size used must conform to all three requirements. Small type size makes it difficult for reviewers to read the application; consequently, the use of small type will be grounds for the Institute to return the application without peer review.

Adherence to type size and line spacing requirements is necessary so that no applicant will have an unfair advantage, by using small type or by providing more text in their applications. These requirements apply to the PDF file as submitted. As a practical matter, if you use a 12-point Times New Roman font without compressing, kerning, condensing or other alterations, the application will typically meet these requirements.

\section{Graphs, Diagrams, and Tables}

You are encouraged to use black and white in graphs, diagrams, tables, and charts. If color is used, you should ensure that the material reproduces well when photocopied in black and white.

Text in figures, charts, and tables, including legends, may be in a type size smaller than 12 point but must be readily legible.

\section{PDF ATTACHMENTS \\ 1. Project Summary/Abstract}

\section{a) Submission}

You must submit the project summary/abstract as a separate PDF attachment at Item 7 of the Other Project Information form (see Part VI.E.4: Research \& Related Other Project Information). 


\section{b) Page limitations}

The project summary/abstract is limited to one single-spaced page.

\section{c) Content}

The project summary/abstract should include the following:

- Title of the project.

- The topic and goal to which you are applying (e.g., Mathematics and Science Education, Development and Innovation goal).

- Purpose: A brief description of the purpose of the project (e.g., to develop and document the feasibility of an intervention) and its significance for improving education outcomes for U.S. students.

- Setting: A brief description of the location (e.g., state or states) where the research will take place and other important characteristics of the locale (e.g., urban/suburban/rural).

- Sample: A brief description of the sample that will be involved in the study (e.g., number of participants, age or grade level, race/ethnicity, SES).

- Intervention/Assessment: If applicable, a brief description of the intervention or assessment to be developed, evaluated, or validated.

- Control Condition: If applicable, a brief description of the control or comparison condition (i.e., who the participants in the control condition are and what they will experience).

- Research Design and Methods: Briefly describe the major features of the design and methodology to be used. (e.g., randomized controlled trial, quasi-experimental design, mixed method design; iterative design process).

- Key Measures: A brief description of key measures and outcomes.

- Data Analytic Strategy: A brief description of the data analytic strategy that will be used to answer research questions.

Please see http://ies.ed.gov/ncser/projects for examples of the content to be included in your project summary/abstract.

\section{Project Narrative}

\section{a) Submission}

You must submit the project narrative as a separate PDF attachment at Item 8 of the Other Project Information form (see Part VI.E.4: Research \& Related Other Project Information).

\section{b) Page limitations}

The project narrative is limited to 25 pages. If the narrative exceeds this page limit, the Institute will remove any pages after the $25^{\text {th }}$ page of the narrative.

To help reviewers locate information and conduct the highest quality review, you should write a concise and easy to read application, with pages numbered consecutively using the header or footer function to place numbers at the top or bottom right-hand corner. 


\section{c) Format for citing references in text}

To ensure that all applicants have the same amount of available space in which to describe their projects in the project narrative, use the author-date style of citation (e.g., James, 2004), such as that described in the Publication Manual of the American Psychological Association, 6th Ed. (American Psychological Association, 2009).

\section{d) Content}

Your project narrative must include four sections in order to be compliant with the requirements of this Request for Applications: (1) Significance, (2) Research Plan, (3) Personnel, and (4) Resources. Information to be included in each of these sections is detailed in Part III: Goal Requirements. The information you include in each of these four sections will provide the majority of the information on which reviewers will evaluate the application.

\section{Appendix A (Required for Resubmissions)}

\section{a) Submission}

If your application is a resubmission you must include Appendix $A$ at the end of the project narrative. If your application is one that you consider to be new but that is similar to a previous application, you should include Appendix A. Include Appendix A after the project narrative as part of the same PDF attachment at Item 8 of the Other Project Information form (see Part VI.E.4: Research \& Related Other Project Information).

\section{b) Page limitations}

Appendix $A$ is limited to three pages.

\section{c) Content}

Appendix $\mathbf{A}$ is required if you are resubmitting an application. Use Appendix $A$ to describe how the revised application is responsive to prior reviewer comments.

If you have submitted a somewhat similar application in the past but are submitting the current application as a new application, you should use Appendix A to provide a rationale explaining why the current application should be considered a "new" application rather than a "resubmitted" application.

\section{Appendix B (Optional)}

\section{a) Submission}

If you choose to have an Appendix B, you must include it at the end of the project narrative, following Appendix A (if included), and submit it as part of the same PDF attachment at Item 8 of the Other Project Information form (see Part VI.E.4: Research \& Related Other Project Information).

\section{b) Page limitations}

Appendix B is limited to 15 pages.

\section{c) Content}

You may include figures, charts (e.g., a timeline for your research project), or tables that supplement the project narrative as well as examples of measures (e.g., tests, surveys, observation and interview protocols) to be used in the project in Appendix $B$. These are the only materials that may be included in Appendix B; all other materials will be removed prior to review of the application. You should include narrative text that describes your project in the 25-page project narrative, not in Appendix B. 


\section{Appendix C (Optional)}

\section{a) Submission}

If you choose to have an Appendix $C$, you must include it at the end of the project narrative, following Appendix B (if no Appendix B is included, then Appendix $C$ should follow Appendix $A$ if it is included) and submit it as part of the same PDF attachment at Item 8 of the Other Project Information form (see Part VI.E.4: Research \& Related Other Project Information).

\section{b) Page limitations}

Appendix $\mathrm{C}$ is limited to 10 pages.

\section{c) Content}

In Appendix C, if you are proposing to study, develop, evaluate, or validate an intervention or assessment you may include examples of curriculum material, computer screen shots, assessment items, or other materials used in the intervention or assessment to be studied, developed, evaluated, or validated. These are the only materials that may be included in Appendix C; all other materials will be removed prior to review of the application. You should include narrative text describing these materials in the 25-page project narrative, not in Appendix C.

\section{Appendix D (Optional)}

\section{a) Submission}

If you choose to have an Appendix $D$, you must include it at the end of the project narrative, following Appendix C (if no Appendix $C$ is included, then Appendix D should follow Appendix B if it is included, or Appendix $A$ if it is included) and submit it as part of the same PDF attachment at Item 8 of the Other Project Information form (see Part VI.E.4: Research \& Related Other Project Information).

\section{b) Page limitations}

Appendix D does not have a page limit.

\section{c) Content}

Include in Appendix D the letters of agreement from partners (e.g., schools and districts), data sources (e.g., state agencies holding administrative data), and consultants. Ensure that the letters reproduce well so that reviewers can easily read them. Do not reduce the size of the letters. See Part VI.D.4. Attaching Files for guidance regarding the size of file attachments.

Letters of agreement should include enough information to make it clear that the author of the letter understands the nature of the commitment of time, space, and resources to the research project that will be required if the application is funded. A common reason for projects to fail is loss of participating schools and districts. Letters of agreement regarding the provision of data should make it clear that the author of the letter will provide the data described in the application for use in the proposed research and in time to meet the proposed schedule.

\section{Appendix E (Efficacy/Replication and Effectiveness Applications)}

\section{a) Submission}

If you are applying under Goal Three: Efficacy and Replication or Goal Four: Effectiveness, include Appendix $E$ at the end of the project narrative, following the other Appendices included, and submit it as part of the same PDF attachment at Item 8 of the Other Project Information form (see Part VI.E.4: Research \& Related Other Project Information). If you are applying under any other research goal, do not include Appendix E. 


\section{b) Page limitations}

Appendix $\mathrm{E}$ is limited to five pages.

\section{c) Content}

Include in Appendix E your Data Management Plan (DMP). The content of the DMP is discussed under (3) Data Management Plan in Goal Three: Efficacy and Replication and Goal Four: Effectiveness.

\section{Bibliography and References Cited}

\section{a) Submission}

You must submit this section as a separate PDF attachment at Item 9 of the Other Project Information form (see Part VI.E.4: Research \& Related Other Project Information).

\section{b) Page limitations}

The Bibliography and References Cited does not have a page limit.

\section{c) Content}

You should include complete citations, including the names of all authors (in the same sequence in which they appear in the publication), titles (e.g., article and journal, chapter and book, book), page numbers, and year of publication for literature cited in the project narrative.

\section{Research on Human Subjects Narrative}

\section{a) Submission}

The human subjects narrative must be submitted as a PDF attachment at Item 12 of the Other Project Information form (see Part VI.E.4: Research \& Related Other Project Information).

\section{b) Page limitations}

The human subjects narrative does not have a page limit.

\section{c) Content}

The human subjects narrative should address the information specified by the U.S. Department of Education's Regulations for the Protection of Human Subjects (see

http://www2.ed.gov/about/offices/list/ocfo/humansub.html for additional information).

\section{Exempt Research on Human Subjects Narrative}

Provide an "exempt" narrative if you checked "yes" on Item 1 of the Research \& Related Other Project Information form (see Part VI.E.4: Research \& Related Other Project Information). The narrative must contain sufficient information about the involvement of human subjects in the proposed research to allow a determination by the Department that the designated exemption(s) are appropriate. The six categories of research that qualify for exemption from coverage by the regulations are described on the Department's website http://www2.ed.gov/policy/fund/guid/humansub/overview.html.

\section{Non-exempt Research on Human Subjects Narrative}

If some or all of the planned research activities are covered (not exempt) from the Human Subjects Regulations and you checked "no" on Item 1 of the Research \& Related Other Project Information form (see Part VI.E.4: Research \& Related Other Project Information), provide a "nonexempt research" narrative. The nonexempt narrative should describe the following: the characteristics of the subject population; the data to be collected from human subjects; recruitment and consent procedures; any potential risks; planned procedures for protecting 
against or minimizing potential risks; the importance of the knowledge to be gained relative to potential risks; and any other sites where human subjects are involved.

Note that the U.S. Department of Education does not require certification of Institutional Review Board approval at the time you submit your application. However, if an application that involves non-exempt human subjects research is recommended/selected for funding, the designated U.S. Department of Education official will request that you obtain and send the certification to the Department within 30 days after the formal request.

\section{Biographical Sketches of Senior/Key Personnel}

\section{a) Submission}

Each sketch will be submitted as a separate PDF attachment and attached to the Research \& Related Senior/Key Person Profile (Expanded) form (see Part VI.E.2: Research \& Related Senior/Key Person Profile [Expanded]).

\section{b) Page limitations}

Each biographical sketch is limited to four pages.

\section{c) Content}

Provide a biographical sketch for the Principal Investigator, each co-Principal Investigator, and each coInvestigator that includes information sufficient to demonstrate that key personnel possess training and expertise commensurate with their specified duties on the proposed project (e.g., publications, grants, and relevant research experience). If you'd like, you may also include biographical sketches for consultants (this form will allow for up to 40 biographical sketches in total).

\section{Current \& Pending Support of Senior/Key Personnel}

\section{a) Submission}

Each list of current and pending support will be submitted as a separate PDF attachment to the Research \& Related Senior/Key Person Profile (Expanded) form (see Part VI.E.2: Research \& Related Senior/Key Person Profile (Expanded)).

\section{b) Page limitations}

Each list is limited to one page.

\section{c) Content}

Provide a list of current and pending grants for the Principal Investigator, each co-Principal Investigator, and each co-Investigator, along with the proportion of his/her time, expressed as percent effort over a 12-month calendar year, allocated to each project. This information should be provided as a table.

Note: Each senior/key person must include the proposed research project as one of his/her pending grants in this list. If the total 12-month calendar year percent effort across all current and pending projects exceeds 100 percent, you must explain how time will be allocated if all pending applications are successful in the Narrative Budget Justification.

\section{Narrative Budget Justification}

\section{a) Submission}

The narrative budget justification must be submitted as a PDF attachment at Section $\mathrm{K}$ of the first project period of the Research \& Related Budget (SF 424) Sections A \& B; C, D, \& E; and F-K form for the Project (see Part VI.E.5 Research \& Related Budget (Total Federal + Non-Federal) - Sections A \& B; C, D, \& E; and F-K). For grant submissions with a subaward(s), a separate narrative budget justification for each 
subaward must be submitted and attached at Section K of the Research \& Related Budget (SF 424) for the specific Subaward/Consortium that has been extracted and attached using the R\&R Subaward Budget (Fed/Non-Fed) Attachment(s) Form (see Part VI.E.6).

\section{b) Page limitations}

The narrative budget justification does not have a page limit.

\section{c) Content}

A narrative budget justification must be submitted for the Project budget, and a separate narrative budget justification must be submitted for any subaward budgets included in the application. Each narrative budget justification should provide sufficient detail to allow reviewers to judge whether reasonable costs have been attributed to the project and its subawards, if applicable. The budget justification should correspond to the itemized breakdown of project costs that is provided in the corresponding Research \& Related Budget (SF 424) Sections A \& B; C, D, \& E; and F-K form for each year of the project. The narrative should include the time commitments for key personnel expressed as annual percent effort (i.e., calculated over a 12-month period) and brief descriptions of the responsibilities of key personnel. For consultants, the narrative should include the number of days of anticipated consultation, the expected rate of compensation, travel, per diem, and other related costs. A justification for equipment purchases, supplies, travel (including information regarding number of days of travel, mode of transportation, per diem rates, number of travelers, etc.), and other related project costs should also be provided in the budget narrative for each project year outlined in the Research \& Related Budget (SF 424).

\section{d) Indirect cost rate}

You must use your institution's federally negotiated indirect cost rate and use the off-campus indirect cost rate where appropriate (see Part IV.A.3: Special Considerations for Budget Expenses).

If your institution does not have a federally negotiated indirect cost rate you should consult a member of the Indirect Cost Group (ICG) in the U.S. Department of Education's Office of the Chief Financial Officer http://www2.ed.gov/about/offices/list/ocfo/fipao/icgreps.html to help you estimate the indirect cost rate to put in your application. 


\section{PART VI: SUBMITTING YOUR APPLICATION}

This part of the RFA describes important submission procedures you need to be aware of to ensure your application is received on time (no later than 4:30:00 p.m. Washington DC time on August 7, 2014) and accepted by the Institute. Any questions that you may have about electronic submission via Grants.gov should first be addressed to the Grants.gov Contact Center at support@grants.gov, http://www.grants.gov/web/grants/about/contact-us.html, or call 1-800-518-4726.

Additional help with submitting an application electronically through the Grants.gov website is available at http://www.grants.gov/web/grants/applicants/applicant-resources.html. The Institute also offers webinars on the application submission process http://ies.ed.gov/funding/webinars/index.asp.

\section{A. MANDATORY ELECTRONIC SUBMISSION OF APPLICATIONS AND DEADLINE}

Applications must be submitted electronically through the Internet using the software and application package provided on the Grants.gov website: http://www.grants.gov/. Applications must be received (fully uploaded and processed by Grants.gov) no later than 4:30:00 p.m. Washington, DC time on August 7, 2014. Applications received by Grants.gov after the 4:30:00 p.m. application deadline will be considered late and will not be sent forward for scientific peer review.

Electronic submission is required unless you qualify for one of the exceptions to the electronic submission requirement and submit, no later than 2 weeks before the application deadline date, a written statement to the Department that you qualify for one of these exceptions. (A description of the Allowable Exceptions to Electronic Submissions is provided at the end of this document.)

Please consider submitting your application ahead of the deadline date (the Institute recommends 3 to 4 days in advance of the closing date and time) to avoid running the risk of a late submission that will not be reviewed. The Institute does not accept late applications.

\section{B. REGISTER ON GRANTS.GOV}

To submit an application through Grants.gov, your institution must be registered with Grants.gov (http://www.grants.gov/web/grants/register.html).

Grants.gov registration involves many steps including registration in the System for Award Management (SAM- http://www.sam.gov; formerly known as the CCR - Central Contractor Registry). Grants.gov recommends that your institution begin the registration process at least 4 weeks prior to the application deadline date.

\section{Register Early}

Registration involves multiple steps (described below) and takes at least 3 to 5 business days, or as long as 4 weeks, to complete. You must complete all registration steps to allow a successful application submission via Grants.gov. You may begin working on your application while completing the registration process, but you will not be permitted to submit your application until all of the Registration Steps are complete.

\section{How to Register}

- Choose "Organization Applicant" for the type of registration.

- Complete the DUNS OR DUNS+4 Number field. 
- If your organization does not already have a DUNS Number, you can request one online by using the form at the Dun \& Bradstreet website http://fedgov.dnb.com/webform or by phone (866-705-5711).

- To submit successfully, you must provide the DUNS number on your application that was used when you registered as an Authorized Organization Representative (AOR) on Grants.gov. This DUNS number is typically the same number used when your organization registered with the SAM. If you don't enter the same DUNS number as the DUNS you registered with, Grants.gov will reject your application.

- $\quad$ Register with the System for Award Management (SAM): http://www.sam.gov.

- You can learn more about the SAM and the registration process for grant applicants in the SAM user guide:

https://www.sam.gov/sam/transcript/Quick Guide for Grants Registrations v1.7.pdf

For further assistance, please consult the tip sheet that the U.S. Department of Education has prepared for help with the SAM system http://www2.ed.gov/fund/grant/apply/samfaqs.html.

- Registration with the SAM may take a week to complete, but could take as many as several weeks to complete, depending on the completeness and accuracy of the data entered into the SAM database by an applicant. The SAM registration must be updated annually.

- Once your SAM registration is active, it will take 24 to 48 hours for the information to be available in Grants.gov. You will only be able to submit your application via Grants.gov once the SAM information is available in Grants.gov.

- Create your Username \& Password

- Complete your AOR profile on Grants.gov and create your username and password. You will need to use your organization's DUNS Number to complete this step. https://apply07.grants.gov/apply/OrcRegister.

- AOR Authorization

- The E-Business Point of Contact (E-Biz POC) at your organization must login to Grants.gov to confirm you as an AOR. Please note that there can be more than one AOR for your organization. In some cases the E-Biz POC is also the AOR for an organization.

\section{SUBMISSION AND SUBMISSION VERIFICATION}

1. Submit Early

The Institute strongly recommends that you not wait until the deadline date to submit an application. Grants.gov will put a date/time stamp on the application and then process it after it is fully uploaded.

The time it takes to upload an application will vary depending on a number of factors including the size of the application and the speed of your Internet connection. If Grants.gov rejects your application due to errors in the application package, you will need to resubmit successfully before 4:30:00 p.m. Washington, DC time on the deadline date as determined by Grants.gov. As an example, if you begin the submission process at 4:00:00 p.m. Washington, DC time on the deadline date, and Grants.gov rejects the application at 4:15:00 p.m. Washington, DC time, there may not be enough time for you to locate the error that caused the submission to be rejected, correct it, and then attempt to 
submit the application again before the 4:30:00 p.m. Washington, DC time deadline. You are strongly encouraged to begin the submission process at least three to four days before the deadline date to ensure a successful, on-time submission.

\section{Verify Submission is OK}

The Institute urges you to verify that Grants.gov and the Institute have received the application on time and that it was validated successfully. To see the date and time that your application was received by Grants.gov, you need to log on to Grants.gov and click on the "Track My Application" link http://www.grants.gov/web/grants/applicants/track-my-application.html. For a successful submission, the date/time received should be no later than 4:30:00 p.m. Washington DC time on the deadline date, AND the application status should be: (1) Validated (i.e., no errors in submission), (2) Received by Agency (i.e., Grants.gov has transmitted the submission to the U.S. Department of Education), or (3) Agency Tracking Number Assigned (the U.S. Department of Education has assigned a unique PR/Award Number to the application).

Note: If the date/time received is later than 4:30:00 p.m. Washington, DC time on the deadline date, the application is late. If the application has a status of "Received" it is still awaiting validation by Grants.gov. Once validation is complete, the status will change either to "Validated" or "Rejected with Errors." If the status is "Rejected with Errors," the application has not been received successfully. Grants.gov provides information on reasons why applications may be rejected in its Frequently Asked Questions (FAQ) page.

- Grants.gov FAQ http://www.grants.gov/web/grants/support/general-support/faqs.html

- Grants.gov Adobe Reader FAQs http://www.grants.gov/web/grants/support/general-support/faqs/adobe-reader-faqs.html

You will receive four emails regarding the status of your submission; the first three will come from Grants.gov and the fourth will come from the U.S. Department of Education. Within 2 days of submitting a grant application to Grants.gov, you will receive three emails from Grants.gov:

- The first email message will confirm receipt of the application by the Grants.gov system and will provide you with an application tracking number beginning with the word "GRANT", for example GRANT00234567. You can use this number to track your application on Grants.gov using the "Track My Application" link http://www.grants.gov/web/grants/applicants/track-myapplication.html before it is transmitted to the U.S. Department of Education.

- $\quad$ The second email message will indicate that the application EITHER has been successfully validated by the Grants.gov system prior to transmission to the U.S. Department of Education OR has been rejected due to errors, in which case it will not be transmitted to the Department.

- $\quad$ The third email message will indicate that the U.S. Department of Education has confirmed retrieval of the application from Grants.gov once it has been validated.

If the second email message indicates that the application, as identified by its unique application tracking number, is valid and the time of receipt was no later than 4:30:00 p.m. Washington DC time, then the application is successful and on-time.

Note: You should not rely solely on e-mail to confirm whether an application has been received on-time and validated successfully. The Institute urges you to use the "Track My Application" link on Grants.gov to verify on-time, valid submissions in addition to the confirmation emails. http://www.grants.gov/web/grants/applicants/track-my-application.html 
Once Grants.gov validates the application and transmits it to the U.S. Department of Education, you will receive an email from the U.S. Department of Education.

- This fourth email message will indicate that the application has been assigned a PR/Award number unique to the application beginning with the letter $\mathrm{R}$, followed by the section of the CFDA number unique to that research competition (e.g., 324A), the fiscal year for the submission (e.g., 15 for fiscal year 2015), and finally four digits unique to the application, for example R324A15XXXX. If the application was received after the closing date/time, this email will also indicate that the application is late and will not be given further consideration.

Note: The Institute strongly recommends that you begin the submission process at least 3 to 4 days in advance of the deadline date to allow for a successful and timely submission.

\section{Late Applications}

If your application is submitted after 4:30:00 p.m. Washington, DC time on the application deadline date your application will not be accepted and will not be reviewed. The Institute does not accept late applications.

However, if you believe that a technical problem with the Grants.gov system prevented you from being able to submit your application on time, you must contact the Grants.gov Support Desk at

support@grants.gov, http://www.grants.gov/web/grants/about/contact-us.html, or call 1-800-518-4726. The Grants.gov Support Desk will assign a Case Number (e.g., 1-12345678) that you must keep as a record of the problems. If you wish to petition that the Institute accept your late application due to technical problems with the Grants.gov system you should contact the program officer for the topic designated in your application and provide an explanation of the problem experienced with Grants.gov, along with the Grants.gov Support Desk Case Number. Your application will be accepted only if it is possible to confirm that a technical problem occurred with the Grants.gov system and that the problem (as documented with the Grants.gov Support Desk) affected your ability to submit the application by 4:30:00 p.m. Washington, DC time on the application deadline date. The Institute will contact you approximately 1 month after the submission deadline as to whether the application will be accepted.

\section{TIPS FOR WORKING WITH GRANTS.GOV}

The Institute strongly encourages you to use the "Check Application for Errors" button at the top of the grant application package to identify errors or missing required information that can prevent an application from being processed and sent forward for review.

Note: You must click the "Save and Submit" button at the top of the application package to upload the application to the Grants.gov website. The "Save and Submit" button will become active only after you have used the "Check Package for Errors" button and then clicked the "Save" button. Once the "Save and Submit" button is clicked, you will need to enter the user name and password that were created upon registration with Grants.gov.

\section{Working Offline}

When you download the application package from Grants.gov, you will be working offline and saving data on your computer. You will need to logon to Grants.gov to upload the completed application package and submit the application.

\section{Dial-Up Internet Connections}

Using a dial-up connection to upload and submit an application can take significantly longer than using a high-speed connection to the internet (e.g., cable modem/DSL/T1). Although times will vary depending

For awards beginning in FY $2015 \quad$ Special Education Research, p. 94

Posted April 16, 2014 
upon the size of the application, it can take a few minutes to a few hours to complete the grant submission using a dial-up connection.

\section{Software Requirements}

You will need Adobe software (at least Adobe Reader 10.1.14) to read and complete the application forms for submission through Grants.gov. You can verify if your Adobe software version is compatible with Grants.gov, and if it is not a compatible version, you can download the necessary version of Adobe from Grants.gov (http://www.grants.gov/web/grants/support/technical-support/recommendedsoftware.html.).

\section{Attaching Files}

The forms included in the application package provide the means for you to attach Adobe Portable Document Format (PDF) files. You must attach read-only, non-modifiable PDF files; any other file attachment will cause your application to be rejected by Grants.gov.

Grants.gov provides help for converting files to a PDF format:

http://www.grants.gov/web/grants/support/technical-support/software/pdf-conversion-software.html.

If you include scanned documents as part of a PDF file (e.g., Letters of Agreement in Appendix D), scan them at the lowest resolution to minimize the size of the file and expedite the upload process. PDF files that contain graphics and/or scanned material can greatly increase the size of the file attachments and can result in difficulties opening the files. The average discretionary grant application package totals 1 to $2 \mathrm{MB}$; therefore, check the total size of your application package before you attempt to submit it. Very large application packages can take a long time to upload, putting the application at risk of being received late and therefore not accepted by the Institute.

PDF files included in the application must be the following:

- In a read-only, non-modifiable format.

- Individual files (attachments that contain files within a file, such as PDF Portfolio files, or an interactive or fillable PDF file will not be read).

- Not password protected.

- Given a file name that is the following:

- Unique - Grants.gov cannot process an application that includes two or more file attachments that have the same name.

○ No more than $\mathbf{5 0}$ characters.

- Contains no special characters (e.g., \&,-,*,\%,l,\#), blank spaces, periods, or accent marks in the file name (you may use an underscore to indicate word separation in file names such as "my_Attached_File.pdf").

Please note that if these guidelines are not followed, your application will be rejected by Grants.gov and not forwarded to the U.S. Department of Education.

\section{E. REQUIRED RESEARCH \& RELATED (R\&R) FORMS AND OTHER FORMS}

You must complete and submit the R\&R forms described below. All of these forms are provided in the application package for this competition (84-324A2015). Please note that fields marked by an asterisk and highlighted in yellow and outlined in red on these forms are required fields and must be completed to ensure a successful submission. 
Note: Although not required fields, Items 4a (Federal Identifier) and b (Agency Routing Number) on the Application for Federal Assistance SF 424 (R\&R) form provide critical information to the Institute and should be filled out for an application to this research grant competition.

\section{Application for Federal Assistance SF 424 (R\&R)}

This form asks for general information about the applicant, including but not limited to the following: contact information; an Employer Identification Number (EIN); a DUNS number; a descriptive title for the project; an indication of the project topic and, for program announcements that have explicit goals, the appropriate goal; Principal Investigator contact information; start and end dates for the project; congressional district; total estimated project funding; and Authorized Organization Representative contact information. Because information on this form populates selected fields on some of the other forms described below, you should complete this form first.

Provide the requested information using the drop down menus when available. Guidance for completing selected items follows.

- $\quad$ Item 1

Type of Submission. Select either "Application" (for a new submission) or "Changed/Corrected Application" (for a resubmission). The Institute does not require Pre-applications for its grant competitions.

- $\quad$ Item 2

Date Submitted. Enter the date the application is submitted to the Institute.

Applicant Identifier. Leave this blank.

- $\quad$ Item 3

Date Received by State and State Application Identifier. Leave these items blank.

- $\quad$ Item 4

Note: This item provides important information that is used by the Institute to screen applications for responsiveness to the competition requirements and for assignment to the appropriate scientific peer review panel. It is critical that you complete this information completely and accurately or the application may be rejected as nonresponsive or assigned inaccurately for scientific review of merit.

- Federal Identifier. Enter information in this field if this is a Resubmission and this has been marked as a "Changed/Corrected Application" under Item 1 Type of Submission. If this application is a revision of an application that was submitted to an Institute grant competition in a prior fiscal year (e.g., FY 2014) that received reviewer feedback, then this application is considered a "Resubmission" (see Item 8 Type of Application). You should enter the PR/Award number that was assigned to the prior submission (e.g., R324A13XXXX or R305A14XXXX) in this field.

$\circ \quad$ Agency Routing Number. Enter the code for the topic and goal that the application addresses in this field. Applications to the Special Education Research (CFDA 84.324A) program must be submitted to a particular topic and goal (see Part II: Topic Requirements and Part III: Goal Requirements for additional information). 


\begin{tabular}{|l|c|}
\hline Topics & Codes \\
\hline Autism Spectrum Disorders & NCSER-ASD \\
\hline Cognition and Student Learning in Special Education & NCSER-CASL \\
\hline Early Intervention and Early Learning in Special Education & NCSER-EIEL \\
\hline Families of Children with Disabilities & NCSER-Fam \\
\hline Mathematics and Science Education & NCSER-MS \\
\hline Professional Development for Teachers and Related Services Providers & NCSER-RWL \\
\hline Reading, Writing, and Language Development & NCSER-SocBeh \\
\hline Social and Behavioral Outcomes to Support Learning & NCSER-SYS \\
\hline Special Education Policy, Finance, and Systems & NCSER-EdTech \\
\hline Technology for Special Education & NCSER-Trans \\
\hline Transition Outcomes for Secondary Students with Disabilities & \\
\hline & \\
\hline Goals & Codes \\
\hline Goal 1: Exploration Projects & Develoration \\
\hline Goal 2: Development and Innovation Projects & Efficacy \\
\hline Goal 3: Efficacy and Replication Projects & Effectiveness \\
\hline Goal 4: Effectiveness Projects & Measurement \\
\hline Goal 5: Measurement Projects & \\
\hline
\end{tabular}

Example: If your application is a Development and Innovation project under the Autism Spectrum Disorders, enter the codes "NCSER-ASD" and "Development."

It is critical that you use the appropriate codes in this field and that the codes shown in this field agree with the information included in the application abstract. Indicating the correct codes facilitates the appropriate processing and review of the application. Failure to do so may result in delays to processing and puts your application at risk for being identified as nonresponsive and not considered for further review.

- $\quad$ Item 5

Applicant Information. Enter all of the information requested, including the legal name of the applicant, the name of the primary organizational unit (e.g., school, department, division, etc.) that will undertake the activity, and the address, including the county and the 9-digit ZIP/Postal Code of the primary performance site (i.e., the Applicant institution) location. This field is required if the Project Performance Site is located in the United States. The field for "Country" is pre-populated with "USA: UNITED STATES." For applicants located in another country, contact the cognizant program officer (see Part II Topic Requirements or the list of program officers in Part VI.H) before submitting the application. Use the drop down menus where they are provided.

Organizational DUNS. Enter the DUNS or DUNS+4 number of the applicant organization. A Data Universal Numbering System (DUNS) number is a unique 9-character identification number provided by the commercial company Dun \& Bradstreet (D\&B) to identify organizations. If your institution does not have a DUNS number and therefore needs to register for one, a DUNS number can be obtained through the Dun \& Bradstreet website http://fedgov.dnb.com/webform/displayHomePage.do.

Note: The DUNS number provided on this form must be the same DUNS number used to register on Grants.gov (and the same as the DUNS number used when registering with the SAM). If the 


\section{DUNS number used in the application is not the same as the DUNS number used to register with Grants.gov, the application will be rejected with errors by Grants.gov.}

Person to Be Contacted on Matters Involving this Application. Enter all of the information requested, including the name, telephone and fax numbers, and email address of the person to be contacted on matters involving this application. The role of this person is primarily for communication purposes on the budgetary aspects of the project. As an example, this may be the contact person from the applicant institution's office of sponsored projects. Use the drop down menus where they are provided.

- $\quad$ Item 6

Employer Identification (EIN) or (TIN). Enter either the Employer Identification Number (EIN) or Tax Identification Number (TIN) as assigned by the Internal Revenue Service. If the applicant organization is not located in the United States, enter 44-4444444.

- $\quad$ Item 7

Type of Applicant. Use the drop down menu to select the type of applicant. If Other, please specify.

Small Business Organization Type. If "Small Business" is selected as Type of Applicant, indicate whether or not the applicant is a "Women Owned" small business - a small business that is at least $51 \%$ owned by a woman or women, who also control and operate it. Also indicate whether or not the applicant is a "Socially and Economically Disadvantaged" small business, as determined by the U.S. Small Business Administration pursuant to section 8(a) of the Small Business Act U.S.C. 637(a).

- $\quad$ Item 8

Type of Application. Indicate whether the application is a "New" application or a "Resubmission" of an application that was submitted under a previous Institute competition and received reviewer comments. Only the "New" and "Resubmission" options apply to Institute competitions. Do not select any option other than "New" or "Resubmission."

Submission to Other Agencies. Indicate whether or not this application is being submitted to another agency or agencies. If yes, indicate the name of the agency or agencies.

- $\quad$ Item 9

Name of Federal Agency. Do not complete this item. The name of the federal agency to which the application is being submitted will already be entered on the form.

- $\quad$ Item 10

Catalog of Federal Domestic Assistance Number. Do not complete this item. The CFDA number of the program competition to which the application is being submitted will already be entered on the form. The CFDA number can be found in the Federal Register Notice and on the face page of the Request for Applications.

- $\quad$ Item 11 
Descriptive Title of Applicant's Project. Enter a distinctive, descriptive title for the project. The maximum number of characters allowed in this item field is 200.

- $\quad$ Item 12

Proposed Project Start Date and Ending Date. Enter the proposed start date of the project and the proposed end date of the project. The start date must not be earlier than July 1, 2015, which is the Earliest Anticipated Start Date listed in this Request for Applications, and must not be later than September 1, 2015.

- $\quad$ Item 13

Congressional District of Applicant. For both the applicant and the project, enter the Congressional District in this format: 2-character State Abbreviation and 3-character District Number (e.g., CA-005 for California's 5th district, CA-012 for California's 12th district). Grants.gov provides help for finding this information http://www.grants.gov/web/grants/applicants/applicant-faqs/applying-for-grants.html under "How can I find my congressional district code?" If the program/project is outside the U.S., enter 00-000.

- $\quad$ Item 14

Project Director/Principal Investigator Contact Information. Enter all of the information requested for the Project Director/Principal Investigator, including position/title, name, address (including county), organizational affiliation (e.g., organization, department, division, etc.), telephone and fax numbers, and email address. Use the drop down menus where they are provided.

- $\quad$ Item 15

\section{Estimated Project Funding}

- Total Federal Funds Requested. Enter the total Federal funds requested for the entire project period.

- Total Non-federal Funds. Enter the total Non-federal funds requested for the entire project period.

- Total Federal \& Non-Federal Funds. Enter the total estimated funds for the entire project period, including both Federal and non-Federal funds.

- Estimated Program Income. Identify any program income estimated for the project period, if applicable.

- $\quad$ Item 16

Is Application Subject to Review by State Executive Order 12372 Process? The Institute is not soliciting applications that are subject to review by Executive Order 12372; therefore, check the box "Program is not covered by E.O. 12372" to indicate "No" for this item.

- $\quad$ Item 17

This is the Authorized Organization Representative's electronic signature. 
By providing the electronic signature, the Authorized Organization Representative certifies the following:

- To the statements contained in the list of certifications

- That the statements are true, complete and accurate to the best of his/her knowledge.

By providing the electronic signature, the Authorized Organization Representative also provides the required assurances, agrees to comply with any resulting terms if an award is accepted, and acknowledges that any false, fictitious, or fraudulent statements or claims may subject him/her to criminal, civil, or administrative penalties.

Note: The certifications and assurances referred to here are described in Part VI.E.7: Other Forms Included in the Application Package).

- $\quad$ Item 18

SF LLL or other Explanatory Documentation. Do not add the SF LLL here. A copy of the SF LLL is provided as an optional document within the application package. See Part VI.E.7: Other Forms Included in the Application Package to determine applicability. If it is applicable to the grant submission, choose the SF LLL from the optional document menu, complete it, and save the completed SF LLL form as part of the application package.

- $\quad$ Item 19

Authorized Representative. The Authorized Representative is the official who has the authority both to legally commit the applicant to (1) accept federal funding and (2) execute the proposed project. Enter all information requested for the Authorized Representative, including name, title, organizational affiliation (e.g., organization, department, division, etc.), address, telephone and fax numbers, and email address of the Authorized Representative. Use the drop down menus where they are provided.

Signature of Authorized Representative. Leave this item blank as it is automatically completed when the application is submitted through Grants.gov.

Date Signed. Leave this item blank as the date is automatically generated when the application is submitted through Grants.gov.

- $\quad$ Item 20

Pre-application. Do not complete this item as the Institute does not require pre-applications for its grant competitions.

\section{Research \& Related Senior/Key Person Profile (Expanded)}

This form asks you to: (a) identify the Project Director/Principal Investigator and other senior and/or key persons involved in the project; (b) specify the role key staff will serve; and (c) provide contact information for each senior/key person identified. The form also requests information about the highest academic or professional degree or other credentials earned and the degree year.

This form also provides the means for attaching the Biographical Sketches of senior/key personnel and the Lists of Current and Pending Funding for senior/key personnel as PDF files. This form will allow for the attachment of a total of 40 biographical sketches and 40 lists of current and pending support: one of 
each for the project director/principal investigator and up to 39 additional sketches and lists for senior/key staff. See Part IV.D.10: Biographical Sketches of Senior/Key Personnel for information about page limitations, format requirements, and content to be included in the biographical sketches and lists of current and pending funding. The persons listed on this form should be the same persons listed in the Personnel section of the Project Narrative.

\section{Project/Performance Site Location(s)}

This form asks you to identify the primary site where project work will be performed. You must complete the information for the primary site. If a portion of the project will be performed at any other site(s), the form also asks you to identify and provide information about the additional site(s). As an example, a research proposal to an Institute competition may include the applicant institution as the primary site and one or more schools where data collection will take place as additional sites. The form permits the identification of eight project/performance site locations in total. This form requires the applicant to identify the Congressional District for each site. See above, Application for Federal Assistance SF 424 (R\&R), Item 13 for information about Congressional Districts. DUNS number information is optional on this form.

\section{Research \& Related Other Project Information}

This form asks you to provide information about any research that will be conducted involving Human Subjects, including: (a) whether human subjects are involved; (b) if human subjects are involved, whether or not the project is exempt from the human subjects regulations; (c) if the project is exempt from the regulations, an indication of the exemption number(s); and, (d) if the project is not exempt from the regulations, whether an Institutional Review Board (IRB) review is pending; and if IRB approval has been given, the date on which the project was approved; and, the Human Subject Assurance number. This form also asks you: (a) whether there is proprietary information included in the application; (b) whether the project has an actual or potential impact on the environment; (c) whether the research site is designated or eligible to be designated as an historic place; and, (d) if the project involves activities outside the U.S., to identify the countries involved.

This form also provides the means for attaching a number of PDF files (see Part V.D: PDF Attachments for information about page limitations, format requirements, and content) including the following:

- Project Summary/Abstract,

- Project Narrative and Appendices,

- Bibliography and References Cited, and

- Research on Human Subjects Narrative.

- $\quad$ Item 1

Are Human Subjects Involved? If activities involving human subjects are planned at any time during the proposed project at any performance site or collaborating institution, you must check "Yes." (You must check "Yes" even if the proposed project is exempt from Regulations for the Protection of Human Subjects.) If there are no activities involving human subjects planned at any time during the proposed project at any performance site or collaborating institution, you may check "No" and skip to Item 2.

Is the Project Exempt from Federal Regulations? If all human subject activities are exempt from Human Subjects regulations, then you may check "Yes." You are required to answer this question if you answered "yes" to the first question "Are Human Subjects Involved?" 
If you answer "yes" to the question "Is the Project Exempt from Federal Regulations?" you are required to check the appropriate exemption number box or boxes corresponding to one or more of the exemption categories. The six categories of research that qualify for exemption from coverage by the regulations are described on the U.S. Department of Education's website http://www2.ed.gov/policy/fund/guid/humansub/overview.html. Provide an Exempt Research on Human Subjects Narrative at Item 12 of this form (see Part V.D.9. Research on Human Subjects Narrative).

If you answer "no" to the question "Is the Project Exempt from Federal Regulations?" you will be prompted to answer questions about the Institutional Review Board (IRB) review.

If no, is the IRB review pending? Answer either "Yes" or "No."

If you answer "yes" because the review is pending, then leave the IRB approval date blank. If you answer "no" because the review is not pending, then you are required to enter the latest IRB approval date, if available. Therefore, you should select "No" only if a date is available for IRB approval.

Note: IRB Approval may not be pending because you have not begun the IRB process. In this case, an IRB Approval Date will not be available. However, a date must be entered in this field if "No" is selected or the application will be rejected with errors by Grants.gov. Therefore, you should check "Yes" to the question "Is the IRB review pending?" if an IRB Approval date is not available.

If you answer "no" to the question "Is the Project Exempt from Federal Regulations?" provide a Non-exempt Research on Human Subjects Narrative at Item 12 of this form (see Part V.D.9. Research on Human Subjects Narrative).

Human Subject Assurance Number: Leave this item blank.

- $\quad$ Item 2

Are Vertebrate Animals used? Check whether or not vertebrate animals will be used in this project.

- $\quad$ Item 3

Is proprietary/privileged information included in the application? Patentable ideas, trade secrets, privileged or confidential commercial or financial information, disclosure of which may harm the applicant, should be included in applications only when such information is necessary to convey an understanding of the proposed project. If the application includes such information, check "Yes" and clearly mark each line or paragraph on the pages containing the proprietary/privileged information with a legend similar to, "The following contains proprietary/privileged information that (name of applicant) requests not be released to persons outside the Government, except for purposes of review and evaluation."

- $\quad$ Item 4

Does this project have an actual or potential impact on the environment? Check whether or not this project will have an actual or potential impact on the environment.

- $\quad$ Item 5 
Is the research site designated or eligible to be designated as a historic place? Check whether or not the research site is designated or eligible to be designated as a historic place. Explain if necessary.

- $\quad$ Item 6

Does the project involve activities outside of the United States or partnerships with international collaborators? Check "Yes" or "No." If the answer is "Yes," then you need to identify the countries with which international cooperative activities are involved. An explanation of these international activities or partnerships is optional.

- $\quad$ Item 7

Project Summary/Abstract. Attach the Project Summary/Abstract as a PDF file here. See Part V.D. PDF Attachments for information about content, formatting, and page limitations for this PDF file.

- $\quad$ Item 8

Project Narrative. Create a single PDF file that contains the Project Narrative as well as, when applicable, Appendix A, Appendix B, Appendix C, Appendix D, and Appendix E. Attach that single PDF file here. See Part V.D. PDF Attachments for information about content, formatting, and page limitations for this PDF file.

- $\quad$ Item 9

Bibliography and References Cited. Attach the Bibliography and References Cited as a PDF file here. See Part V.D. PDF Attachments for information about content, formatting, and page limitations for this PDF file.

- $\quad$ Item 10

Facilities and Other Resources. The Institute does not want an attachment here. Explanatory information about facilities and other resources must be included in the Resources Section of the 25-page Project Narrative for the application and may also be included in the Narrative Budget Justification. In the project narrative of competitive proposals, applicants describe having access to institutional resources that adequately support research activities and access to schools in which to conduct the research. Strong applications document the availability and cooperation of the schools or other education delivery settings that will be required to carry out the research proposed in the application via a letter of agreement from the education organization. Include letters of agreement in Appendix D.

- $\quad$ Item 11

Equipment. The Institute does not want an attachment here. Explanatory information about equipment may be included in the narrative budget justification.

- $\quad$ Item 12

Other Attachments. Attach a Research on Human Subjects Narrative as a PDF file here. You must attach either an Exempt Research on Human Subjects Narrative or a Non-Exempt Research on 
Human Subjects Narrative. See Part V.D. PDF Attachments for information about content, formatting, and page limitations for this PDF file.

If you checked "Yes" to Item 1 of this form "Are Human Subjects Involved?" and designated an exemption number(s), then you must provide an "Exempt Research" narrative. If some or all of the planned research activities are covered by (not exempt from) the Human Subjects Regulations, then you must provide a "Nonexempt Research" narrative.

\section{Research \& Related Budget (Total Federal+Non-Federal)-Sections A \& B; C, D, \& E; F-K}

This form asks you to provide detailed budget information for each year of support requested for the applicant institution (i.e., the Project Budget). The form also asks you to indicate any non-federal funds supporting the project. You should provide this budget information for each project year using all sections of the R\&R Budget form. Note that the budget form has multiple sections for each budget year: A \& B; C, $\mathrm{D}, \& \mathrm{E} ;$ and F-K.

- Sections A \& B ask for information about Senior/Key Persons and Other Personnel

- Sections C, D \& E ask for information about Equipment, Travel, and Participant/Trainee Costs

- Sections F - K ask for information about Other Direct Costs and Indirect Costs

You must complete each of these sections for as many budget periods (i.e., project years) as you are requesting funds.

Note: The narrative budget justification for each of the project budget years must be attached at Section K of the first budget period; otherwise you will not be able to enter budget information for subsequent project years.

Note: Budget information for a subaward(s) on the project must be entered using a separate form, the R\&R Subaward Budget (Fed/Non-Fed) Attachment(s) Form, described in Part VI.E.6. This is the only form that can be used to extract the proper file format to complete subaward budget information. The application will be rejected with errors by Grants.gov if subaward budget information is included using any other form or file format.

Enter the Federal Funds requested for all budget line items as instructed below. If any Non-Federal funds will be contributed to the project, enter the amount of those funds for the relevant budget categories in the spaces provided.

All fields asking for total funds in this form will auto calculate.

- Organizational DUNS.

If you completed the SF 424 R\&R Application for Federal Assistance form first the DUNS number will be pre-populated here. Otherwise, the organizational DUNS number must be entered here. See Part VI.E.1 for information on the DUNS number.

- $\quad$ Budget Type.

Check the box labeled "Project" to indicate that this is the budget requested for the primary applicant organization. If the project involves a subaward(s), you must access the R\&R Subaward 
Budget (Fed/Non-Fed) Attachment(s) Form to complete a subaward budget (see Part VI.E.6 for instructions regarding budgets for a subaward).

- $\quad$ Budget Period Information.

Enter the start date and the end date for each budget period. The system permits data entry for up to five budget periods; however, enter only the number of budget periods allowed for the project as determined by the Award Duration Maximums for the relevant research goal selected for your project (see Part III: Goal Requirements).

- $\quad$ Budget Sections A \& B

A. Senior/Key Person. The project director/principal investigator information will be pre-populated here from the SF 424 R\&R Application for Federal Assistance form if it was completed first. Then, enter all of the information requested for each of the remaining senior/key personnel, including the project role of each and the number of months each will devote to the project, i.e., calendar or academic + summer. You may enter the annual compensation (base salary - dollars) paid by the employer for each senior/key person; however, you may choose to leave this field blank. Regardless of the number of months devoted to the project, indicate only the amount of salary being requested for each budget period for each senior/key person. Enter applicable fringe benefits, if any, for each senior/key person. Enter the Federal dollars and, if applicable, the NonFederal dollars.

B. Other Personnel. Enter all of the information requested for each project role listed - for example Postdoctoral Associates, Graduate Students, Undergraduate Students, Secretary/Clerical, etc. - including, for each project role, the number of personnel proposed and the number of months devoted to the project (calendar or academic + summer). Regardless of the number of months devoted to the project, indicate only the amount of salary/wages being requested for each project role. Enter applicable fringe benefits, if any, for each project role category. Enter the Federal dollars and, if applicable, the Non-Federal dollars.

Total Salary, Wages, and Fringe Benefits $(A+B)$. This total will auto calculate.

- $\quad$ Budget Sections C, D \& E

C. Equipment Description. Enter all of the information requested for Equipment. Equipment is defined as an item of property that has an acquisition cost of $\$ 5,000$ or more (unless the applicant organization has established lower levels) and an expected service life of more than 1 year. List each item of equipment separately and justify each in the narrative budget justification. Allowable items ordinarily will be limited to research equipment and apparatus not already available for the conduct of the work. General-purpose equipment, such as a personal computer, is not eligible for support unless primarily or exclusively used in the actual conduct of scientific research. Enter the Federal dollars and, if applicable, the Non-Federal dollars.

Total C. Equipment. This total will auto calculate.

D. Travel. Enter all of the information requested for Travel.

Enter the total funds requested for domestic travel. In the narrative budget justification, include the purpose, destination, dates of travel (if known), applicable per diem rates, and number of individuals for each trip. If the dates of travel are not known, specify the estimated length of the trip (e.g., 3 days). Enter the Federal dollars and, if applicable, the Non-Federal dollars. 
Enter the total funds requested for foreign travel. In the narrative budget justification, include the purpose, destination, dates of travel (if known), applicable per diem rates, and number of individuals for each trip. If the dates of travel are not known, specify the estimated length of the trip (e.g., 3 days). Enter the Federal dollars and, if applicable, the Non-Federal dollars.

Total D. Travel Costs. This total will auto calculate.

E. Participant/Trainee Support Costs. Do not enter information here; this category is not used for project budgets for this competition.

Number of Participants/Trainees. Do not enter information here; this category is not used for project budgets for this competition.

Total E. Participants/Trainee Support Costs. Do not enter information here; this category is not used for project budgets for this competition.

- $\quad$ Budget Sections F-K

F. Other Direct Costs. Enter all of the information requested under the various cost categories. Enter the Federal dollars and, if applicable, the Non-Federal dollars.

Materials and Supplies. Enter the total funds requested for materials and supplies. In the narrative budget justification, indicate the general categories of supplies, including an amount for each category. Categories less than $\$ 1,000$ are not required to be itemized.

Publication Costs. Enter the total publication funds requested. The proposed budget may request funds for the costs of documenting, preparing, publishing or otherwise making available to others the findings and products of the work conducted under the award. In the narrative budget justification, include supporting information.

Consultant Services. Enter the total costs for all consultant services. In the narrative budget justification, identify each consultant, the services he/she will perform, total number of days, travel costs, and total estimated costs. Note: Travel costs for consultants can be included here or in Section D. Travel.

ADP/Computer Services. Enter the total funds requested for ADP/computer services. The cost of computer services, including computer-based retrieval of scientific, technical, and education information may be requested. In the narrative budget justification, include the established computer service rates at the proposing organization if applicable.

Subaward/Consortium/Contractual Costs. Enter the total funds requested for: 1) all subaward/consortium organization(s) proposed for the project and 2) any other contractual costs proposed for the project. Use the R\&R Subaward Budget (Fed/Non-Fed) Attachment(s) Form to provide detailed subaward information (see Part VI.E.6).

Equipment or Facility Rental/User Fees. Enter the total funds requested for equipment or facility rental/user fees. In the narrative budget justification, identify each rental user fee and justify.

Alterations and Renovations. Leave this field blank. The Institute does not provide funds for construction costs. 
Other. Describe any other direct costs in the space provided and enter the total funds requested for this "Other" category of direct costs. Use the narrative budget justification to further itemize and justify.

Total F. Other Direct Costs. This total will auto calculate.

- G. Direct Costs

Total Direct Costs (A thru F). This total will auto calculate.

- H. Indirect Costs

Enter all of the information requested for Indirect Costs. Principal investigators should note that if they are requesting reimbursement for indirect costs, this information is to be completed by their Business Office.

Indirect Cost Type. Indicate the type of base (e.g., Salary \& Wages, Modified Total Direct Costs, Other [explain]). In addition, indicate if the Indirect Cost type is Off-site. If more than one rate/base is involved, use separate lines for each. When calculating your expenses for research conducted in field settings, you should apply your institution's negotiated off-campus indirect cost rate, as directed by the terms of your institution's negotiated agreement with the federal government.

Institutions, both primary grantees and sub-awardees, not located in the territorial US cannot charge indirect costs.

If you do not have a current indirect rate(s) approved by a Federal agency, indicate "None--will negotiate". If your institution does not have a federally negotiated indirect cost rate, you should consult a member of the Indirect Cost Group (ICG) in the U.S. Department of Education's Office of the Chief Financial Officer http://www2.ed.gov/about/offices/list/ocfo/fipao/icgreps.html to help you estimate the indirect cost rate to put in your application.

Indirect Cost Rate (\%). Indicate the most recent Indirect Cost rate(s) (also known as Facilities \& Administrative Costs [F\&A]) established with the cognizant Federal office, or in the case of forprofit organizations, the rate(s) established with the appropriate agency.

If your institution has a cognizant/oversight agency and your application is selected for an award, you must submit the indirect cost rate proposal to that cognizant/oversight agency office for approval.

Indirect Cost Base (\$). Enter the amount of the base (dollars) for each indirect cost type. Depending on the grant program to which you are applying and/or the applicant institution's approved Indirect Cost Rate Agreement, some direct cost budget categories in the grant application budget may not be included in the base and multiplied by the indirect cost rate. Use the narrative budget justification to explain which costs are included and which costs are excluded from the base to which the indirect cost rate is applied. If your grant application is selected for an award, the Institute will request a copy of the applicant institution's approved Indirect Cost Rate Agreement.

Indirect Cost Funds Requested. Enter the funds requested (Federal dollars and, if applicable, the Non-Federal dollars) for each indirect cost type. 
Total H. Indirect Costs. This total will auto calculate.

Cognizant Agency. Enter the name of the Federal agency responsible for approving the indirect cost rate(s) for the applicant. Enter the name and telephone number of the individual responsible for negotiating the indirect cost rate. If a Cognizant Agency is not known, enter "None."

- Total Direct and Indirect Costs

Total Direct and Indirect Costs $(\mathrm{G}+\mathrm{H})$. This total will auto calculate.

- J. Fee.

Do not enter a dollar amount here as you are not allowed to charge a fee on a grant or cooperative agreement.

- K. Budget Justification

Attach the Narrative Budget Justification as a PDF file at Section $\mathrm{K}$ of the first budget period (see Part V.D.12 for information about content, formatting, and page limitations for this PDF file).

Note that if the justification is not attached at Section $\mathrm{K}$ of the first budget period, you will not be able to access the form for the second budget period and all subsequent budget periods. The single narrative must provide a budget justification for each year of the entire project.

- $\quad$ Cumulative Budget. This section will auto calculate all cost categories for all budget periods included.

\section{R\&R Subaward Budget (Fed/Non-Fed) Attachment(s) Form}

This form provides the means to both extract and attach the Research \& Related Budget (Total Fed + Non-Fed) form that is to be used by an institution that will hold a subaward on the grant. Please note that separate budgets are required only for subawardee/consortium organizations that perform a substantive portion of the project. As with the Primary Budget, the extracted Research \& Related Budget (Total Fed + Non-Fed) form asks you to provide detailed budget information for each year of support requested for a subaward/consortium member with substantive involvement in the project. The budget form also asks for information regarding non-federal funds supporting the project at the subaward/consortium member level. You should provide this budget information for each project year using all sections of the R\&R Budget form. Note that the budget form has multiple sections for each budget year: A \& B; C, D, \& E; and F-K.

- Sections A \& B ask for information about Senior/Key Persons and Other Personnel.

- Sections C, D \& E ask for information about Equipment, Travel, and Participant/Trainee Costs.

- Sections F - K ask for information about Other Direct Costs and Indirect Costs.

"Subaward/Consortium" must be selected as the Budget Type, and all sections of the budget form for each project year must be completed in accordance with the R\&R (Federal/Non-Federal) Budget instructions provided above in Part VI.E.5. Note that subaward organizations are also required to provide their DUNS or DUNS+4 number.

You may extract and attach up to 10 subaward budget forms. When you use the button "Click here to extract the R\&R Budget (Fed/Non-Fed) Attachment," a Research \& Related Budget (Total Fed + Non- 
Fed) form will open. Each institution that will hold a subaward to perform a substantive portion of the project must complete one of these forms and save it as a PDF file with the name of the subawardee organization. Once each subawardee institution has completed the form, you must attach these completed subaward budget form files to the R\&R Subaward Budget (Fed/Non-Fed) Attachment(s) Form. Each subaward budget form file attached to this form must have a unique name.

Note: This R\&R Subaward Budget (Fed/Non-Fed) Attachment(s) Form must be used to attach only one or more Research \& Related Budget (Total Fed + Non-Fed) form(s) that have been extracted from this form. Note the form's instruction: "Click here to extract the R\&R Budget (Fed/Non-Fed) Attachment". If you attach a file format to this form that was not extracted from this attachment form your application will be rejected with errors by Grants.gov.

\section{Other Forms Included in the Application Package}

You are required to submit the first two forms identified here. You are not required to submit the third form, Disclosure of Lobbying Activities - Standard Form LLL, unless it is applicable. To determine applicability, please review the provisions in Item 1 "Lobbying" of the ED 80-0013 - Combined Assurance Form.

- SF 424B-Assurances-Non-Construction Programs.

- $\quad$ ED 80-0013 - Combined Assurance.

- Disclosure of Lobbying Activities - Standard Form LLL (if applicable). 


\section{F. SUMMARY OF REQUIRED APPLICATION CONTENT}

\begin{tabular}{|c|c|c|c|}
\hline R\&R Form & Required & Instructions Provided & Additional Information \\
\hline $\begin{array}{l}\text { Application for Federal Assistance } \\
\text { SF } 424(R \& R)\end{array}$ & $\square$ & Part VI.E.1 & $\begin{array}{c}\text { Form provided in Grants.gov } \\
\text { application package }\end{array}$ \\
\hline $\begin{array}{l}\text { Senior/Key Person Profile } \\
\text { (Expanded) }\end{array}$ & $\square$ & Part VI.E.2 & $\begin{array}{c}\text { Form provided in Grants.gov } \\
\text { application package }\end{array}$ \\
\hline $\begin{array}{l}\text { Project/Performance Site } \\
\text { Location(s) }\end{array}$ & $\square$ & Part VI.E.3 & $\begin{array}{l}\text { Form provided in Grants.gov } \\
\text { application package }\end{array}$ \\
\hline Other Project Information & $\square$ & Part VI.E.4 & $\begin{array}{c}\text { Form provided in Grants.gov } \\
\text { application package }\end{array}$ \\
\hline $\begin{array}{l}\text { Budget (Total Federal + Non- } \\
\text { Federal): } \\
\text { Sections A \& B } \\
\text { Sections C, D, \& E } \\
\text { Sections F - K }\end{array}$ & $\square$ & Part VI.E.5 & $\begin{array}{l}\text { Form provided in Grants.gov } \\
\text { application package }\end{array}$ \\
\hline $\begin{array}{l}\text { R\&R Subaward Budget (Fed/Non- } \\
\text { Fed) Attachment(s) Form }\end{array}$ & -- & Part VI.E.6 & $\begin{array}{l}\text { Form provided in Grants.gov } \\
\text { application package. Use this } \\
\text { form to extract and attach a } \\
\text { subaward budget(s). }\end{array}$ \\
\hline $\begin{array}{l}\text { SF 424B Assurances - Non- } \\
\text { Construction Programs } \\
\text { ED 80-0013 - Combined } \\
\text { Assurance } \\
\text { Disclosure of Lobby Activities - } \\
\text { Standard Form LLL (if } \\
\text { applicable) }\end{array}$ & $\begin{array}{l}\square \\
\square \\
--\end{array}$ & Part VI.E.7 & $\begin{array}{l}\text { Forms provided in Grants.gov } \\
\text { application package }\end{array}$ \\
\hline Project Summary/Abstract & $\square$ & Part V.D.1 & $\begin{array}{l}\text { Add as an attachment (PDF file) } \\
\text { using Item } 7 \text { of the "Other } \\
\text { Project Information" form }\end{array}$ \\
\hline $\begin{array}{l}\text { Project Narrative and Appendices } \\
\text { - } \text { Narrative } \\
\text { - } \text { Appendix A } \\
\text { - Appendix B } \\
\text { - Appendix C } \\
\text { - Appendix D } \\
\text { - Appendix E }\end{array}$ & $\begin{array}{l}\square \\
-- \\
-- \\
-- \\
-- \\
--\end{array}$ & Part V.D.2-7 & $\begin{array}{l}\text { The Project Narrative, and if } \\
\text { applicable Appendix A, } \\
\text { Appendix B, Appendix C, } \\
\text { Appendix D, and Appendix E } \\
\text { must ALL be included together } \\
\text { in one PDF file and attached at } \\
\text { Item } 8 \text { of the "Other Project } \\
\text { Information" form. }\end{array}$ \\
\hline Bibliography and References Cited & $\square$ & Part V.D.8 & $\begin{array}{l}\text { Add as an attachment (PDF file) } \\
\text { using Item } 9 \text { of the "Other } \\
\text { Project Information" form. }\end{array}$ \\
\hline $\begin{array}{l}\text { Research on Human Subjects } \\
\text { Narrative, if human subjects are } \\
\text { involved }\end{array}$ & $\square$ & Part V.D.9 & $\begin{array}{l}\text { Add as an attachment (PDF file) } \\
\text { using Item } 12 \text { of the "Other } \\
\text { Project Information" form. }\end{array}$ \\
\hline
\end{tabular}




\begin{tabular}{|l|c|c|l|}
\hline $\begin{array}{l}\text { Biographical Sketches of } \\
\text { Senior/Key Personnel }\end{array}$ & $\square$ & Part V.D.10 & $\begin{array}{l}\text { Add each as a separate } \\
\text { attachment (PDF file) using the } \\
\text { "Senior/Key Person Profile } \\
\text { (Expanded)" form. }\end{array}$ \\
\hline $\begin{array}{l}\text { Lists of Current \& Pending } \\
\text { Support for Senior/Key Personnel }\end{array}$ & $\square$ & Part V.D.11 & $\begin{array}{l}\text { Add each as a separate } \\
\text { attachment (PDF file) using the } \\
\text { "Senior/Key Person Profile } \\
\text { (Expanded)" form. }\end{array}$ \\
\hline Narrative Budget Justification & $\square$ & Part V.D.12 & $\begin{array}{l}\text { Add as an attachment (PDF file) } \\
\text { using Section K - Budget Period } \\
\text { of the "Budget (Total Federal } \\
\text { + Non-Federal)" form. }\end{array}$ \\
\hline
\end{tabular}




\section{G. APPLICATION CHECKLIST}

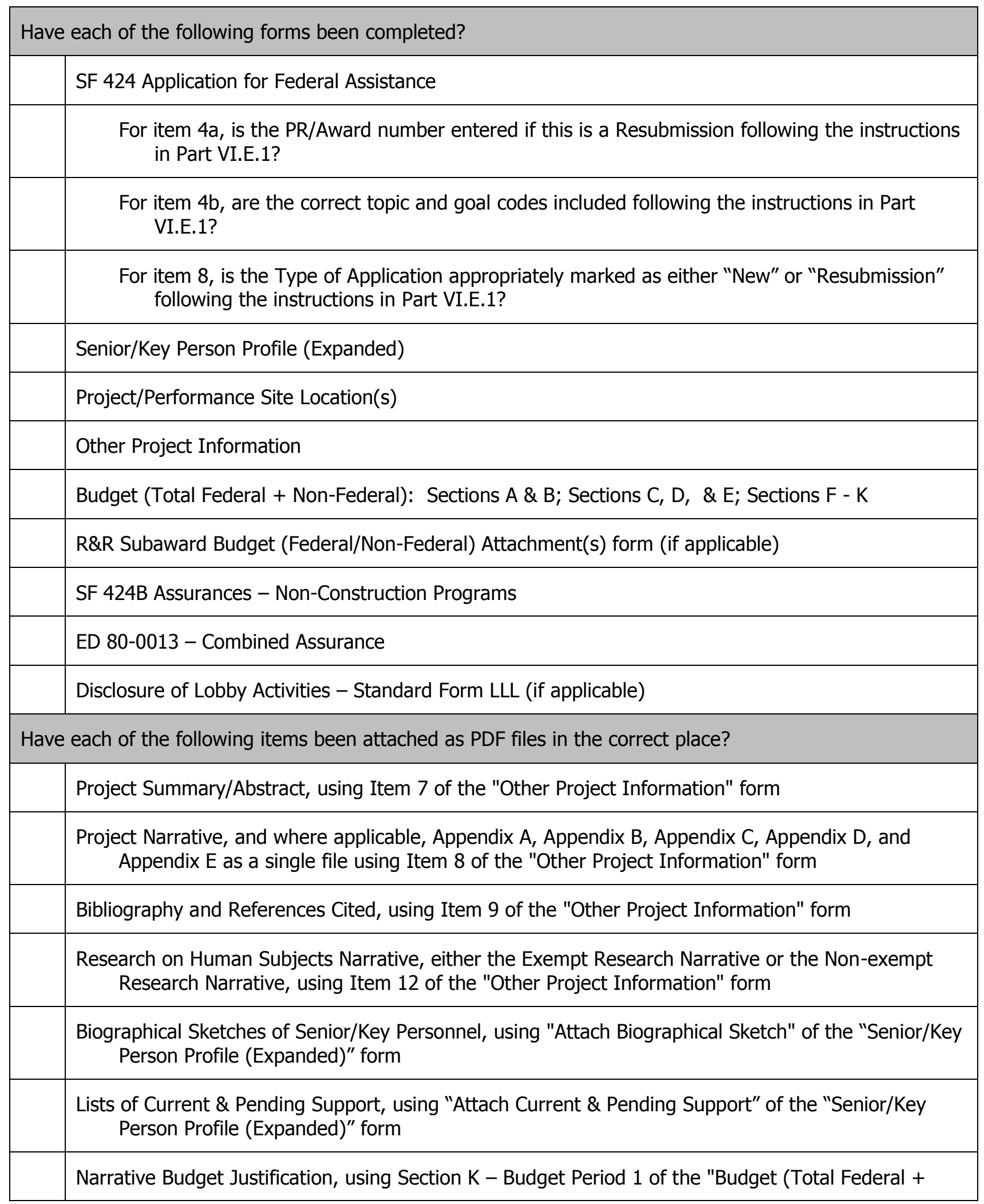




\begin{tabular}{|l|l|}
\hline & Non-Federal" form \\
\hline $\begin{array}{c}\text { Budget (Total Federal + Non-Federal): Sections A \& B; Sections C, D, \& E; Sections F - K for the } \\
\text { Subaward(s), using the "R\&R Subaward Budget (Federal/Non-Federal) Attachment(s)" form, as } \\
\text { appropriate }\end{array}$ \\
\hline Have the following actions been completed? \\
\hline $\begin{array}{l}\text { The "Check Package for Errors" button at the top of the grant application package has been used to } \\
\text { identify errors or missing required information that prevents an application from being } \\
\text { processed }\end{array}$ \\
\hline $\begin{array}{l}\text { The "Track My Application" link has been used to verify that the upload was fully completed and that } \\
\text { the application was processed and validated successfully by Grants.gov before 4:30:00 p.m., } \\
\text { Washington, DC time on the deadline date }\end{array}$ \\
\hline
\end{tabular}




\section{H. PROGRAM OFFICER CONTACT INFORMATION}

As a reminder, please contact program officers with any questions you may have about the best topic and goal for your application. Program officers function as knowledgeable colleagues who can provide substantive feedback on your research idea, including reading a draft of your project narrative. Program officers can also help you with any questions you may have about the content and preparation of PDF file attachments. However, any questions you have about individual forms within the application package and electronic submission of your application through Grants.gov should be directed first to the Grants.gov Contact Center at support@grants.gov, http://www.grants.gov/web/grants/about/contactus.html, or call 1-800-518-4726.

\section{Autism Spectrum Disorders}

Kimberley Sprague, Ed.M.

Email: Kimberley.Sprague@ed.gov

Telephone: (202) 208-1609

\section{Cognition and Student Learning in Special Education}

Kimberley Sprague, Ed.M.

Email: Kimberley.Sprague@ed.gov

Telephone: (202) 208-1609

\section{Early Intervention and Early Learning in Special Education}

Amy Sussman, Ph.D.

Email: Amy.Sussman@ed.gov

Telephone: (202) 219-2126

\section{Families of Children with Disabilities}

Jacquelyn Buckley, Ph.D.

Email: Jacquelyn.Buckley@ed.gov

Telephone: (202) 219-2130

\section{Mathematics and Science Education}

Rob Ochsendorf, Ed.D.

Email: Robert.Ochsendorf@ed.gov

Telephone: (202) 219-2234

\section{Professional Development for Teachers and Related Services Providers}

Rob Ochsendorf, Ed.D.

Email: Robert.Ochsendorf@ed.gov

Telephone: (202) 219-2234

Reading, Writing, and Language Development

Kristen Rhoads, Ph.D.

Email: Kristen.Rhoads@ed.gov

Telephone: (202) 219-0377

\section{Social and Behavioral Outcomes to Support Learning}

Jacquelyn Buckley, Ph.D.

Email: Jacquelyn.Buckley@ed.gov

Telephone: (202) 219-2130

\section{Special Education Policy, Finance, and Systems}

Kristen Rhoads, Ph.D. 
Email: Kristen.Rhoads@ed.gov

Telephone: (202) 219-0377

\section{Technology for Special Education}

Rob Ochsendorf, Ed.D.

Email: Robert.Ochsendorf@ed.gov

Telephone: (202) 219-2234

\section{Transition Outcomes for Secondary Students with Disabilities}

Kimberley Sprague, Ed.M.

Email: Kimberley.Sprague@ed.gov

Telephone: (202) 208-1609 


\section{GLOSSARY}

Assessment: "Any systematic method of obtaining information from tests and other sources, used to draw inferences about characteristics of people, objects, or programs" (AERA, 1999).

Assessment framework: Includes the definition of the construct(s); theoretical model on which the assessment is based; and the rationale for validity evidence to support its use for the intended purpose and population.

Authentic education setting: Your proposed research must be relevant to education in the United States and meet the Setting Requirements for the Topic that you select. Setting refers to the environment where education is being delivered not the physical location of the researcher. In general, topics require that research is conducted in authentic education settings or on data collected from authentic education settings (although some topics also allow for research conducted in laboratory settings). Authentic education setting varies by education level as set out below.

- Authentic Education Settings for Infants and Toddlers are defined as:

- Homes

- Child care

- Natural settings for early intervention services

- Authentic Preschool Settings are defined as:

- Homes

- Child care

- Preschool programs

- Natural settings for early childhood special education services

- Authentic K-12 Education Settings are defined as:

- Schools and alternative school settings (e.g., alternative schools or juvenile justice settings).

- School systems (e.g., local education agencies or state education agencies).

- Settings that deliver supplemental education services (as defined in Section 1116(e) of the Elementary and Secondary Education Act of 1965, as amended by the No Child Left Behind Act of 2001) (http://www2.ed.gov/policy/elsec/leg/esea02/index.html).

Case: A case is a unit of intervention administration and data analysis. A case may be a single participant or a cluster of participants (e.g., a classroom or community).

Compliant: The part of the process of screening applications for acceptance for review that focuses on compliance with the application rules (e.g., page length and formatting requirements, completion of all parts of the application).

Concurrent validity: Evidence that indicates how accurately scores can predict criterion scores that are obtained at a similar time.

Convergent validity: Evidence based on the relationship between scores and other measures of the same constructs (AERA, 1999).

Construct: The concept or the characteristic that an assessment is designed to measure. 
Construct coverage: The degree to which an assessment measures the full range of skills, abilities, and/or content needed to adequately represent the target construct.

Development process: The process used to develop and/or refine an intervention.

Differential item functioning (DIF): A statistical property of an assessment item in which different groups of test takers who have the same total test scores have different average item scores or, in some cases, different rates of choosing various item options (AERA, 1999).

Discriminant validity: Evidence based on the relationship between scores and measures of different constructs (AERA, 1999).

Effectiveness study: The independent evaluation of a fully-developed education intervention with prior evidence of efficacy to determine whether it produces a beneficial impact on student education outcomes relative to a counterfactual when implemented under routine practice in authentic education settings.

Effectiveness follow-up study: Studies that follow students who took part in an Effectiveness study as they enter later grades (or different authentic education settings) in which they do not continue to receive the intervention in order to determine if the beneficial effects are maintained in succeeding time periods.

Efficacy study: A study that tests an intervention's beneficial impacts on student education outcomes in comparison to an alternative practice, program, or policy

Efficacy follow-up study: An efficacy study that tests the longer-term impacts of an intervention that has been shown to have beneficial impacts on student education outcomes in a previous or ongoing efficacy study.

End user: The person intended to be responsible for the implementation of the intervention. Efficacy/Replication studies and Effectiveness studies should test an intervention implemented by the end user.

Feasibility: The extent to which the intervention can be implemented within the requirements and constraints of an authentic education setting.

Fidelity of implementation: The extent to which the intervention is being delivered as it was designed to be by end users in an authentic education setting.

Final manuscript: The author's final version of a manuscript accepted for publication that includes all modifications from the peer-review process.

Final research data: The recorded factual materials commonly accepted in the scientific community as necessary to document and support research findings. For most studies, an electronic file will constitute the final research data. This data set will include both raw data and derived variables, which will be fully described in accompanying documentation. Researchers are expected to take appropriate precautions to protect the privacy of human subjects. Note that final research data does not mean summary statistics or tables, but rather, the factual information on which summary statistics and tables are based. Final research data do not include laboratory notebooks, preliminary analyses, drafts of scientific papers, plans for future research, peer-reviewed reports, or communications with colleagues. 
Horizontal equating: Putting two or more assessments that are considered interchangeable on a common scale.

Ideal conditions: Conditions that provide a more controlled setting under which the intervention may be more likely to have beneficial impacts. For example, ideal conditions can include more implementation support than would be provided under routine practice in order to ensure adequate fidelity of implementation. Ideal conditions can also include a more homogeneous sample of students, teachers, schools, and/or districts than would be expected under routine practice in order to reduce other sources of variation that may contribute to outcomes.

Intervention: The wide range of education curricula, instructional approaches, professional development, technology, and practices, programs, and policies that are implemented at the student, classroom, school, district, state, or federal level to improve student education outcomes.

Laboratory research: An approach to research that allows for careful control of extraneous factors (e.g., by conducting research in a more controlled environment or with a more controlled situation than would be expected in authentic education settings). Laboratory research may be conducted in a laboratory or in an authentic education setting.

Malleable factors: Things that can be changed by the education system to improve student education outcomes.

Moderators: Factors that affect the strength or the direction of the relationship between the intervention and student education outcomes (e.g., an intervention's impacts may differ by such student characteristics as achievement level, disability category, motivation, or social-economic status; and by organizational or contextual factors, such as classroom or school size).

Mediators: Factors through which the relationship between the intervention and student education outcomes occurs (e.g., many interventions aimed at changing individual student education outcomes work through changing teacher behavior, student peer behavior, and/or student behavior).

Pilot study: A study designed to provide evidence of the promise of the fully-developed intervention for achieving its intended outcomes when it is implemented in an authentic education setting. A pilot study differs from studies conducted during the development process. The latter are designed to inform the iterative development process (e.g., by identifying areas of further development, testing individual components of the intervention); therefore, they are expected to lead to further development and revision of the intervention. The pilot study is designed to help determine whether a finalized version of the intervention performs as expected. Depending on the results, pilot studies may lead to further development of the intervention or they may lead to a rigorous evaluation of the intervention.

Predictive validity: Evidence that indicates how accurately scores can predict criterion scores that are obtained at a later time (AERA, 1999).

Reliability: "The degree to which scores for a group of test takers are consistent over repeated applications of a measurement procedure and hence are inferred to be dependable and repeatable for an individual test taker; the degree to which scores are free of errors of measurement for a given group" (AERA, 1999).

Replication study: An efficacy study to generate additional evidence that an intervention improves student education outcomes by testing an intervention that has been shown to have beneficial impacts on student education outcomes in a previous efficacy study. 
Responsive: The part of the process of screening applications for acceptance for review that focuses on responsiveness to the Request for Applications. This screening includes making sure applications 1) are submitted to the correct competition and/or goal and 2) meet the basic requirements set out in the Request for Applications.

Retrospective study: An efficacy study that analyzes retrospective (historical) secondary data to test an intervention implemented in the past, and, that as a result, may not be able meet the requirements for Efficacy/Replication projects regarding fidelity of implementation and comparison group practice

Routine conditions: Conditions under which an intervention is implemented that reflect (1) the everyday practice occurring in homes, childcare, natural settings for infants and toddlers, classrooms, schools, and districts and (2) the heterogeneity of the target population.

Student education outcomes: The outcomes to be changed by the intervention. The intervention may be expected to directly affect these outcomes or indirectly affect them through intermediate student or instructional personnel outcomes. There are four types of student education outcomes for this competition. The topic you choose will determine the types of student education outcomes you can study.

- Developmental Outcomes: outcomes pertaining to cognitive, communicative, linguistic, social, emotional, adaptive, functional or physical development.

- Student academic outcomes: The Institute supports research on a diverse set of student academic outcomes that fall under two categories. The first category includes academic outcomes that reflect learning and achievement in the core academic content areas (e.g., measures of understanding and achievement in reading, writing, math, and science). The second category includes academic outcomes that reflect students' successful progression through the education system (e.g., course and grade completion and retention in grade $\mathrm{K}$ through 12; high school graduation and dropout; postsecondary enrollment, progress, and completion).

- Social and behavioral competencies: Social skills, attitudes, and behaviors that may be important to students' academic and post-academic success.

- Functional Outcomes: skills or activities that are not considered academic or related to a child's academic achievement; "functional" is often used in the context of routine activities of everyday living.

Theory of change: The underlying process through which key components of a specific intervention are expected to lead to the desired student education outcomes. A theory of change should be specific enough to guide the design of the evaluation (e.g., selecting an appropriate sample, measures and comparison condition).

Usability: The extent to which the intended user understands or can learn how to use the intervention effectively and efficiently, is physically able to use the intervention, and is willing to use the intervention.

Validity: The degree to which accumulated evidence and theory support specific interpretations of scores entailed by proposed uses of an assessment (AERA, 1999).

Vertical equating: Putting two or more assessments that are considered to measure the same construct across different levels of development on a common scale. 


\section{REFERENCES}

Allor, J., Mathes, P., Roberts, J., Cheatham, J. \& Champlin, T. (2010). Comprehensive reading instruction for students with intellectual disabilities: Findings from the first three years of a longitudinal study. Psychology in the Schools, 47, 445-466.

American Educational Research Association (1999). Standards for Educational and Psychological Testing. AERA: Washington, DC.

American Psychological Association, Research Office (2009). Publications Manual of the American Psychological Association (6th ed.). Washington, DC: American Psychological Association.

Bergeron, J. P., Lederberg, A. R., Easterbrooks, S. R., Miller, E. M., \& Connor, C. M. (2009). Building the alphabetic principle in young children who are deaf and hard of hearing. The Volta Review, 109(2-3), 87-119.

Browder, D., Mimms, P., Spooner, F., \& Ahlgrim, L. (2008). Teaching elementary students with disabilities to participate in shared stories. Research and Practice for Persons with Severe Disabilities, 33, 3-12.

Centers for Disease Control and Prevention (2014). Prevalence of Autism Spectrum Disorders Among Children Aged 8 Years- Autism and Developmental Disabilities Monitoring Network, 11 Sites, United States, 2010. Surveillance Summaries. Autism and Developmental Disabilities Monitoring Network Surveillance Year 2010 Principal Investigators. March 28, 2014; 63(10) 1-21.

Diamond, K. E. \& Powell, D. R. (2011). An iterative approach to the development of a professional development intervention for Head Start teachers. Journal of Early Intervention, 1, 75-93.

Elementary and Secondary Education Act of 1965, as amended 2001 P.L. 107-110, 115 Stat. 1425 (2002).

Fleury, V. P., Hedges, S., Hume, K., Browder, D. M., Thompson, J. L., Fallin, K., ... Vaughn, S. (2014). Addressing the academic needs of adolescents with Autism Spectrum Disorder in secondary education. Remedial and Special Education, 35, 68-79.

Fuchs, L. S. \& Fuchs, D. (2001). Principles for sustaining research-based practices in the schools: A case study. Focus on Exceptional Children, 6, 1-14.

Fuchs, L. S., Fuchs, D., \& Compton, D. L. (2010). Rethinking response to intervention at middle and high school. School Psychology Review, 39, 22-28.

Individuals with Disabilities Education Improvement Act of 2004, P.L. 108-446, 118 Stat. 2647 (2004).

Kessler, R., Berglund, P., Demler, O., Jin, R., \& Walters, E. E. (2005). Lifetime prevalence and age-ofonset distributions of DSM-IV disorders in the National Comorbidity Survey Replication. Archive of General Psychiatry, 62, 593-602.

Koehler, M. J., \& Levin, J. R. (1998). Regulated randomization: A potentially sharper analytical tool for the multiple-baseline design. Psychological Methods, 3, 206-217. 
Kratochwill, T. R., Hitchcock, J., Horner, R. H., Levin, J. R., Odom, S. L., Rindskopf, D. M. \& Shadish, W. R. (2010). Single-case designs technical documentation, pp. 14-16. Retrieved from What Works Clearinghouse website: http://ies.ed.gov/ncee/wwc/pdf/wwc scd.pdf.

Kratochwill, T. R., \& Levin, J. R. (2010). Enhancing the scientific credibility of single-case intervention research: Randomization to the rescue. Psychological Methods, 15, 124-144.

Levin, J. R., \& Wampold, B. E. (1999). Generalized single-case randomization tests: Flexible analyses for a variety of situations. School Psychology Quarterly, 14, 59-93.

Masten, A.S., Roisman, G. I., Long, J. D., Burt, K. B., Obradović, J., Riley, J. R., Boelcke-Stennes, K., \& Tellegen, A. (2005). Developmental cascades: Linking academic achievement and externalizing and internalizing symptoms over 20 years. Developmental Psychology, 41(5), 733-746.

Newman, L., Wagner, M., Cameto, R., \& Knokey, A. M. (2009). The Post-High School Outcomes of Youth with Disabilities up to 4 Years After High School. A Report of Findings from the National Longitudinal Transition Study-2 (NLTS2) (NCSER 2009-3017). Menlo Park, CA: SRI International. Available at www.nlts2.org/reports/2009 04/nlts2 report 200904 complete.pdf.

Reddy, L. A., Newman, E., De Thomas, C. A., \& Chun, V. (2009). Effectiveness of school-based prevention and intervention programs for children and adolescents with emotional disturbance: A meta-analysis. Journal of School Psychology, 47, 77-99.

Shadish, W. R. (1996). Meta-analyses and the exploration of causal mediating processes: A primer of examples, methods, and issues. Psychological Methods, 1(1), 47-65.

Shadish, W. R., Cook, T. D., \& Campbell, D. T. (2002). Experimental and Quasi-Experimental Designs for Generalized Causal Inference. Boston, MA: Houghton Mifflin Company.

U.S. Department of Education, Institute of Education Sciences, National Assessment of Educational Progress (NAEP) Data, 2009, 2011, and 2013. Retrieved from http://nces.ed.gov/nationsreportcard/

U.S. Department of Education, Institute of Education Sciences, School and Staffing Survey (SASS) Data, 2013. Retrieved from http://nces.ed.gov/surveys/sass/index.asp

U.S. Department of Education, Office of Special Education and Rehabilitative Services, Office of Special Education Programs, 31th Annual Report to Congress on the Implementation of the Individuals with Disabilities Education Act, 2009, vol. 1, Washington, DC, 2012.

van Steensel, F.J.A., Bögels, S.M., \& de Bruin, E.I. (2013). Psychiatric comorbidity in children with Autism Spectrum Disorders: A comparison with children with ADHD. Journal of Child and Family Studies, 22, 368-376.

Vaughn, S., Wexler, J., Roberts, G., Barth, A. A., Cirino, P. T., Romain, M. A., \& Denton, C. D. (2011). Effects of individualized and standardized interventions on middle school students with reading disabilities. Exceptional Children, 77, 391-407.

Wagner, M., Newman, L, Cameto, R., \& Levine, P. (2006). The academic achievement and functional performance of youth with disabilities. A report from the National Longitudinal Transition Study2. Menlo Park, CA: SRI International. 


\title{
ALLOWABLE EXCEPTIONS TO ELECTRONIC SUBMISSIONS
}

You may qualify for an exception to the electronic submission requirement and submit an application in paper format if you are unable to submit the application through the Grants.gov system because: (a) you do not have access to the Internet; or (b) you do not have the capacity to upload large documents to the Grants.gov system; and (c) no later than two weeks before the application deadline date (14 calendar days or, if the fourteenth calendar date before the application deadline date falls on a Federal holiday, the next business day following the Federal holiday), you mail or fax a written statement to the Institute explaining which of the two grounds for an exception prevents you from using the Internet to submit the application. If you mail the written statement to the Institute, it must be postmarked no later than two weeks before the application deadline date. If you fax the written statement to the Institute, the faxed statement must be received no later than two weeks before the application deadline date. The written statement should be addressed and mailed or faxed to:

Ellie Pelaez, Office of Administration and Policy Institute of Education Sciences, U.S. Department of Education

555 New Jersey Avenue, NW, Room 600E

Washington, DC 20208

FAX: (202) 219-1466

If you request and qualify for an exception to the electronic submission requirement you may submit an application via mail, commercial carrier or hand delivery. To submit an application by mail, mail the original and two copies of the application on or before the deadline date to:

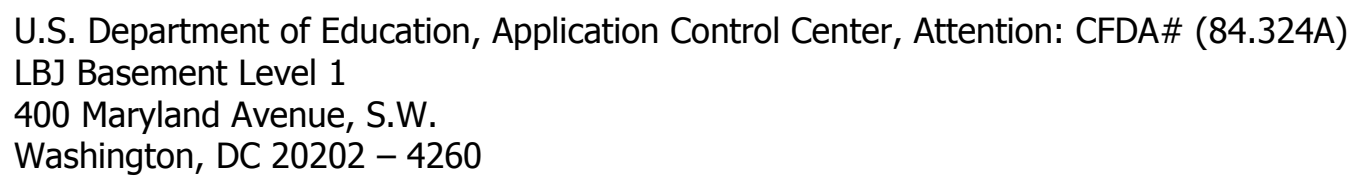

You must show one of the following as proof of mailing: (a) a legibly dated U.S. Postal Service Postmark; (b) a legible mail receipt with the date of mailing stamped by the U.S. Postal Service; (c) a dated shipping label, invoice, or receipt from a commercial carrier; or (d) any other proof of mailing acceptable to the U.S. Secretary of Education (a private metered postmark or a mail receipt that is not dated by the U.S. Postal Services will not be accepted by the Institute). Note that the U.S. Postal Service does not uniformly provide a dated postmark. Before relying on this method, you should check with your local post office. If your application is postmarked after the application deadline date, the Institute will not consider your application. The Application Control Center will mail you a notification of receipt of the grant application. If this notification is not received within 15 business days from the application deadline date, call the U.S. Department of Education Application Control Center at (202) 245-6288.

To submit an application by hand, you or your courier must hand deliver the original and two copies of the application by 4:30:00 p.m. (Washington, DC time) on or before the deadline date to:

\author{
U.S. Department of Education \\ Application Control Center \\ Attention: CFDA\# 84.324A \\ 550 12th Street, S.W. \\ Potomac Center Plaza - Room 7039 \\ Washington, DC $20202-4260$
}

The Application Control Center accepts application deliveries daily between 8:00 a.m. and 4:30 p.m. (Washington, DC time), except Saturdays, Sundays and federal holidays. 